
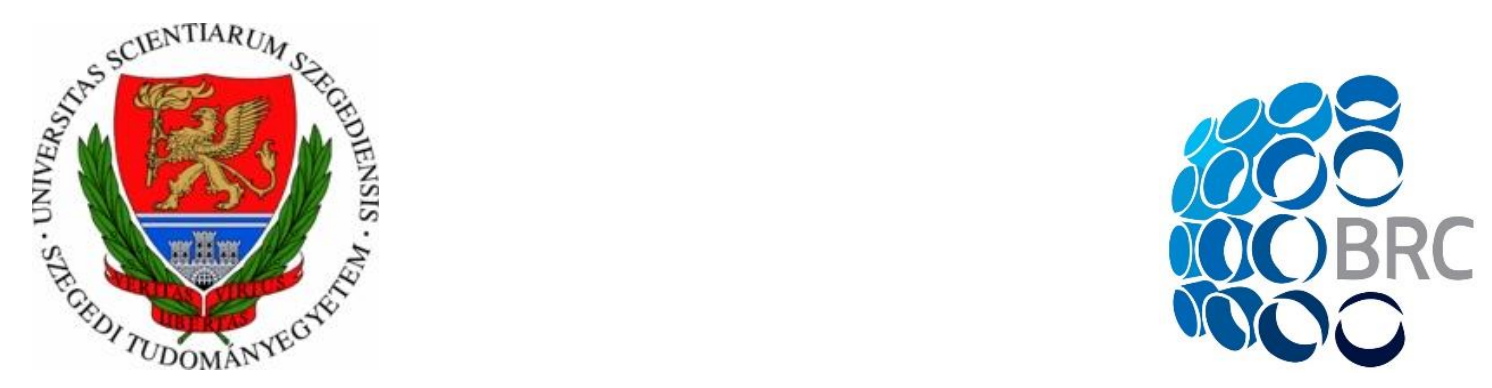

\title{
INVOLVEMENT OF THE NEUROVASCULAR UNIT IN THE FORMATION OF BRAIN METASTASES
}

\author{
Ph.D. thesis
}

\section{Kinga Mészáros-Molnár}

Supervisor: Imola Wilhelm M.D., Ph.D.

Doctoral School of Theoretical Medicine, University of Szeged, Szeged, Hungary

Institute of Biophysics, Biological Research Centre, Szeged, Hungary

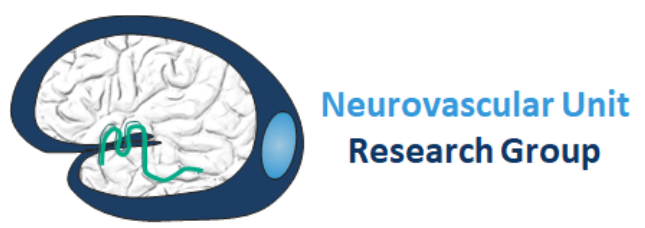

Szeged 
,You cannot get through a single day without having an impact on the world around you. What you do makes a difference, and you have to decide what kind of difference you want to make."

Jane Goodall 


\section{Table of Contents}

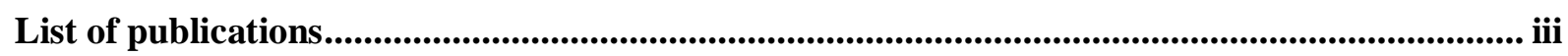

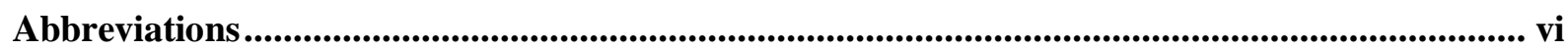

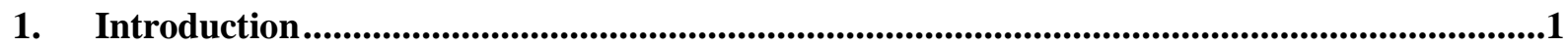

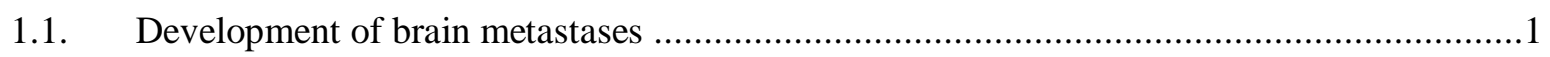

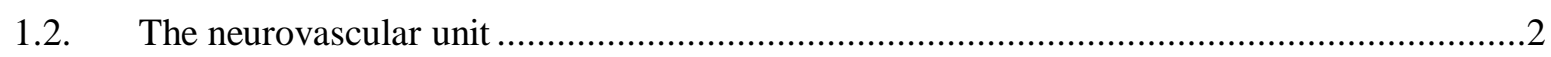

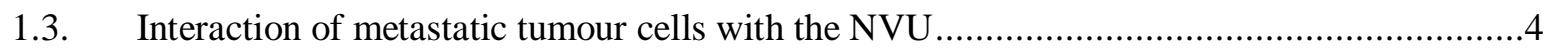

1.3.1. Cerebral endothelial cells and their role in brain metastasis formation ..........................4

1.3.2. Janus-faced role of astrocytes in brain metastases ...................................................

1.3.3. Brain pericytes: dark horses in the brain metastatic disease ..........................................

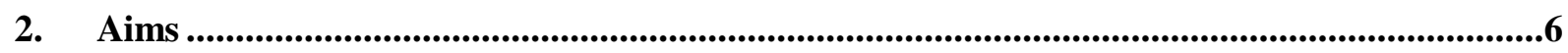

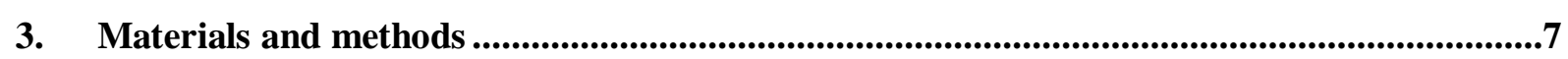

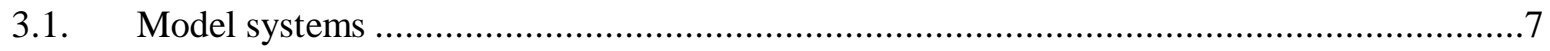

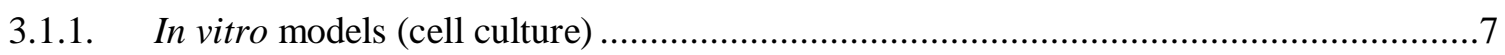

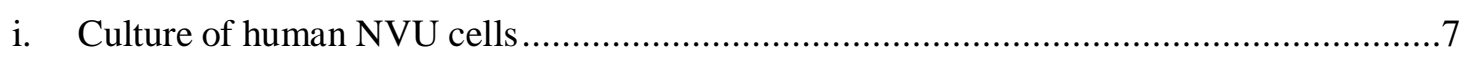

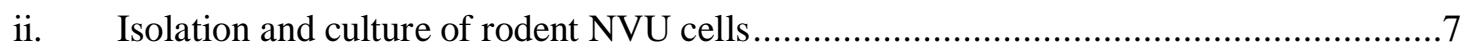

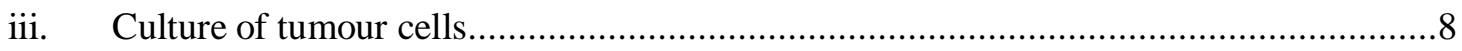

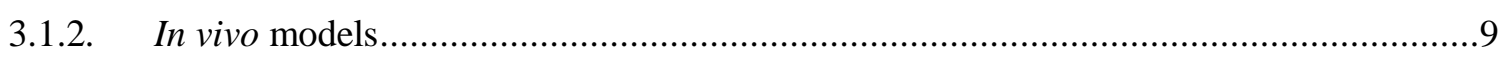

i. Injection of tumour cells into the common carotid artery or the left ventricle....................

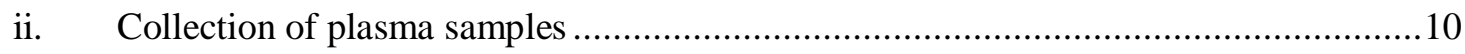

iii. Preparation of cranial window for two-photon microscopy ...................................... 10

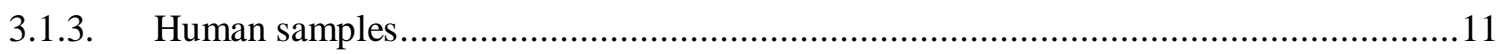

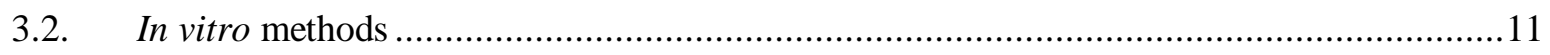

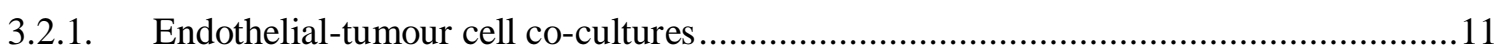

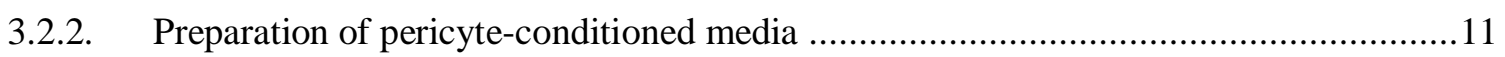

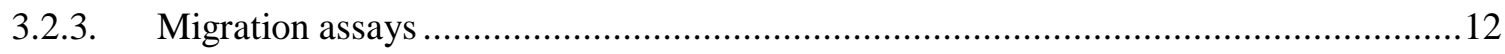

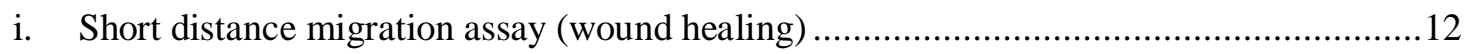

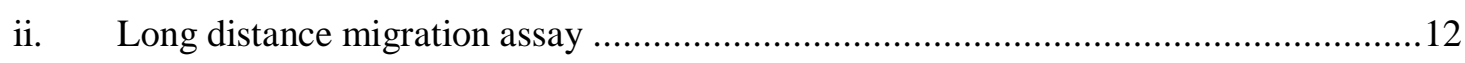

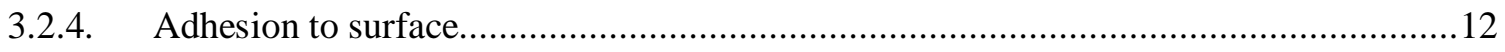

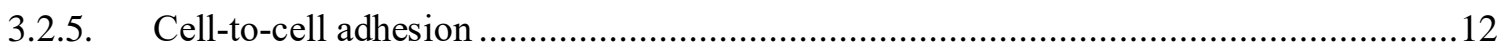

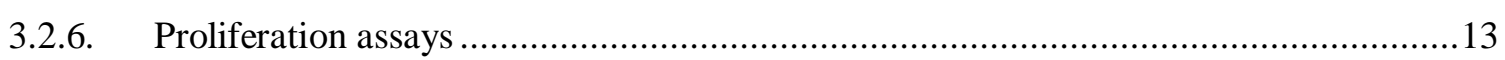

i. Phase-contrast imaging and cell number counting ….................................................. 13

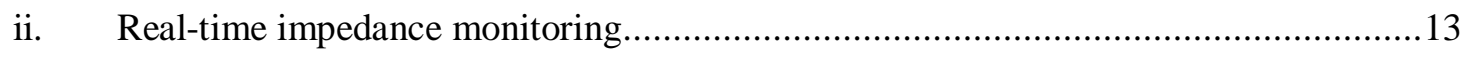

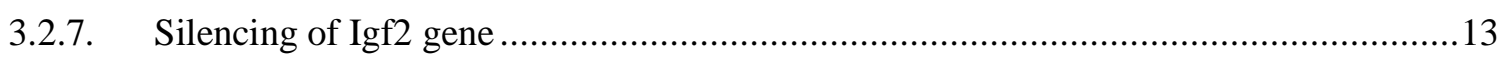

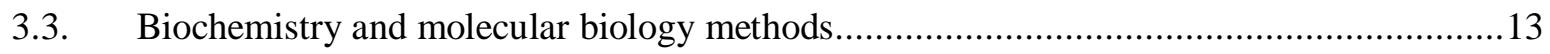

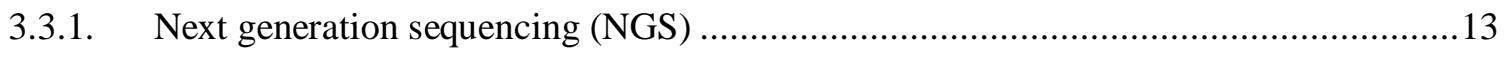

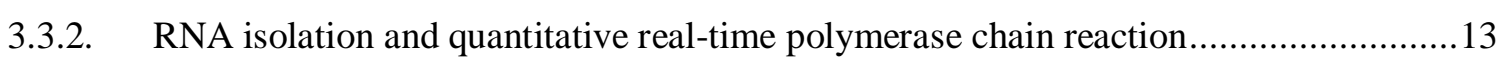

3.3.3. Methanol-chloroform precipitation and western-blot .................................................. 14 


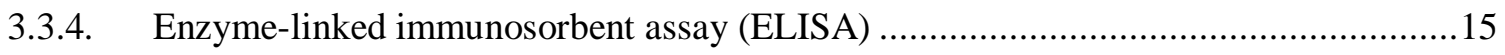

3.4. Immunofluorescence on human and mouse brain sections .............................................16

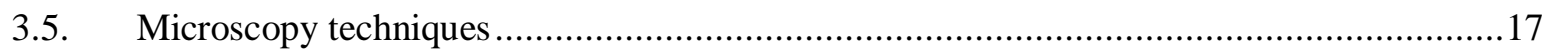

3.5.1. Preparation of ultrasections and transmission electron microscopy (TEM) ..................17

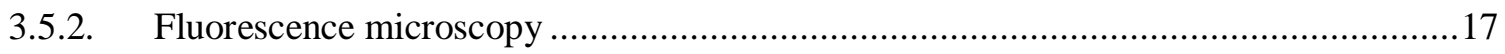

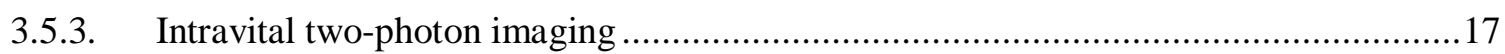

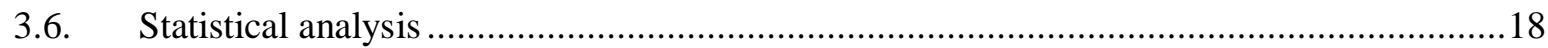

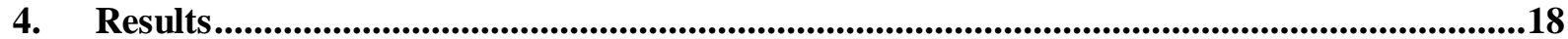

4.1. Interactions of metastasizing breast cancer cells with CECs ..............................................18

4.2. Interactions of metastasizing breast cancer cells with astrocytes ..................................23

4.3. Direct interaction of brain metastatic tumour cells with pericytes in vivo and in vitro........25

4.4. Effects of pericytes on tumour cell adhesion .....................................................................29

4.5. Effects of pericytes on tumour cell proliferation .......................................................... 31

4.6. Insulin-like growth factor (IGF) expression in cerebral pericytes ...................................33

4.7. Role of brain pericyte-secreted IGFs in proliferation of TNBC cells ..................................36

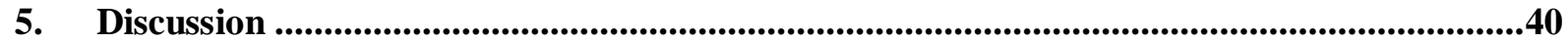

5.1. Endothelial-tumour cell interactions during brain metastasis formation ...........................40

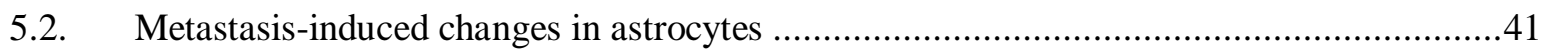

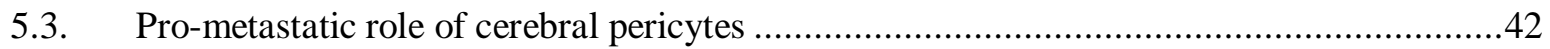

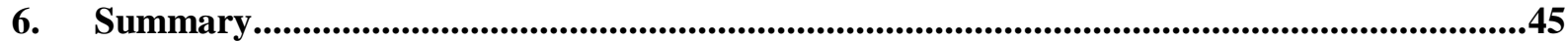

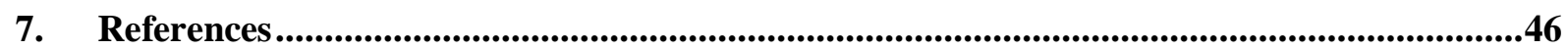

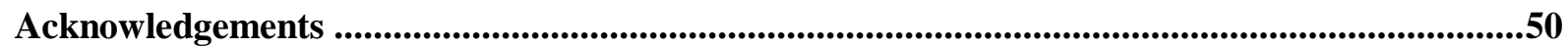

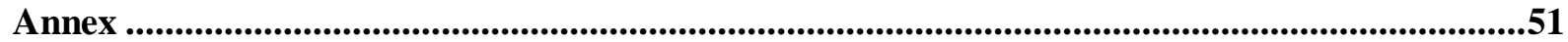




\section{List of publications}

Full papers directly related to the subject of the thesis

I. Molnár, K., Mészáros, Á., Fazakas C., Kozma, M., Győri, F., Reisz, Z., Tiszlavicz, L., Farkas, A.E., Nyúl-Tóth, Á., Haskó, J., Krizbai, I.A., Wilhelm, I. (2020) Pericyte-secreted IGF2 promotes breast cancer brain metastasis formation. Mol Oncol. 2020 Sep; 14(9): 2040-2057. (IF2019 = 6.574, Journal Ranking: D1)

II. Sereno, M., Haskó, J., Molnár, K., Medina, S.J., Reisz, Z., Malhó, R., Videira, M., Tiszlavicz, L., Booth, S.A., Wilhelm, I., Krizbai, I.A., Brito MA. (2020) Downregulation of circulating miR 802-5p and miR 194-5p and upregulation of brain MEF2C along breast cancer brain metastasization. Mol Oncol. 2020 Mar;14(3):520538. (IF2019 = 6.574, Journal Ranking: D1)

III. Haskó, J., Fazakas C., Molnár, K., Mészáros, Á., Patai, R., Szabó, G., Erdélyi, F., NyúlTóth, Á., Győri, F., Kozma, M., Farkas, A.E., Krizbai, I.A., Wilhelm, I. (2019) Response of the neurovascular unit to brain metastatic breast cancer cells. Acta Neuropathol Commun. 2019 Aug 19;7(1):133. (IF = 6.270, Journal Ranking: D1)

IV. Herman, H., Fazakas C., Haskó, J., Molnár, K., Mészáros, Á., Nyúl-Tóth, Á., Szabó, G., Erdélyi, F., Ardelean, A., Hermenean, A., Krizbai, I.A., Wilhelm, I. (2019) Paracellular and transcellular migration of metastatic cells through the cerebral endothelium. J Cell Mol Med. 2019 Apr;23(4):2619-2631. (IF = 4.486, Journal Ranking: Q1)

V. Wilhelm, I., Fazakas C., Molnár, K., Végh, A.G., Haskó, J., Krizbai, I.A. (2018) Foe or friend? Janus-faces of the neurovascular unit in the formation of brain metastases. J Cereb Blood Flow Metab. 2018 Apr;38(4):563-587. (IF = 6.040, Journal Ranking: D1) 
Full papers not included in the thesis

1. Molnár, K.; Lőrinczi, B.; Fazakas, C.; Szatmári, I.; Fülöp, F.; Kmetykó, N.; Berkecz, R.; Ilisz, I.; Krizbai, I.A.; Wilhelm, I.; Vécsei, L. (2021) SZR-104, a Novel Kynurenic Acid Analogue with High Permeability through the Blood-Brain Barrier. Pharmaceutics 2021, 13, 61. (IF2019 = 4.421, Journal Ranking: Q1)

2. Nógrádi, B., Nyúl-Tóth, Á., Kozma, M., Molnár, K., Patai, R., Siklós, L., Wilhelm, I., Krizbai, I.A. (2020) Upregulation of Nucleotide-Binding Oligomerization Domain-, LRR- and Pyrin Domain-Containing Protein 3 in Motoneurons Following Peripheral Nerve Injury in Mice. Front Pharmacol. 2020 Nov 26; 11:584184. (IF2019 = 4.225, Journal Ranking: Q1)

3. Grexa, I., Fekete, T., Molnár, J., Molnár, K., Vizsnyiczai, G., Ormos, P., Kelemen, L. (2020) Single-cell elasticity measurement with an optically actuated microrobot. Micromachines (Basel). 2020 Sep 22;11(9):E882. (IF2019 = 2.523, Journal Ranking: Q2)

4. Mészáros, Á., Molnár, K., Nógrádi, B., Hernádi, Z., Nyúl-Tóth, Á., Wilhelm, I., Krizbai, I.A. (2020) Neurovascular inflammaging in health and disease. Cells. $2020 \mathrm{Jul}$ 4;9(7):1614. (IF2019 = 4.366, Journal Ranking: Q2)

5. Nyúl-Tóth, Á., Kozma, M., Nagyőszi, P., Nagy, K., Fazakas C., Haskó, J., Molnár, K., Farkas, A.E., Végh, A.G., Váró, G., Galajda, P., Wilhelm, I., Krizbai, I.A. (2017) Expression of pattern recognition receptors and activation of the non-canonical inflammasome pathway in brain pericytes. Brain Behav Immun. 2017 Aug;64:220-231. $(\mathrm{IF}=6.306$, Journal Ranking: D1)

6. Török, N., Molnár, K., Füvesi, J., Karácsony, M., Zsiros, V., Fejes-Szabó, A., Fiatal, S., Ádány, R., Somogyvári, F., Stojiljković, O., Vécsei, L., Bencsik K. (2015) Chemokine receptor $\mathrm{V} \Delta 32$ deletion in multiple sclerosis patients in Csongrád County in Hungary and the North-Bácska region in Serbia. Hum Immunol. 2015 Jan;76(1):5964. (IF = 2.127, Journal Ranking: Q1) 
1. Figueira, I., Galego, S., Custódio-Santos, T., Vicente, R., Molnár, K., Haskó, J., Malhó, R., Videira, M., Wilhelm, I., Krizbai, I., Brito, M.A. Picturing breast cancer brain metastasis development to unravel molecular players and cellular crosstalk.

2. Fazakas, C., Kozma, M., Molnár, K., Kincses, A., Dér, A., Fejér, A., Horváth, B., Wilhelm, I., Krizbai, IA., Végh, AG. Breast adenocarcinoma-derived exosomes lower first-contact de-adhesion strength of adenocarcinoma cells to brain endothelial layer.

3. Török, N., Maszlag-Török, R., Molnár, K., Szolnoki, Z., Somogyvári, F., Boda, K., Tanaka, M., Klivényi, P., Vécsei, L. Single nucleotide polymorphisms of indoleamine 2,3-dioxygenase 1 influenced the age onset of Parkinson's disease. 


\section{Abbreviations}

AM

ANOVA

AQP4

BBB

BCA

BSA

cDNA

CEC

CNS

DMEM

DMEM/F12

DNA

EBM-2

E-cadherin

ECM

EDTA

EdU

EGFP

ELISA

EmGFP

EMT

EV

FAK

FBS

GBM

GFAP

Her2

HUVEC

IGF

IGF1R
Astrocyte medium

Analysis of variance

Aquaporin-4

Blood-brain barrier

Bicinchoninic acid assay

Bovine serum albumin

complementary DNA

Cerebral endothelial cell

Central nervous system

Dulbecco's Modified Eagle Medium

DMEM Nutrient F-12 Ham

Deoxyribonucleic acid

Endothelial cell basal medium-2

Epithelial cadherin

Extracellular matrix

Ethylenediaminetetraacetic acid

5-ethynyl-2'-deoxyuridine

Enhanced green fluorescent protein

Enzyme-linked immunosorbent assay

Emerald green fluorescent protein

Epithelial-to-mesenchymal transition

Extracellular vesicle

Focal adhesion kinase

Foetal bovine serum

Glioblastoma multiforme

Glial fibrillary acidic protein

Human epidermal growth factor receptor 2

Human umbilical vein endothelial cells

Insulin-like growth factor

Type 1 insulin-like growth factor receptor 


\begin{tabular}{|c|c|}
\hline JAM & Junctional adhesion protein \\
\hline MAPK & Mitogen-activated protein kinase \\
\hline $\mathrm{MEF} 2 \mathrm{C}$ & Myocyte enhancer factor $2 \mathrm{C}$ \\
\hline miRNA & micro RNA \\
\hline mRNA & messenger RNA \\
\hline N-cadherin & Neural cadherin \\
\hline NGS & New generation sequencing \\
\hline NVU & Neurovascular unit \\
\hline $\mathrm{P} / \mathrm{S}$ & Penicillin/streptomycin \\
\hline PA & Plasminogen activator \\
\hline $\mathrm{PB}$ & Phosphate buffer \\
\hline PBS & Phosphate buffered saline \\
\hline PDGFR $\beta$ & Platelet-derived growth factor receptor $\beta$ \\
\hline PFA & Paraformaldehyde \\
\hline PM & Pericyte medium \\
\hline PPP & Picropodophyllin \\
\hline qPCR & Quantitative polymerase chain reaction \\
\hline RIPA & Radioimmunoprecipitation assay buffer \\
\hline RNA & Ribonucleic acid \\
\hline RPMI & Roswell Park Memorial Institute 1640 medium \\
\hline SDS-PAGE & Sodium dodecyl sulphate-polyacrylamide gel electrophoresis \\
\hline SLC & Solute carrier \\
\hline SMA & Smooth muscle actin \\
\hline STED & Stimulated emission depletion \\
\hline TBS-T & Tris-buffered saline with $0.1 \%$ Tween-20 \\
\hline TEM & Transmission electron microscopy \\
\hline TNBC & Triple negative breast cancer \\
\hline VE-cadherin & Vascular endothelial cadherin \\
\hline YFP & Yellow fluorescent protein \\
\hline $\mathrm{ZO}$ & Zonula occludens \\
\hline
\end{tabular}




\section{Introduction}

\subsection{Development of brain metastases}

Brain metastases are secondary tumours formed after haematogenous spreading of cancer cells from a primary or metastatic malignant lesion into the central nervous system (CNS). According to epidemiological data, in the brain, metastases occur more frequently than primary malignant tumours $[1,2]$.

Brain metastases are devastating complications of few tumour cell types, commonly taking their origin from lung cancer, breast cancer and melanoma [3]. From all malignant tumours, lung cancer emerges most frequently in brain metastasis. Approximately $40 \%$ of lung cancer patients develop brain metastases during their disease [4]. After lung cancer, the second most frequent cause of brain metastases is breast cancer, which is a complex and heterogeneous disease and a leading cause of cancer-related death in women worldwide [5]. Every twelfth female is affected in Western Europe and the United States of America, overall, it claims more than half a million human lives every year [6]. Breast cancer is responsible for about $30 \%$ of the total incidence of brain metastases [7]. Brain lesions primarily occur in triple negative (estrogen receptor, progesterone receptor and human epidermal growth factor receptor 2 (Her2/neu) negative) and in Her2/neu-overexpressing mammary tumours. In frequency, the third most common cause of brain metastasis is malignant melanoma, which accounts for 5$20 \%$ of the cases. Nonetheless, melanoma has the highest predilection to metastasize the brain. Nearly $20 \%$ of melanoma patients are found to have CNS metastasis at the time of the diagnosis and autopsy reports show that $75 \%$ of those who died of this disease developed brain metastasis $[8]$.

The most frequent intracranial metastatic site is the brain parenchyma (cerebrum, cerebellum and brainstem), most commonly the cerebral grey matter-white matter border; however, dura, leptomeninges, pituitary gland, pineal gland, choroid plexus and ventricles can also be affected. Depending on the localization, already small metastatic lesions can cause severe neurological problems. Surrounding brain parenchyma is often oedematous. The main symptoms are often non-specific, like headache, vomiting, nausea, hemiparesis, visual changes and seizures. Brain metastases often occur in conjunction with extracranial metastases, of which lung metastases are the most frequent.

Presence of brain metastases results in a very poor outcome, meaning that the median survival for non-treated patients is usually few months. Despite some significant therapeutic 
progress in non-cerebral malignancies, the treatment of brain metastases is still a complicated challenge. In practice, beside palliative care, treatment options include surgery and radiotherapy (whole-brain radiotherapy and stereotactic radiosurgery). The estimated frequency of brain metastases varies significantly between countries, but the overall cases occur approximately in 9-10\% of diagnosed cancer patients [9].

Since the efficiency of metastasis formation highly depends not only on the metastatic cells but also on the environment, it is essential to understand the unique properties of the brain microenvironment formed by cellular and non-cellular elements of the neurovascular unit (NVU).

\subsection{The neurovascular unit}

The NVU is a relatively new concept in neuroscience that describes the close relationship between brain cells and their blood vessels [10]. It is formed by cerebral endothelial cells (CECs) conjoined by cellular junctions, together with pericytes, glial cells and neurons [11]. Besides cellular elements, the basement membrane is also an integral part of the NVU, which contributes to the integrity of the blood-brain barrier (BBB). The vascular basement membrane consists of a three-dimensional network predominantly composed of extracellular matrix (ECM) proteins-i.e. laminins, collagen IV isoforms, nidogens, and heparan sulfate proteoglycans - that mutually support interactions between CECs, pericytes, and astrocytes [12]. As a morphological unit, the NVU has important functional roles, including constitution and maintenance of the BBB and regulation of cerebral blood flow and homeostasis.

BBB-forming CECs are very flat cells (with an average thickness range of 0.3-1 $\mu \mathrm{m}$ ) with neighbouring cells usually overlapping, and interconnected by tight junctions, thus forming the tightest endothelial barrier in the organism [13]. However, they possess numerous properties that enable them to regulate the transport of water, ions, molecules and cells through the blood vessels and maintain CNS homeostasis [14-16]. CECs express numerous specific solute carriers (SLC) which facilitate the flux of essential solutes and nutrients (such as glucose and amino acids) from blood to brain or from brain to blood [17].

Beside its carrier function, the BBB is primarily a defense line that strictly limit the transport of potentially harmful substances and cellular elements from the blood to the brain. The paracellular barrier is represented by tight junctions and restricts the free movement of watersoluble substances between two adjacent cells [18]. Tight junction proteins consist of transmembrane and cytoplasmic plaque proteins. The three major integral membrane proteins 
are claudins (mainly claudin-5), occludin and junctional adhesion proteins (JAM-1 and JAM3) involved in intercellular contacts and interactions with cytoplasmic scaffolding proteins such as zonula occludens (ZO-1 and ZO-2) proteins, actin cytoskeleton and associated proteins, such as protein kinases, small GTPases and heterotrimeric G-proteins [3, 19]. Beside tight junction proteins, adherens junctions are also parts of the interendothelial junctional complex. They are composed of cadherins (mostly VE-cadherin and low levels of $\mathrm{N}$ - and E-cadherin) and catenins ( $\alpha-, \beta-, \gamma-$ and p120-catenin) [20]. Besides continuous tight junctions interconnecting the cells, CECs are equipped with other barrier features, including efflux transporters and metabolic enzymes.

Barrier properties of CECs are induced and maintained by the neural environment, especially mural cells (pericytes) and astrocytes. In contrast to lymph vessels, blood vessels are normally supported by mural cells [21]. In case of larger vessels (arteries, arterioles, veins and venules) these cells are vascular smooth muscle cells, but in capillaries, pericytes are the mural cells located in proximity to the endothelium. Pericyte abundance varies between different organs. The CNS vasculature has the highest pericyte density with a ratio of 1:1-3:1 between CECs and pericytes, while the pericyte coverage is $30-80 \%$ [22, 23].

Pericytes are located in the duplication of the basement membrane of microvessels, and they actively communicate with CECs and astrocytes through direct physical contact or paracrine signalling [24]. Besides thin-stranded pericytes on capillaries, transitional forms of pericytes are also found on pre-capillary arterioles, and post-capillary venules [25]. Pericytes have an important role in the maintenance of the barrier properties of the BBB, in the regulation of endothelial proliferation, blood vessel maturation and angiogenesis [23, 26]. Similarly to smooth muscle cells of larger vessels, pericytes can induce vasoconstriction of capillaries to regulate vascular diameter and capillary blood flow [24, 27]. Pericytes are relatively undifferentiated, pluripotent cell types that can differentiate into fibroblasts, smooth muscle cells or macrophages if required [26].

Astrocytes are star-shaped glial cells in the CNS. They have a crucial role in maintaining the barrier properties of the BBB [28]. Furthermore, astrocytes supply surrounding neurons with nutrients and maintain extracellular ion balance via the clearance of excess potassium and neurotransmitters during neuronal activity [29]. End-feet of astrocytes cover almost the whole surface of the capillary walls forming the glia limitans perivascularis, thereby ensheathing not only endothelial cells but also the intimately associated pericytes [30]. In contact with blood vessels, highly polarized astrocytic foot processes are rich in the aquaporin-4 (AQP4) water channel, which is widely used as a marker protein for glia limitans perivascularis [31]. 


\subsection{Interaction of metastatic tumour cells with the NVU}

To form metastasis, tumour cells have to complete a defined set of events, such as disseminating from the primary tumour as individual cancer cells and multi-cellular clusters, entering the blood or lymphatic vessels (intravasation), invading the target organ and surviving in the alien microenvironment [32]. Initial steps of brain metastasis formation are common with the development of non-cerebral metastases; however, interaction of metastatic cells with the NVU confers very unique aspects to brain tumours.

Presence of the BBB [3], tumour heterogeneity and plasticity [33] and unique molecular features of brain metastatic cells [34] all contribute to the poor outcome of cerebral secondary tumours and the limited effectiveness of current treatments. Therefore, it is surprising that some cancer types give metastases preferentially to the brain. This phenomenon draws the attention to the possibility that cells of the NVU (including CECs, astrocytes and microglia) have Janusfaced attitudes towards tumour cells, i.e. killing the vast majority of brain invading metastatic cells, but protecting those that are able to overcome the detrimental mechanisms.

\subsubsection{Cerebral endothelial cells and their role in brain metastasis formation}

Since the CNS lacks the classical lymphatic vessel system, metastatic cells can reach the brain only through the bloodstream. CECs form the first defense line cancer cells interact with during metastasis formation. Although the main steps of the transmigration process (rolling, adhesion and transmigration/diapedesis) may show some similarities with leukocyte diapedesis, due to different physiological, molecular and mechanical characteristics of immune and metastatic cells, there may be significant differences [3, 35]. In respect to the routes of leukocyte transmigration, one could distinguish two fundamental approaches, the paracellular pathway (through the interendothelial junctions) and the transcellular pathway (through individual endothelial cells). During neuroinflammation, leukocyte diapedesis can either occur by forming a paracellular gap or - primarily — via the formation of a transcellular pore [36, 37]. Albeit the explicit underlying molecular mechanisms involved in the extravasation of leukocytes have been largely described, much less is known about the extravasation routes and mechanisms of tumour cells $[35,38]$. Arrest of metastatic cells does not seem to be random, since breast cancer cells, for instance, tend to extravasate through the microvasculature of lungs, liver and brain, where vessels are more curved and branched which is favourable for tumour cells [39]. As a unique feature of brain metastasis formation, tumour cells spend several days in cerebral capillaries before proceeding to diapedesis through the vessel wall. CECs express a variety of 
cell adhesion molecules (integrins, selectins and the members of immunoglobulin superfamily) which are necessary for e.g. leukocyte adhesion during inflammation. Cancer cells also take advantage of some of these adhesion molecules to interact with endothelial cells [40]. After overcoming the endothelium and completing transmigration, tumour cells infiltrate the brain parenchyma, where mainly utilize a non-angiogenic process and co-opt the pre-existing tissue vessels to provide the tumour mass with essential nutrients and oxygen [41].

\subsubsection{Janus-faced role of astrocytes in brain metastases}

Astrocytes interact in various ways with incoming cancer cells, and these interactions can give both pro-metastatic and anti-metastatic stimuli for metastasizing cells. In the surroundings of brain tumours and metastases, reactive astrogliosis can be observed, astrocytes upregulate glial fibrillary acidic protein (GFAP) expression, change their phenotype to hyperplastic and isolate the tumour mass from the neural tissue [42]. On the other hand, astrocytes were shown to reduce apoptosis through gap junctions in human melanoma cells treated with various chemotherapeutic drugs if cells were in direct contact with each other [43]. Furthermore, astrocytes express the ECM-degrading enzyme heparanase and endothelin isoforms, which can support brain invasion [44] and they can support the growth and survival of the breast cancer cells by activating the mitogen-activated protein kinase (MAPK) and Akt pathways in cancer cells through secreted factors $[45,46]$. Reactive astrocytes are the main sources of plasminogen activator (PA) which converts plasminogen to plasmin, an endopeptidase which acts defensively against metastatic invasion and supresses metastasis formation. On the other hand, lung and breast cancer cells express high levels of PA inhibitor serpins to prevent plasmin production and its anti-metastatic effects [47].

\subsubsection{Brain pericytes: dark horses in the brain metastatic disease}

A growing number of evidence suggests that brain pericytes take part in different neurological diseases, such as stroke, Alzheimer's disease, ischaemia, traumatic brain injury and also glioblastoma multiforme (GBM) [48-50]. In GBM, $\alpha$-smooth muscle actin ( $\alpha$-SMA)expressing pericytes undergo abnormal proliferation, which is a characteristic for glioblastomainduced malformed vasculature [51]. Additionally, others found evidence for GBM cell/pericyte fusion-hybrids, some of which are located on abnormally constricted vessels ahead of the tumour and linked to tumour-promoting hypoxia [52]. Interactions of brain pericytes with 
metastatic tumour cells are largely unexplored, but pericytes have recently emerged as important players in creating the pre-metastatic niche in peripheral organs [53].

\section{Aims}

In our experiments, we aimed at understanding reactions of the cellular elements of the NVU to the presence of metastatic tumour cells. We brought pericytes in the focus because the molecular details of the interactions of brain pericytes with metastatic tumour cells are largely unknown. We were primarily interested in breast cancer, especially triple negative breast cancer (TNBC) since it is the most aggressive and successful brain metastasizing breast cancer subtype and one of the leading causes of brain metastases. We had previous results showing that melanoma cells utilize the paracellular migration during their invasion into the brain parenchyma. For this reason, we used these cells as a comparison.

Using in vitro and in vivo methods and human surgical samples as well, our specific aims were the following:

- To determine the possible transmigration routes of breast cancer cells: whether they use the paracellular or the transcellular way.

- To understand the reactions of CECs to invading TNBC cells.

- To explore whether metastasizing TNBC cells breach the glia limitans perivascularis and to find new mechanisms of interaction between cancer cells and astrocytes.

- To assess the role of pericytes in adhesion and proliferation of tumour cells in vitro and in vivo.

- To decipher the role of pericyte-secreted insulin-like growth factors (IGFs) in the proliferation of TNBC cells in the brain. 


\section{Materials and methods}

\subsection{Model systems}

\subsubsection{In vitro models (cell culture)}

\section{i. Culture of human NVU cells}

Human brain vascular pericytes (abbreviated as HBVP; obtained from ScienCell Research Laboratories) were cultured on poly-L-lysine-coated dishes in Pericyte Medium (PM; ScienCell Research Laboratories) supplemented with 5\% fetal bovine serum (FBS; Sigma Aldrich) and penicillin/streptomycin solution (P/S; ScienCell Research Laboratories) and used between passage numbers 2 and 6. Human astrocytes (HA; ScienCell Research Laboratories) were grown on poly-L-lysine-coated dishes in Astrocyte Medium (AM) supplemented with 5\% FBS and P/S (all from ScienCell Research Laboratories) and used between passage numbers 2 and 4. Human microvascular cerebral endothelial cells (hCMEC/D3, shortly D3) were cultured on rat-tail collagen-coated dishes in Endothelial Cell Basal Medium-2 (EBM-2) with EGM-2MV kit including supplements and 2\% FBS (all from Lonza) and used between passage numbers 30 and 40.

\section{ii. Isolation and culture of rodent NVU cells}

Venus-YFP-expressing primary mouse brain endothelial cells (abbreviated as MBEC) were isolated from 6 to 8-week-old FVB/Ant:TgCAG-yfp_sb \#27 mice (obtained from Institute of Experimental Medicine, Budapest, Hungary; expressing Venus-YFP (yellow fluorescent protein) in endothelial cells). Primary rat brain endothelial cells (RBEC) were isolated from 2 to 3 -week-old rats. The same isolation protocol was used for isolation from mice and rats. The animals were sacrificed by cervical dislocation. After collection of the brains, meninges were removed and cerebral cortices were cut into small pieces and digested with $1 \mathrm{mg} / \mathrm{ml}$ collagenase type 2 (Sigma Aldrich) and $1 \mathrm{mg} / \mathrm{ml}$ DNase I for 55 minutes at $37^{\circ} \mathrm{C}$. After the first enzymatic digestion tissue was centrifuged with $20 \%$ bovine serum albumin (BSA; Sigma Aldrich) in low-glucose Dulbecco's Modified Eagle Medium (DMEM; Thermo Fisher Scientific) to remove myelin. The second digestion was performed with $1 \mathrm{mg} / \mathrm{ml}$ collagenase/dispase (Roche) and DNase I for 50 minutes at $37^{\circ} \mathrm{C}$. Microvessel fragments were collected after centrifugation on Percoll gradient (Sigma Aldrich) and plated onto fibronectin and collagen type IV coated dishes. Endothelial cells growing out of the microvessels were 
cultured in DMEM Nutrient F-12 Ham (DMEM/F12; Thermo Fisher Scientific), 10\% plasmaderived serum (PDS; First Link), insulin-transferrin-sodium selenite (ITS) supplement (Sigma Aldrich), heparin (Sigma Aldrich) and basic fibroblast growth factor (bFGF; Sigma Aldrich). In the first 2 days, $4 \mu \mathrm{g} / \mathrm{ml}$ puromycin was added to the culture medium to remove contaminating cells. Murine pericytes were collected after the first enzymatic digestion and were seeded onto rat tail collagen-coated dishes. Cells were kept in PM medium supplemented with 5\% FBS and P/S solution. Mouse pericytes were used for experiments after passage 5. Mouse astrocytes were isolated from BALB/c (The Jackson Laboratory) P1 to P3 mouse pups. Animals were sacrificed by decapitation. After brains were collected, meninges were removed and brain tissue was collected into DMEM medium. Using a needle, tissue was triturated 5times. Tissue pieces were allowed to settle down and $3 \mathrm{ml}$ of supernatant was transferred into $15 \mathrm{ml}$ tube. Sediment was resuspended and trituration was repeated until $15 \mathrm{ml}$ of suspended cells were collected. Astrocytes were seeded onto poly-L-lysine coated dishes and were kept in low-glucose DMEM (Thermo Fisher Scientific) supplemented with 10\% FBS.

\section{iii. Culture of tumour cells}

MDA-MB-231 (shortly MDA) human TNBC cells were kept in low-glucose DMEM with 5\% FBS. Enhanced green fluorescent protein (EGFP)-expressing MDA-MB-231 cells (shortly EGFP-MDA) were obtained by transfection of the cells with the pEGFP-C1 plasmid using TurboFect reagent (Thermo Fisher Scientific) and selection with $500 \mu \mathrm{g} / \mathrm{ml} \mathrm{G418}$ (Thermo Fisher Scientific). A2058 human melanoma cells (obtained from the European Collection of Authenticated Cell Cultures) were maintained in Minimum Essential Medium Eagle with Earle's salts and non-essential amino acids (EMEM; Sigma Aldrich) supplemented with 5\% FBS and Glutamax (Thermo Fisher Scientific). Enhanced green fluorescent protein (EGFP)-expressing A2058 cells (shortly EGFP-A2058) were obtained by transfection of the cells with the pEGFP-C1 plasmid using TurboFect reagent and selection with $500 \mu \mathrm{g} / \mathrm{ml}$ G418. 4T1 mouse triple negative mammary carcinoma cells were kept in Roswell Park Memorial Institute 1640 medium (RPMI; Thermo Fisher Scientific) with Glutamax supplemented with $5 \%$ FBS. 4T1 cells were transfected with pcDNA3.1(+)/Luc2 $=$ tdT plasmid (abbreviated as tdTomato-4T1) using Lipofectamine 2000 (Thermo Fisher Scientific) and underwent singlecell cloning, after sorting of red fluorescent cells using a BD FACSAria Fusion flow cytometer (BD Biosciences). The media of tdTomato-4T1 cells contained $500 \mu \mathrm{g} / \mathrm{ml} \mathrm{G} 418$ for further selection and maintenance of red fluorescence. Emerald GFP-expressing EmGFP-4T1 cells were obtained by retroviral transfection and selected on blasticidin S (Sigma Aldrich). B16/F10 
murine melanoma cells were kept in RPMI 1640 medium with Glutamax supplemented with $5 \%$ FBS.

All cell lines were regularly tested for mycoplasma contamination using the MycoAlert Mycoplasma Detection Kit (Lonza). Only mycoplasma-negative cultures were used for experiments.

\subsubsection{In vivo models}

All mice were housed and treated in accordance with widely accepted standards and the protocols were approved by the institutional care and the Regional Animal Health and Food Control Station of Csongrád County (permit number: XVI./764/2018). Surgeries were carried out on 6-10 week old female BALB/c mice or FVB/Ant:TgCAG-yfp_sb \#27 mice. The wellbeing of the animals was monitored daily during the post-operative period. No infection or wound dehiscence was detected, neither any signs of chronic pain. Maximum 5\% weight loss was observed, the operation-induced mortality rate was $2-3 \%$.

\section{i. Injection of tumour cells into the common carotid artery or the left ventricle}

For ex vivo experiments, FVB/Ant:TgCAG-yfp_sb \#27 mice received 3 x $10^{6}$ tdTomato-4T1 cells by intracardiac injection and left for 4-10 days. In another set of experiments (presented in Figure 5C), BALB/c mice were injected with $10^{6} 4 \mathrm{~T} 1$ cells into the common carotid artery and were sacrificed on day 7 post-surgery. In experiments presented in Figure 6A, $10^{6}$ tdTomato-4T1 cells were injected into the common carotid artery and sacrificed after 7 days. At the indicated time points, animals were anaesthetized and transcardially perfused with phosphate buffered saline (PBS), then with 4\% paraformaldehyde (PFA) in PBS. Brains were removed and post-fixed by immersion in the same fixative at $4^{\circ} \mathrm{C}$ overnight. The following day, the fixative was replaced with $30 \%$ sucrose solution in $0.1 \mathrm{M}$ phosphate buffer (PB), and the brains were stored at $4^{\circ} \mathrm{C}$ for further processing.

Certain FVB/Ant:TgCAG-yfp_sb \#27 mice inoculated with tdTomato-4T1 cells were subjected to in vivo proliferation assay and treated intraperitoneally with 5-ethynyl-2'deoxyuridine (EdU, Thermo Fisher Scientific, $100 \mathrm{mg} / \mathrm{kg}$ ), a thymidine analogue, 24 hours before tissue collection.

For testing the effect of picropodophyllin (PPP) on tumour growth in vivo, on days 5 and 6 post-injection, mice received $40 \mathrm{mg} / \mathrm{kg}$ PPP (Alfa Aesar, Thermo Fisher Scientific) in corn oil 
or vehicle only, intraperitoneally. On day 8 , mice were transcardially perfused and fixed, as described above.

After fixation, whole mouse brains were prepared for sectioning with a freezing microtome (Reichert-Jung, Leica Biosystems) or a vibratome (VT1000 S, Leica Biosystems) (for claudin5 and AQP4 stainings), and $20 \mu \mathrm{m}$ or $50 \mu \mathrm{m}$ thick coronal brain sections were cut, respectively, which were kept in PBS with $0.02 \%$ sodium azide until further processing.

\section{ii. Collection of plasma samples}

Blood samples were collected for analysis of miRNA expression in plasma by nextgeneration sequencing (NGS) and further validation by quantitative polymerase chain reaction (qPCR). Approximately $500 \mu 1$ blood samples were collected directly from the heart of live mice under isoflurane anaesthesia. The samples were collected using syringes previously washed with ethylenediaminetetraacetic acid (EDTA, $0.5 \mathrm{M}, \mathrm{pH}=8$ ) into tubes containing $40 \mu 1$ of the anticoagulant. After collection, the blood samples were centrifuged for 10 minutes at $380 \times \mathrm{g}$, at $4{ }^{\circ} \mathrm{C}$, and the plasma was collected. The plasma samples were stored at $-80{ }^{\circ} \mathrm{C}$ until further analysis.

\section{iii. Preparation of cranial window for two-photon microscopy}

FVB/Ant:TgCAG-yfp_sb \#27 mice were injected with tdTomato-4T1 cells, as described above. In another set of experiments, BALB/c female mice were intracardially injected with 3 x $10^{6}$ EmGFP-4T1 and left for 10 days later. Anaesthetized animals were mounted on a stereotaxic frame incorporating a heating pad. Craniotomy $(\mathrm{d}=3.5 \mathrm{~mm})$ was performed over the right parietal cortex with a micro drill (H.MH-170, High Speed Rotary Handpiece, Foredom, Blackstone Industries) fitted with a $0.5 \mathrm{~mm}$ burr, followed by the removal of the dura. Astrocytes were labelled by topical application of $10 \mu \mathrm{M}$ SR101 (Sigma Aldrich) in RingerHEPES solution for 2-3 minutes. A coverslip of $5 \mathrm{~mm}$ diameter was then placed over the exposed brain surface and the edge of the glass was sealed with cyanoacrylate glue. An aluminium plate was glued onto the skull for head fixation. The exposed bone and the

aluminium bar were covered with cyanoacrylate glue and dental cement (Unifast III, GC Europe) to increase stability. Astrocyte-tumour cell interactions were investigated in a time frame of 30 minutes to 2 hours after cranial window installation due to the temporary astrocyte staining. 


\subsubsection{Human samples}

Human TNBC brain metastasis and control brain samples were acquired from the Department of Pathology, University of Szeged. Human samples were collected in accordance with the permission of the Human Investigation Review Board, University of Szeged (permit number: EMLOSEB001, issued on January 31, 2017), in agreement with the Declaration of Helsinki of the World Medical Association. Surgical samples were fixed in PFA and embedded into paraffin blocks. Five $\mu \mathrm{m}$ thick slices were used for immunofluorescence staining. After deparaffinization in xylol, samples were rehydrated through a descending series of alcohol to distilled water.

\subsection{In vitro methods}

\subsubsection{Endothelial-tumour cell co-cultures}

For transmigration experiments, primary RBECs were gently trypsinized and passed onto fibronectin/collagen-coated filter inserts $\left(8 \mu \mathrm{m}\right.$ pore size, $1.13 \mathrm{~cm}^{2}$, Corning-Costar Transwell Clear; for electron microscopy) which were placed in 12-well plates. After reaching confluency, endothelial cells were supplemented with $550 \mathrm{nM}$ hydrocortisone, $250 \mu$ M CPT-cAMP (Sigma Aldrich) and 17.5 $\mu \mathrm{M}$ RO-201724 (Roche) from the apical side and astrocyte-conditioned medium (collected from confluent astrocyte cultures after 72 hours) from the basolateral side for 24 hours in order to tighten the junctions. In this way we could achieve high transendothelial electrical resistance values. $10^{5}$ CellTracker Red CMTPX (Thermo Fisher Scientific)-labelled melanoma and breast cancer cells were plated into the upper compartment onto the endothelial monolayer in serum-free medium for 8 hours.

For immunofluorescence studies, D3 cells were cultured until confluence on microscope slides (Ibidi). CellTracker Red CMTPX-stained tumour cells were seeded upon the endothelial monolayer in a density of $10^{5}$ cells $/ \mathrm{cm}^{2}$ surface and left for 5 hours.

\subsubsection{Preparation of pericyte-conditioned media}

Human and mouse pericytes were grown until 90\% confluency in $6 \mathrm{~cm}$ culture dishes. Growth medium was replaced with HBVP complete medium $(\mathrm{PM}+5 \% \mathrm{FBS}+\mathrm{P} / \mathrm{S})$ and left for 2 days. Non-conditioned complete medium was used as a negative control. All media were filtered through $0.2 \mu \mathrm{m}$ pore size syringe filters to remove cells and debris. 
Extracellular vesicles (EVs) were depleted from HBVP control and conditioned media by using a serial centrifugation protocol: $700 \times g, 5$ minutes; $1,000 \times g, 8$ minutes; $10,000 \times g$, 30 minutes and 150,000 x $g$, 90 minutes. Media were collected and filtered through $0.1 \mu \mathrm{m}$ pore size syringe filters.

\subsubsection{Migration assays}

\section{i. Short distance migration assay (wound healing)}

$3 \times 10^{4}$ MDA cells together with $1.5 \times 10^{4} \mathrm{HBVP}$ and $3 \times 10^{4} \mathrm{D} 3$ cells were seeded into rattail collagen-coated silicone 3-well culture inserts (Ibidi). After reaching confluency, the insert was removed and culture medium was changed to Leibovitz's L-15 medium (Sigma Aldrich) supplemented with $1 \%$ FBS. Migration of tumour and NVU cells was monitored for 24 hours in phase-contrast.

\section{ii. Long distance migration assay}

$3 \times 10^{4}$ HBVP cells, $6 \times 10^{4}$ EGFP-MDA and $6 \times 10^{4}$ D3 cells were seeded into every second well of a rat-tail collagen-coated silicone 12-well culture insert (Ibidi). After reaching confluency, the insert was removed. After 5 days, phase-contrast and fluorescence images were taken from the whole area and an overview image was generated.

\subsubsection{Adhesion to surface}

$5 \times 10^{5}$ tumour cells were seeded into 6-well plates in pericyte-conditioned or control media and left for 20 minutes (A2058, 4T1 and B16) or 120 minutes (MDA). Floating cells were collected by centrifugation and phase-contrast images were taken from attached cells. The efficiency of cell adhesion was determined by counting the adherent cells.

\subsubsection{Cell-to-cell adhesion}

D3, HBVP, or HA cells were seeded into 12-well plates (poly-L-lysine coated) in a density of $2 \times 10^{4}$ cells/well. After 24 hours, $1.5 \times 10^{4}$ cells/well EGFP-MDA or EGFP-A2058 were seeded onto the cells and incubated for $24 \mathrm{~h}$. Phase-contrast and fluorescence images were taken with a Nikon Eclipse TE2000U microscope connected to a digital camera (Spot RT KE, Diagnostic Instruments). Attached fluorescent cells were counted using Fiji software. 


\subsubsection{Proliferation assays}

\section{i. Phase-contrast imaging and cell number counting}

$10^{4}$ tumour cells/well were plated into 6-well plates in control or pericyte-conditioned medium in the presence or the absence of $100 \mathrm{nM}$ PPP. Fresh medium was given every other day. In order to identify the effect of EVs in tumour cell proliferation, we cultured the tumour cells in EV-depleted control and pericyte-conditioned medium the same way as described above. For cell counting, phase-contrast images were taken every day. After 4 days, cells were collected in radioimmunoprecipitation assay buffer (RIPA) for western-blot analysis.

\section{ii. Real-time impedance monitoring}

$10^{4}$ tumour cells were seeded into E-plates in control or pericyte-conditioned medium with or without $100 \mathrm{nM}$ PPP. Fresh medium was provided after 48 hours. Electrical impedance was measured in real-time using the xCELLigence system (ACEA Biosciences).

\subsubsection{Silencing of Igf 2 gene}

Stealth ${ }^{\mathrm{TM}}$ siRNA duplex oligoribonucleotides were designed using Invitrogen BLOCK-iT ${ }^{\mathrm{TM}}$ RNAi designer and purchased from Thermo Fisher Scientific. The following sequences were used: sense, 5'-UCGAUGCUGGUGCUUCUCACCUUCU-3' and antisense, 5'AGAAGGUGAGAAGCACCAGCAUCGA-3'. HBVP cell transfection was performed with Lipofectamine 2000, as previously described [54].

\subsection{Biochemistry and molecular biology methods}

\subsubsection{Next generation sequencing (NGS)}

NGS and subsequent data analysis was performed by Sarah J. Medina and Stephanie A. Booth (Prion Diseases Section, Public Health Agency of Canada, National Microbiology Laboratory, Winnipeg, Canada).

\subsubsection{RNA isolation and quantitative real-time polymerase chain reaction}

For miRNA analysis, we first isolated total RNA from the collected mouse plasma samples using the miRCURY RNA Isolation Kit for biofluids (Exiqon), according to manufacturer's instruction. RNA was then transcribed into cDNA, using the reverse transcription kit Universal 
cDNA Synthesis Kit II (Exiqon), according to manufacturer's instructions for plasma. However, the initial RNA volume was increased 4-times in a final volume of reaction of $15 \mu 1$. Prior to the reverse transcription reaction, the synthetic RNA Spike-in Uni-SP6 (Exiqon) was added to the mixture. The qPCR was performed using the same equipment and miRCURY LNA SYBR Green PCR Kit (Exiqon) according to manufacturer's instructions using cDNA diluted 1:6. The following conditions were used: 50 cycles of $95{ }^{\circ} \mathrm{C}$ for 15 seconds, $56{ }^{\circ} \mathrm{C}$ for 30 seconds, $72{ }^{\circ} \mathrm{C}$ for 30 seconds, followed by a melting curve analysis. Predesigned LNA primer pairs were purchased from Exiqon for each of the selected miRNAs (mmu-miR-802-5p, mmumiR-194-5p) and for miR-16-5p that was used as an endogenous control to normalize the expression level.

For gene expression analysis, total RNA was isolated using TriFast $^{\mathrm{TM}}$ reagent (VWR International). Maxima First Strand cDNA Synthesis Kit (Thermo Fisher Scientific) was used to transcribe RNA into cDNA. Amplification was performed using iTaq ${ }^{\mathrm{TM}}$ Universal SYBR ${ }^{\circledR}$ Green Supermix (Bio-Rad) or Luminaris Color HiGreen qPCR Master Mix kit (Thermo Fisher Scientific) on a Bio-Rad iQ5 instrument under the following conditions: 40 cycles of $95{ }^{\circ} \mathrm{C}$ for 15 seconds, $56-60{ }^{\circ} \mathrm{C}$ for 30 seconds, $72{ }^{\circ} \mathrm{C}$ for 30 seconds, followed by a melting curve analysis, using primers detailed in Table $\mathbf{1}$.

\begin{tabular}{|c|c|c|}
\hline Gene & Forward primer $\left(5^{\prime}=>3^{\prime}\right)$ & Reverse primer $\left(5^{\prime}=>3^{\prime}\right)$ \\
\hline human IGF1 & AGAGCCTGCGCAATGGAATA & GAGATGCGAGGAGGACATGG \\
\hline human IGF2 & GACCGCGGCTTCTACTTCA & GGGGTATCTGGGGAAGTTGT \\
\hline human IGFR1 & GGCACAATTACTGCTCCAAAGAC & CAAGGCCCTTTCTCCCCAC \\
\hline human IGFR2 & AGCGAGAGCCAAGTGAACTC & TCGCTGTAAGCAGCTGTGAA \\
\hline mouse IGF1 & TGCTAAATCTCACTGTCACTGCT & CAGAGCGCCAGGTAGAAGAG \\
\hline mouse IGF2 & CCCCAGCCCTAAGATACCCT & CACCAACATCGACTTCCCCA \\
\hline GAPDH & GTGAAGGTCGGTGTCAACG & GTGAAGACGCCAGTAGACTC \\
\hline
\end{tabular}

Table 1. Primers used for real-time PCR.

\subsubsection{Methanol-chloroform precipitation and western-blot}

Conditioned media were centrifuged to settle cell debris and an equal volume of methanol and 1/4 volume of chloroform were added. Samples were vortexed, incubated for 5 minutes on ice and centrifuged at $10,000 \times \mathrm{g}$ for 5 minutes at $4{ }^{\circ} \mathrm{C}$. After phase separation, aqueous phase was removed and protein samples were washed with ice-cold methanol. Samples were vortexed 
and centrifuged again, supernatants were discarded and protein pellets were air-dried. Pellets were reconstituted in $2 \mathrm{x}$ Laemmli buffer and heated up to $95^{\circ} \mathrm{C}$ for 5 minutes.

Cells were lysed in RIPA buffer. Protein concentration was determined by using bicinchoninic acid assay (BCA, Thermo Fisher Scientific). Laemmli buffer was added to the samples and incubated at $95{ }^{\circ} \mathrm{C}$ for 5 minutes. Samples were electrophoresed using standard denaturing sodium dodecyl sulphate-polyacrylamide gel (SDS-PAGE) and blotted on polyvinylidene difluoride $(0.2 \mu \mathrm{m}$ pore size, Bio-Rad, or $0.45 \mu \mathrm{m}$ pore size, BioTrace, Pall Corporations) or nitrocellulose membranes $(0.2 \mu \mathrm{m}$ pore size, Bio-Rad). After blocking with $3 \%$ BSA or 5\% non-fat milk in Tris-buffered saline with $0.1 \%$ Tween-20 (TBS-T), membranes were incubated with primary antibodies (Table 2) overnight at $4{ }^{\circ} \mathrm{C}$. Blots were washed in TBS$\mathrm{T}$ three-times for 10 minutes, incubated for 1 hour in horseradish peroxidase-conjugated antirabbit IgG or anti-mouse IgG secondary antibodies (Jackson ImmunoResearch) diluted 1:3000 in TBS-T and then washed again in TBS-T.

Immunoreaction was visualized with Clarity Chemiluminescence Substrate (Bio-Rad) in a ChemiDoc MP System (Bio-Rad). Densitometry analysis was performed with Image Lab Software, version 5.2 (Bio-Rad).

\begin{tabular}{|c|c|c|}
\hline Primary antibody & Catalog number & Dilution \\
\hline mouse monoclonal anti-p-actin & sc-47778 (Santa Cruz Biotechnology) & $1: 1000$ \\
\hline rabbit polyclonal anti-fibronectin & ab2413 (Abcam) & $1: 1000$ \\
\hline rabbit polyclonal anti-collagen IV & ab6586 (Abcam) & $1: 1000$ \\
\hline mouse monoclonal anti-cyclin D1 & sc-8396 (Santa Cruz Biotechnology) & $1: 500$ \\
\hline m. monoclonal anti-E cadherin & C20820 (BD Transduction Laboratories) & $1: 250$ \\
\hline rabbit polyclonal anti-FAK & 3285 (Cell Signaling Technology) & $1: 500$ \\
\hline rabbit polyclonal anti-pFAK & 3283 (Cell Signaling Technology) & $1: 500$ \\
\hline mouse monoclonal anti-Src & 2110 (Cell Signaling Technology) & $1: 250$ \\
\hline rabbit polyclonal anti-pSrc & 2101 (Cell Signaling Technology) & $1: 250$ \\
\hline
\end{tabular}

Table 2: Primary antibodies used for western-blot analysis.

\subsubsection{Enzyme-linked immunosorbent assay (ELISA)}

After collection of conditioned media, HBVP cells were trypsinized and counted in a haemocytometer. Conditioned media were centrifuged at $1,000 \mathrm{x} g$ for 15 minutes at $4{ }^{\circ} \mathrm{C}$. IGF1 
and IGF2 content of conditioned media was measured using commercial ELISA kits (CSBE04580h and CSB-E04583h, respectively; Cusabio) following the manufacturer's instructions.

\subsection{Immunofluorescence on human and mouse brain sections}

Antigen retrieval was performed by boiling human sections in $10 \mathrm{mM}$ sodium citrate $(\mathrm{pH}=$ 6) for 15 minutes or by incubating mouse sections at $80{ }^{\circ} \mathrm{C}$ for 30 minutes in $10 \mathrm{mM}$ sodium citrate $(\mathrm{pH}=6)$. All sections were permeabilized in PBS with 0.5\% Triton X-100 (Sigma Aldrich) for 20 minutes, then blocked with 3\% BSA in PBS containing 0.5\% Triton X-100 for 1 hour. Primary antibodies (Table 3) were diluted in 1\% BSA with $0.5 \%$ Triton X-100 and sections were incubated overnight at $4{ }^{\circ} \mathrm{C}$ on an orbital shaker. Slides were extensively washed in PBS. Alexa Fluor 488-labelled anti-rabbit, Alexa Fluor 594-labelled anti-mouse, Alexa Fluor 647-labelled anti-goat IgG (Thermo Fisher Scientific) and STAR RED-labelled anti-rabbit IgG (Abberior) were used as secondary antibodies in a dilution of 1:300 in PBS for 60 minutes at room temperature in the dark. Sections were washed, counterstained with a nuclear dye (Hoechst 33342; Sigma Aldrich) for 10 minutes, washed again with PBS, rinsed in distilled water and mounted in FluoroMount-G (SouthernBiotech).

\begin{tabular}{|c|c|c|}
\hline Primary antibody & Catalog number & Dilution \\
\hline goat polyclonal anti-CD13 & AF2335 (BioTechne) & $1: 150$ \\
\hline rabbit monoclonal anti-PDGFRß & 3169 (Cell Signaling Technology) & $1: 100$ \\
\hline rabbit polyclonal anti-IGF1 & ab9572 (Abcam) & $1: 100$ \\
\hline rabbit polyclonal anti-IGF2 & ab226989 (Abcam) & $1: 100$ \\
\hline m. monoclonal anti-cytokeratin & MA5-12231 (Thermo Fisher Scientific) & $1: 150$ \\
\hline mouse monoclonal anti-claudin-5 & $35-2500$ (Thermo Fisher Scientific) & $1: 100$ \\
\hline rabbit polyclonal anti-GFAP & ab7260 (Abcam) & $1: 100$ \\
\hline rabbit polyclonal anti-AQP4 & sc-20812 (Santa Cruz Biotechnology) & $1: 100$ \\
\hline mouse monoclonal anti-N-cadherin & 610920 (BD Transduction Laboratories) & $1: 100$ \\
\hline rabbit polyclonal anti-MEF2C & PA5-28247 (Thermo Fisher Scientific) & $1: 250$ \\
\hline
\end{tabular}

Table 3: Primary antibodies used for immunofluorescence staining. 


\subsection{Microscopy techniques}

\subsubsection{Preparation of ultrasections and transmission electron microscopy (TEM)}

The filter inserts containing CECs and tumour cells were fixed for 2.5 hours in $2.7 \%$ glutaraldehyde and post-fixed for 75 minutes in $2 \%$ osmium tetroxide. After dehydration in graded ethanol baths, the samples were immersed in graded ethanol-Epon baths and then embedded in Epon 812. The blocks were cut with a Leica EM UC7 ultramicrotome, and the 50 $\mathrm{nm}$ thick sections were stained with uranyl acetate and lead citrate, then analyzed with a Tecnai 12 Biotwin TEM.

\subsubsection{Fluorescence microscopy}

Immunofluorescence signals were visualized with Leica SP5 and Leica SP8 confocal laser scanning microscopes with $63 \mathrm{x}$ and $100 \mathrm{x}$ oil immersion objectives or a STED (stimulated emission depletion) super-resolution-capable STEDYCON (Abberior Instruments) built on an Axio Observer Z1 inverted epifluorescence microscope (Zeiss) equipped with an alpha PlanApochromat 100x/1.46 oil immersion objective.

For assessing the effect of PPP on tumour growth in the brain, coronary brain sections were prepared from all animals from parietal cortical regions and the same volumes were used for imaging with a Leica SP5 microscope. Tumour-covered areas in control and PPP-treated animals were measured with Fiji software using a custom-made macro.

\subsubsection{Intravital two-photon imaging}

Mice were anaesthetized with isoflurane and kept on a heating system-incorporated stereotaxic stage. The head was immobilized and positioned via the attached aluminium bar. Intravital microscopy was carried out with a FEMTO2D Dual microscope (Femtonics) using a 60x, large working distance water immersion objective using MES software (v6.0, Femtonics). Two-photon excitation was performed using a tunable Mai Tai HP Ti-sapphire laser (SpectraPhysics) at $810 \mathrm{~nm}$, which was found optimal for EmGFP excitation and also adequate for SR101 detection. Laser power was set to $10-40 \%$ depending on the depth of imaging (0-400 $\mu \mathrm{m}$ from the brain surface). Emission wavelengths were collected by GaAsP photomultipliers. 


\subsection{Statistical analysis}

Student's t-test and Analysis of variance (ANOVA) were performed using the Excel 2016 Data Analysis plugin. For post-hoc tests, we applied SigmaPlot version 12.3.

\section{Results}

\subsection{Interactions of metastasizing breast cancer cells with CECs}

Development of brain metastases is largely dependent on the ability of tumour cells to migrate through the tightest endothelium of the organism, which forms the BBB. Involvement of CECs in extravasation of cancer cells into the CNS is largely uncharacterized. We were primarily interested in understanding whether the tumour cells utilize only the paracellular transmigration pathway (through interendothelial junctions), as we have previously observed for melanoma cells [38], or transcellular migration (through the endothelial cell body) is also a possibility for the tumour cells to breach the brain endothelium.

We addressed this question using our in vitro transmigration experimental setup, where we plated cancer cells onto confluent layers of CECs and compared diapedesis of melanoma and TNBC cells using TEM. After 8 hours of co-culturing cancer cells with CECs, we observed several tumour cells attached to brain endothelial cells in close proximity to the interendothelial junctions. In the neighbourhood of the tumour cells, filopodia-like endothelial protrusions could be seen, partially engulfing the invading cells (Figure 1A, B). We have also detected several breast cancer cells completely covered by endothelial processes, incorporating the tumour cell into the monolayer (Figure 1C).

Melanoma cells transmigrated only paracellularly, through the tight and adherens junctions between endothelial cells (Figure 1A), in accordance with our previous confocal microscopy results $[38,55]$. The same transmigration path was used by breast cancer cells as well (Figure 1B); however, much less frequently. In addition, mammary carcinoma cells were able to also exploit the transcellular pathway — through individual endothelial cells — during their migration from the apical to the basolateral side of CECs (Figure 1D). 

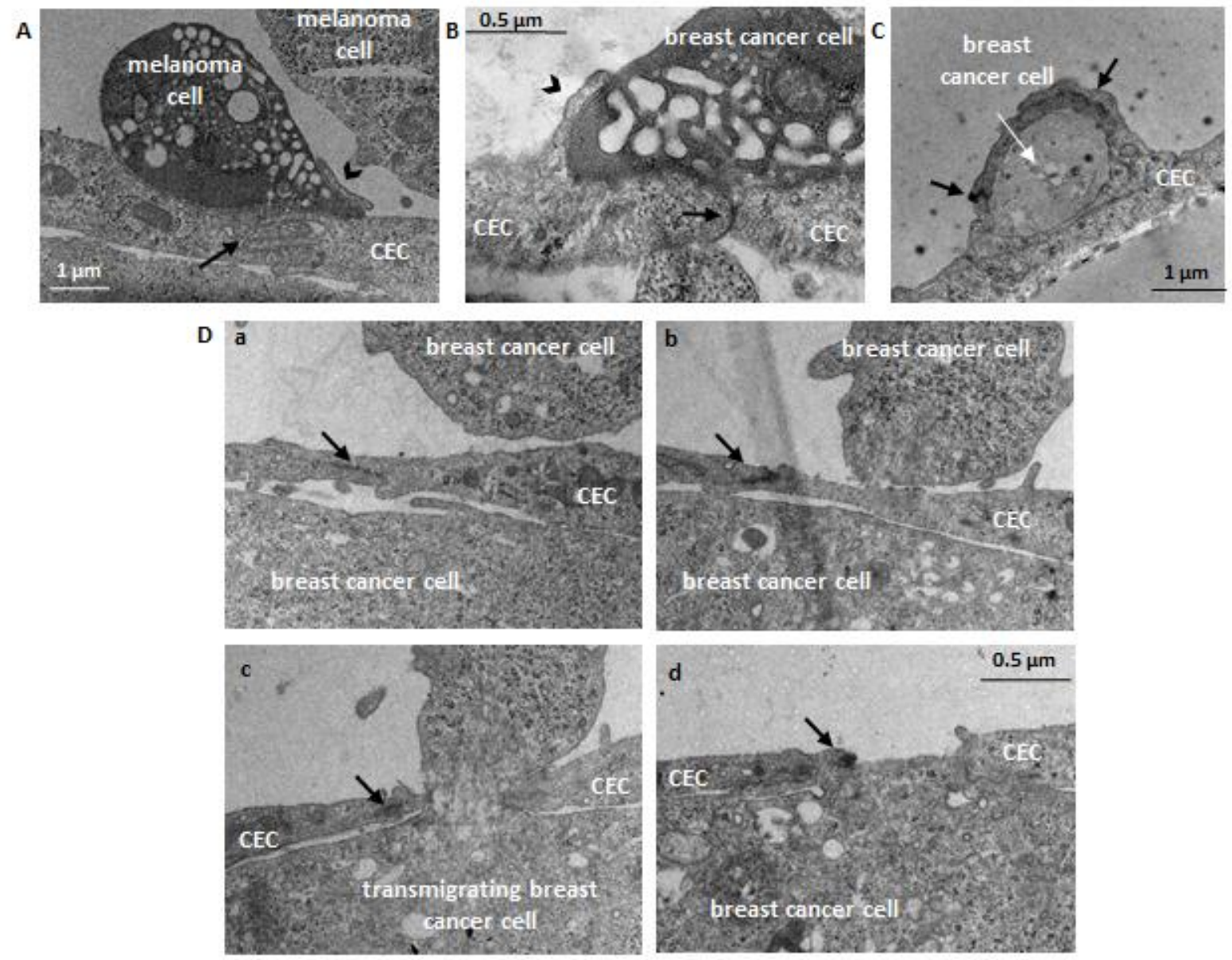

Figure 1: Interaction of tumour cells with CECs during brain metastasis development in vitro. (A) Paracellular transmigration of a melanoma cell through a CEC monolayer, as assessed by TEM. Melanoma cells (B16/F10) were seeded on the top of confluent RBEC monolayers and left for 8 hours. Arrows indicate interendothelial junctions, arrowhead shows endothelial protrusions. (B) Paracellular transmigration of a breast cancer cell through a CEC monolayer. Breast cancer cells (MDA) were seeded on the top of confluent RBEC monolayers, left for 8 hours and analysed by TEM. Arrow indicates interendothelial junctions, arrowhead shows endothelial protrusions. (C) Breast cancer cells completely covered by endothelial protrusions. (D) Transcellular migration of a breast cancer cells through a CEC. MDA cells were seeded onto a confluent monolayer of RBECs and left for 8 hours. Images presented are electron micrograph series of a transmigrating breast cancer cell. Arrows indicate interendothelial junctions.

In line with our in vitro results, we observed transcellular migration of breast cancer cells through cerebral capillaries of mice injected with tumour cells in vivo. Figure $2 \mathrm{~A}$ shows a breast cancer cell arrested in a brain microvessel, which left the junctions intact during extravasation, as indicated by continuous claudin-5 immunostaining.

We observed several other endothelial changes before and during the transmigration process of TNBC cells, including formation of apical endothelial protrusions in vitro (Figure 1A, B, C) and development of basolateral claudin-5-positive blebs (Figure 2A) in initial phase of the transmigration process. In addition, after 24-48 hours spent in the lumen of parenchymal vessels, mammary carcinoma cells induced vasoconstriction and formation of endothelial 
plugs, which protruded into the lumen both upstream and downstream of the cancer cells to isolate the tumour cells from the circulation (Figure 2B). Confocal microscopy images indicated that plugs were formed by the nuclei of endothelial cells, which protruded into and obstructed the vessel lumen (Figure 2B). Interestingly, these plugs were formed as a result of endothelial reorganization and not cell division (Figure 2C). In addition, in some cases, tumour cell-containing capillaries were obstructed by vasoconstriction (Figure 2D).

A

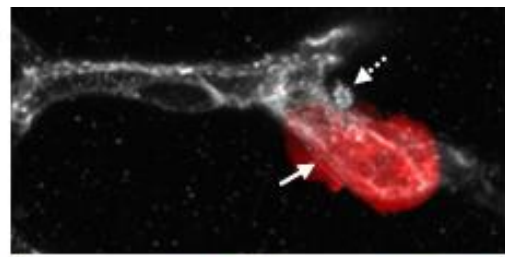

B

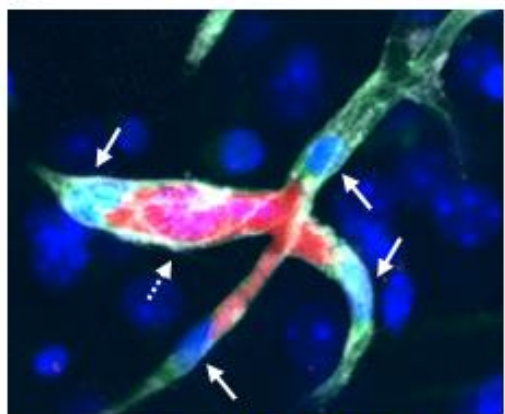

C

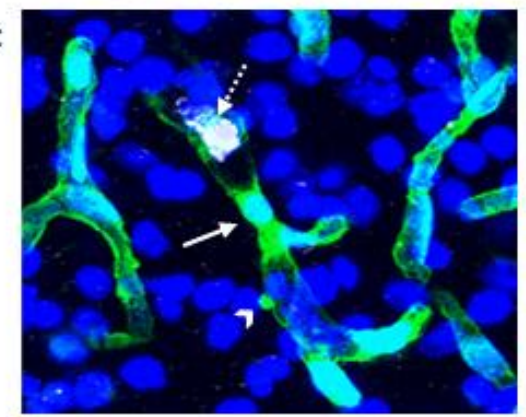

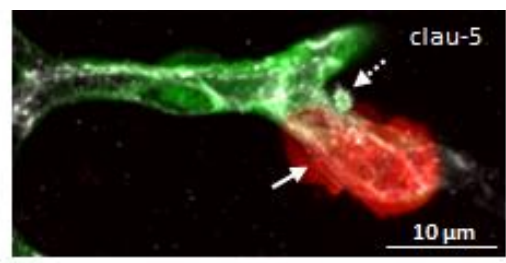
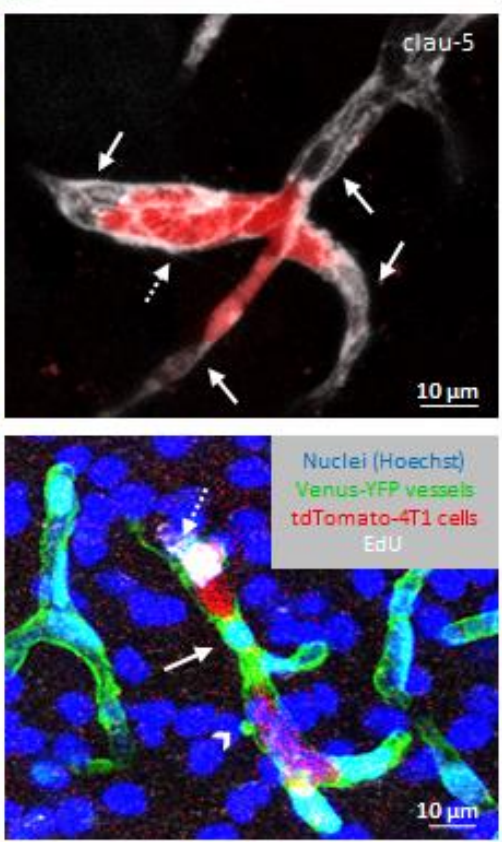
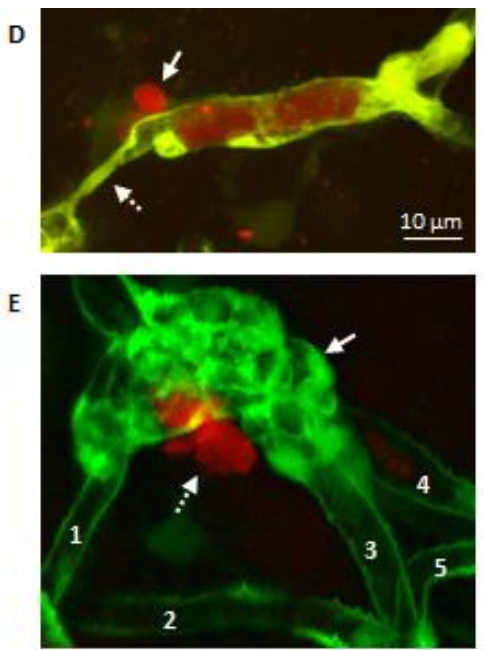

36 hours later

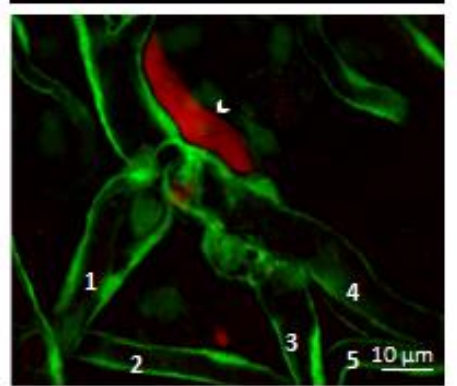

Figure 2: Interaction of tumour cells with CECs during brain metastasis development in vivo. (A) Claudin5 staining of intact tight junctions in the neighbourhood of a breast cancer cell (arrow) extravasating from a cerebral capillary on a mouse brain section (confocal z-projection). Td-tomato-4T1 cells were injected into mice expressing Venus-YFP in endothelial cells and left for 4 days. Dashed arrow indicates a claudin-5-positive bleb on the basolateral side of the endothelium. (B) Claudin-5 immunostaining on day 4 after the injection of tdTomato-4T1 cells into the circulation of mice having Venus-YFP-labelled endothelial cells; confocal z-projection. Arrows indicate endothelial nuclei protruded into the lumen; dashed arrow shows dilated capillary. (C) EdU-positivity of intraluminal tumour cell (dashed arrow), but not of endothelial nucleus (arrow) in the plug (confocal z-projections). Arrowheads depict an endothelial bleb. (D) Representative two-photon micrograph (z-projection) of a blebbing breast cancer cell (arrow) migrating from the lumen of the capillary to the brain parenchyma. Dotted arrow indicates vasoconstriction. (E) Two-photon micrograph (z-projection) presenting intensive blebbing of cerebral microvessels during transmigration of cancer cells. Arrow indicates blebbing, dashed arrow shows extravasating tumour cell. Numbers indicate matching vessels in the two images.

By examining 6-9 cancer cells/animal in the brains of 10 tumour-inoculated mice using confocal microscopy, we found that majority of the tumour cell-containing microvessels were completely $(61.03 \%)$ or partially $(23.90 \%)$ closed by endothelial plugs. In addition, $9.01 \%$ of 
them were obstructed by vasoconstriction and only 6.06\% remained open. These numbers indicate that it is a general phenomenon in brain capillaries that tumour cells are isolated by endothelial cells from the circulation.

Migration of the tumour cells through the cerebral endothelium was frequently accompanied by blebbing of metastatic (Figure 2D) and/or endothelial cells (Figure 2E). Intensive blebbing of intravascular tumour cells (Figure 2D) was frequent, observed in 11 of 14 transmigrations (78.57\%) imaged in two-photon microscopy. In the neighbourhood of extravasating cancer cells, endothelial blebbing (Figure 2E) was similar in frequency to tumour cell blebbing, present in 11 of 14 events observed by two-photon microscopy (78.57\%) and in 10 of the 11 cases of tumour blebbing (90.91\% overlap). Ranging from a few extraluminal blebs to moderate or intensive vacuolization (Figure 2E), blebbing of CECs was always linked to the presence of the tumour cells. Interestingly, even severe endothelial blebbing could be reversed and the vessels were restored in 1-2 days after the tumour cells completed transendothelial migration (Figure 2E).

Furthermore, CECs, which were involved in plug formation, were found to overexpress Ncadherin. Interestingly, CECs not involved in plug formation and transmigrating breast cancer cells were all $\mathrm{N}$-cadherin negative (Figure 3A). In contrast, $\mathrm{N}$-cadherin was shown to mediate interactions between melanoma and endothelial cells both in the brain and the periphery [56, 57]. Similarly, when melanoma cells were seeded upon a confluent monolayer of CECs in vitro, tumour cells tended to rapidly intercalate among CECs. We observed the appearance of Ncadherin in the melanoma-melanoma and melanoma-endothelial contact regions (Figure 3B). However, almost no $\mathrm{N}$-cadherin was detected in endothelial-breast cancer cell co-cultures (Figure 3C), suggesting that $\mathrm{N}$-cadherin is not involved in the transmigration process itself. 
A
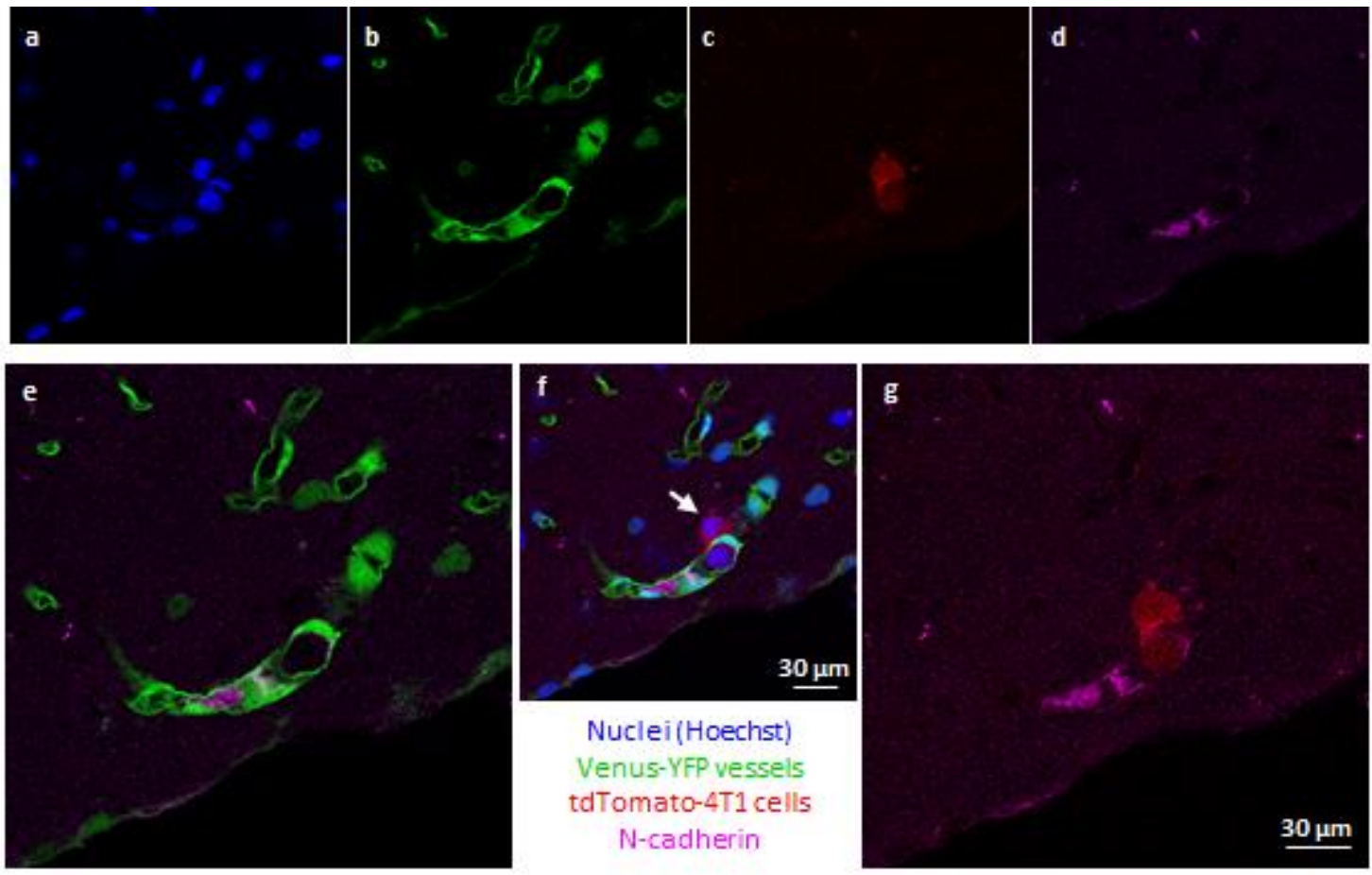

g

Nuclei (Hoechst)

Venus-YFP vessels

tdTomato-4T1 cells

$\mathrm{N}$-cadherin

$30 \mu \mathrm{m}$

\section{$\mathrm{CEC}+$ melanomacells: $\mathrm{N}$-cahderin, Nuclei}

(Hoechst)
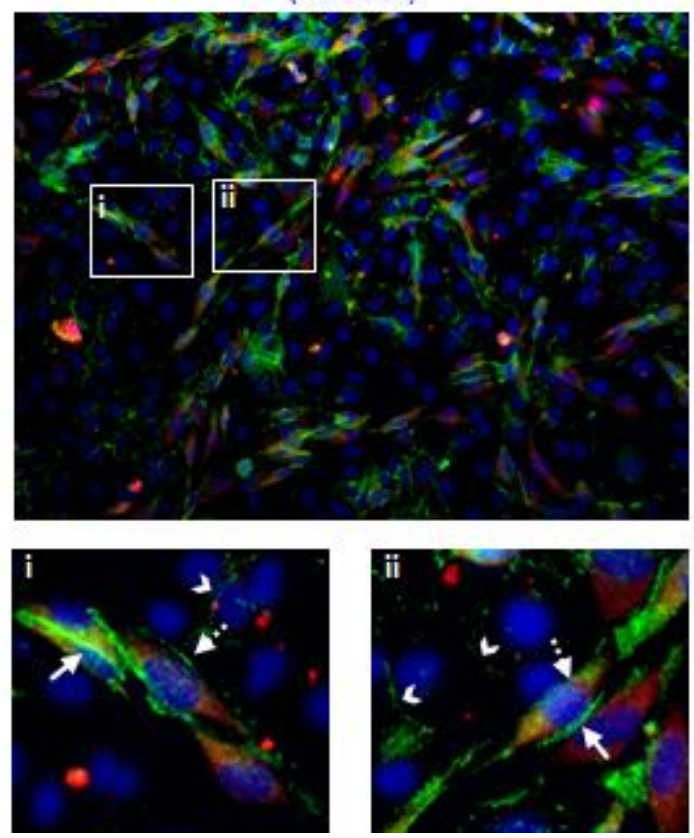

C
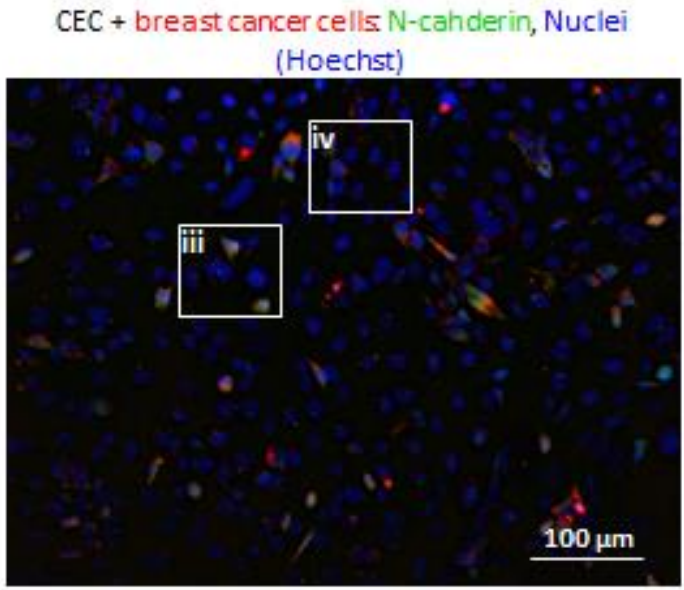

iii

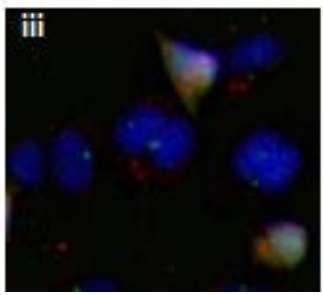

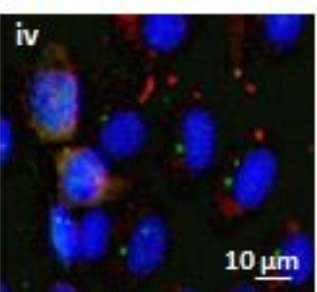

Figure 3: Role of N-cadherin in the transendothelial migration of breast cancer cells. (A) 4T1 mouse TNBC cells expressing tdTomato red fluorescent protein were injected into mice expressing Venus-YFP in endothelial cells. Mice were killed after 5 days. Representative confocal micrographs show that CECs are N-cadherin-positive only in the neighbourhood of transmigrating 4T1 breast cancer cells. Transmigrating cell on day 5 after inoculation of tumour cells is indicated by white arrow. (B) CellTracker Red CMTPX-stained A2058 melanoma cells were seeded onto a confluent monolayer of D3 cells and left for 5 hours. Representative immunofluorescence images are shown. The two bottom panels (i and ii) are higher magnifications of the respective sectors in the top image. Arrows indicate $\mathrm{N}$-cadherin enrichment in the melanoma-melanoma junctions, dotted arrows point to $\mathrm{N}$-cadherin in the melanoma-endothelial contact regions, while arrowheads indicate $\mathrm{N}$-cadherin in interendothelial junctions. (C) CellTracker Red CMTPX-stained MDA cells were seeded onto a confluent monolayer of D3 cells and left for 5 hours. Representative immunofluorescence images are shown. The two bottom panels (iii and iv) are higher magnifications of the respective sectors in the top image. 


\subsection{Interactions of metastasizing breast cancer cells with astrocytes}

Beside CECs, astrocytes are the most active players in immediately responding to and continuously associating with invading tumour cells. Our aim was to understand whethersimilarly to immune cells during neuroinflammation — breast cancer cells are able to penetrate the glia limitans perivascularis (formed by astrocytic end-feet) or immediately dissociate them from the vessels after migration through the endothelium.

A

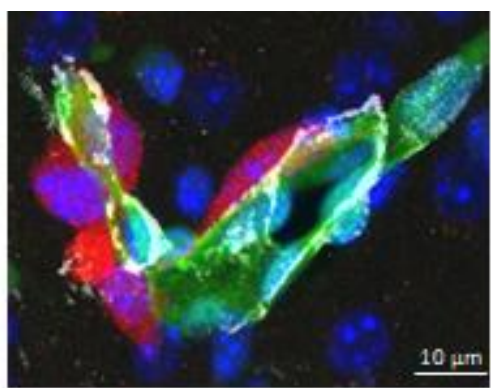

A, C Nuclei(Hoechst)

Endothelium (YFP)

Tumourcells (todTomato)

grey (AQP4)

B
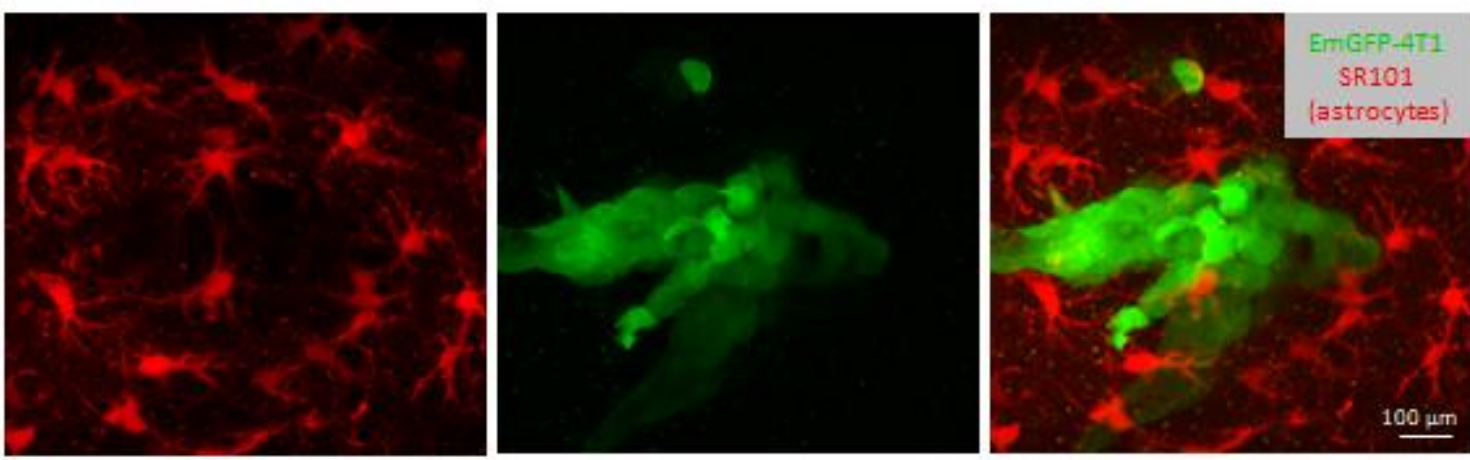

C
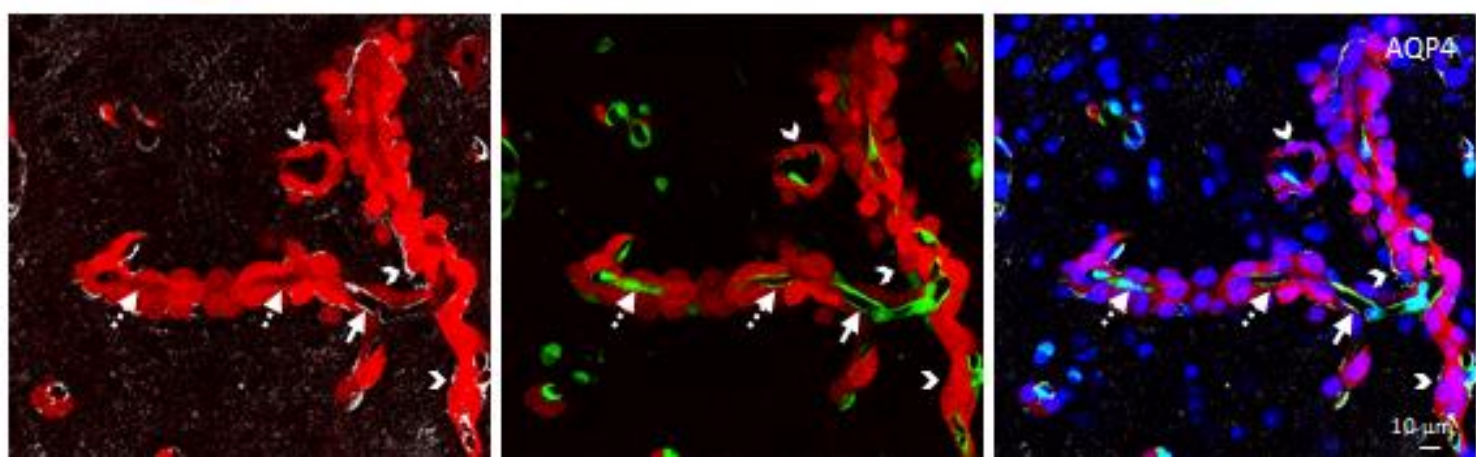

Figure 4: Interaction of breast cancer cells with astrocytes. (A) Confocal z-projection showing AQP4-positive astrocyte end-feet co-opted by extravasated metastatic cells. (B) Astrocytes expelled from the growing metastatic lesion on day 10 after inoculation, as shown in a two-photon z-projection image. 4T1 mouse TNBC cells were injected into Balb/c mice. (C) AQP4-positive astrocyte end-feet gradually retracted from the capillary wall to the surface of the metastatic tumour. Tdtomato-4T1 mouse TNBC cells (red) were injected into mice expressing Venus-YFP in endothelial cells. Confocal z-projection of metastatic lesions from the brain of an animal on day 10. Arrows show vascular AQP4 staining, dotted arrows indicate absence of vascular AQP4 staining, while arrowheads point to AQP4 staining on the surface of the tumour. 
Using mice inoculated with tdTomato-4T1 cells, we observed that the extravasated part of breast cancer cells passed through the glia limitans perivascularis right after breaching the endothelial wall, as indicated by localization of AQP4-marked astrocyte end-feet between the endothelium and tumour cells (Figure 4A). As metastatic lesions were growing, astrocytes were expelled from the tumour mass (Figure 4B). In parallel, reactive astrocytes surrounding metastatic lesions gradually retracted their end-feet from the vessels to the parenchymal border of the tumour, which gained a discontinuous end-foot coverage (Figure 4C).

Peri-tumoural astrocytes become activated upon metastasis formation [58, 59]. Through seeking for new biomarkers for early detection of brain metastases, we found a new element of astrocyte reaction in TNBC brain metastasis, namely myocyte enhancer factor 2C (MEF2C) (Figure 5). We performed a high-throughput NGS analysis from plasma samples of TNBC cellinoculated mice (Figure 5A), followed by a qPCR validation (Figure 5B), and we found downregulation of miR-802-5p and miR-194-5p as an early event in brain metastatic breast cancer in mice. By using miRNA target prediction, we showed that MEF2C is a specific target of both of these miRNAs, and is negatively regulated by them. $\mathrm{MEF} 2 \mathrm{C}$ is a transcription factor initially described to be activated during embryogenesis to regulate tissue-specific gene expression and promote organ development. Subsequently, MEF2C was recognized to be also expressed during adult life in many types of cells, including neuronal and endothelial cells [60]. In our model, in addition to being expressed in metastatic cells, among cells of the NVU, MEF2C expression was restricted to astrocytes in the neighbourhood of breast cancer cells, pointing to a role of MEF2C in the crosstalk between tumour cells and astrocytes (Figure 5C). 
A

\begin{tabular}{|c|c|c|c|}
\hline miRNA & Control & Treated & $\begin{array}{c}\text { Fold } \\
\text { change }\end{array}$ \\
\hline $\begin{array}{c}\text { mmu-miR- } \\
802-5 p\end{array}$ & 191.45 & 85.61 & 0.45 \\
\hline $\begin{array}{c}\text { mmu-miR- } \\
194-5 p\end{array}$ & 24.27 & 4.5 & 0.19 \\
\hline
\end{tabular}

B

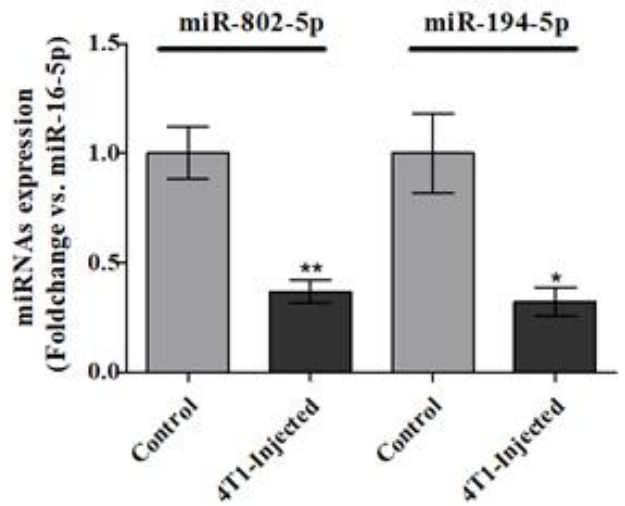

C
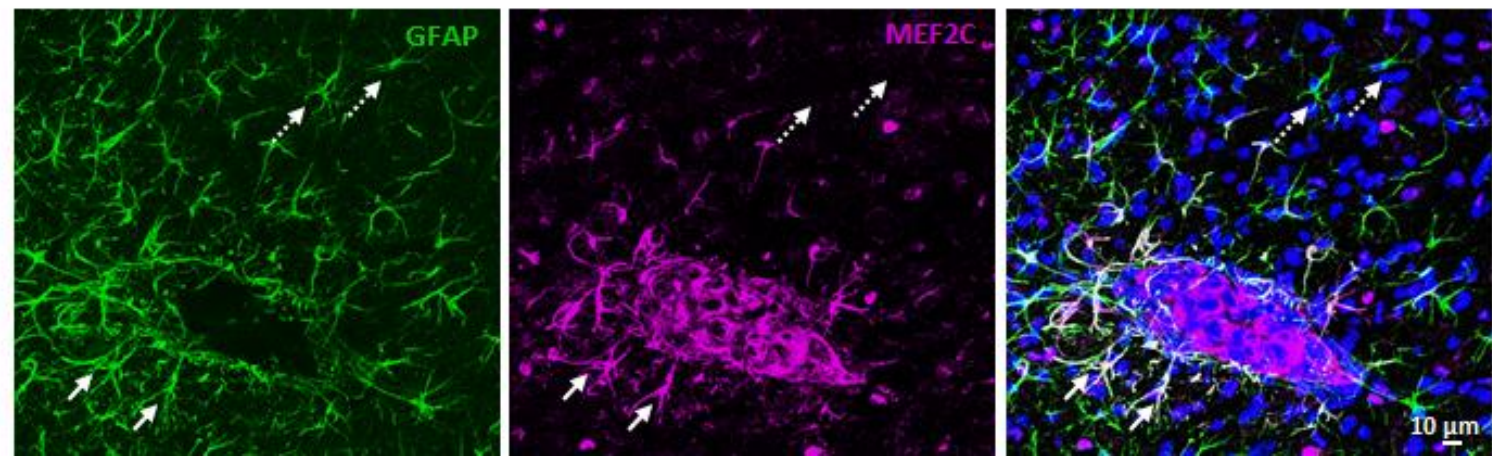

Figure 5: Changes of miRNA levels during early breast cancer brain metastasization and MEF2C expression in the peri-tumoral astrocytes. (A) Overview of the NGS results, regarding the altered expression of miRNAs in plasma along brain metastasization of breast cancer. Control = plasma samples from control mice, treated = plasma samples of mice 3 days after injection with $4 \mathrm{~T} 1$ cells. Values represent readcounts in each samples and fold change shows the ratio between the control and treated groups. (B) Validation of NGS results by qPCR for miR-802-5p and miR-194-5p. Results are shown as mean values \pm SD and expressed as fold change $v s$. miR$16-5 \mathrm{p}$ (endogenous control). $* \mathrm{P}<0.05$ and $* * \mathrm{P}<0.01 v$ s. control, by a two-tailed unpaired Student's t-test. (C) MEF2C expression in the peri-tumoural astrocytes. Brain sections from 4T1-injected BALB/c mice were analysed with confocal microscopy (z-projection). Arrows show MEF2C-positive peri-tumoural astrocytes, while dotted arrows indicate distant, MEF2C-negative astrocytes.

\subsection{Direct interaction of brain metastatic tumour cells with pericytes in vivo and in vitro}

Cells belonging to the NVU are known to interact with malignant cells after the transmigration through the BBB, but much less is known about the role of pericytes. Since we observed that tumour co-opted endothelial cells maintained tight junctions in the absence of astrocyte end-foot coverage, we hypothesized that pericytes — which also help to maintain BBB properties of CECs - remained in close contact with the vessels (i.e. were co-opted together with the endothelium). Indeed, we found that platelet-derived growth factor receptor $\beta$ (PDGFR $\beta$ )-positive pericytes were localized to capillaries inside metastatic lesions in the mouse brain 7 days after inoculation with TNBC cells (Figure 6A). In human TNBC brain metastases, PDGFR $\beta$-positive perivascular cells were found in the stroma (Figure 6B), in single or multiple layers, as previously shown [61]. In addition, we also detected single 
pericyte-like cells expressing the pericyte-specific markers PDGFR $\beta$ and CD13, scattered among the tumour cells, especially in less cell-dense areas, probably in the proximity of necrotic zones (Figure 6C).
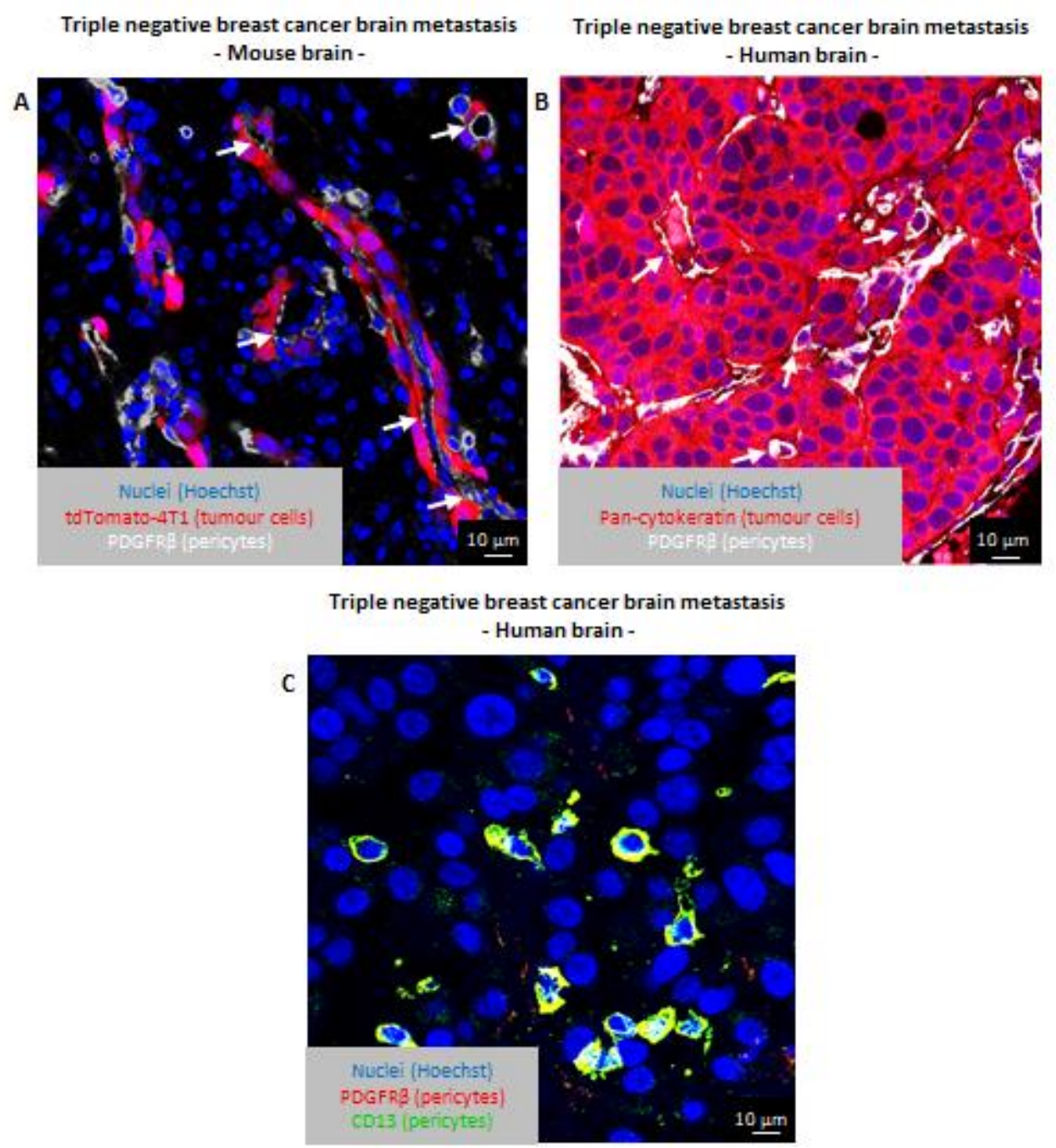

Figure 6: Localization of pericytes inside the metastatic lesions. (A) Brain sections of BALB/c mice 7 days after injection of tdTomato-4T1 cells (red) showing PDGFR $\beta$-positive pericytes localized along capillaries inside the tumour mass. (B) Human triple negative brain metastatic tissue with PDGFR $\beta$-positive pericytes in the stroma. Arrows indicate pericytes inside the tumour mass. (C) Human triple-negative brain metastatic tissue with PDGFR $\beta$ and CD13 double-positive pericyte-like cells scattered among tumour cells.

All these data prompted us to hypothesize that direct interactions between tumour cells and pericytes might influence brain metastasis development. Therefore, we first modelled contacts between metastatic cells and pericytes using an in vitro setup, by plating the tumour cells onto sparse cultures of brain pericytes and other cells of the NVU. Breast cancer cells preferentially gathered onto the top of pericytes, avoiding the cell-free culture surface, and this was independent of the coating of the culture dish (Figure 7A). In contrast, when breast cancer cells 
were co-cultured with CECs, they seldom adhered onto endothelial cells, but rather into gaps among them. In co-culture with astrocytes, direct contacts of the tumour cells were more frequent than with endothelial cells, but less preferred than interaction with pericytes. In contrast to breast cancer cells, the highest number of melanoma cells attached to free surfaces among the cells, independent of the cell type they were co-cultured with (Figure 7B).

A

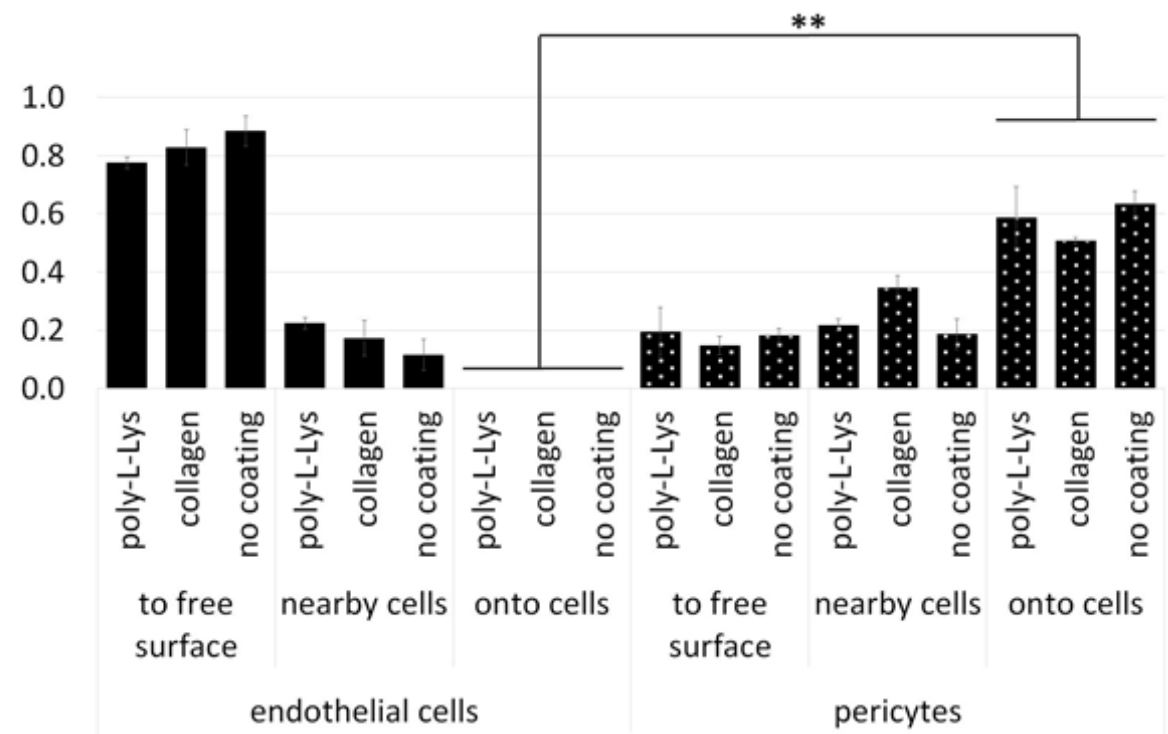

adhesion of breast cancer cells to

B

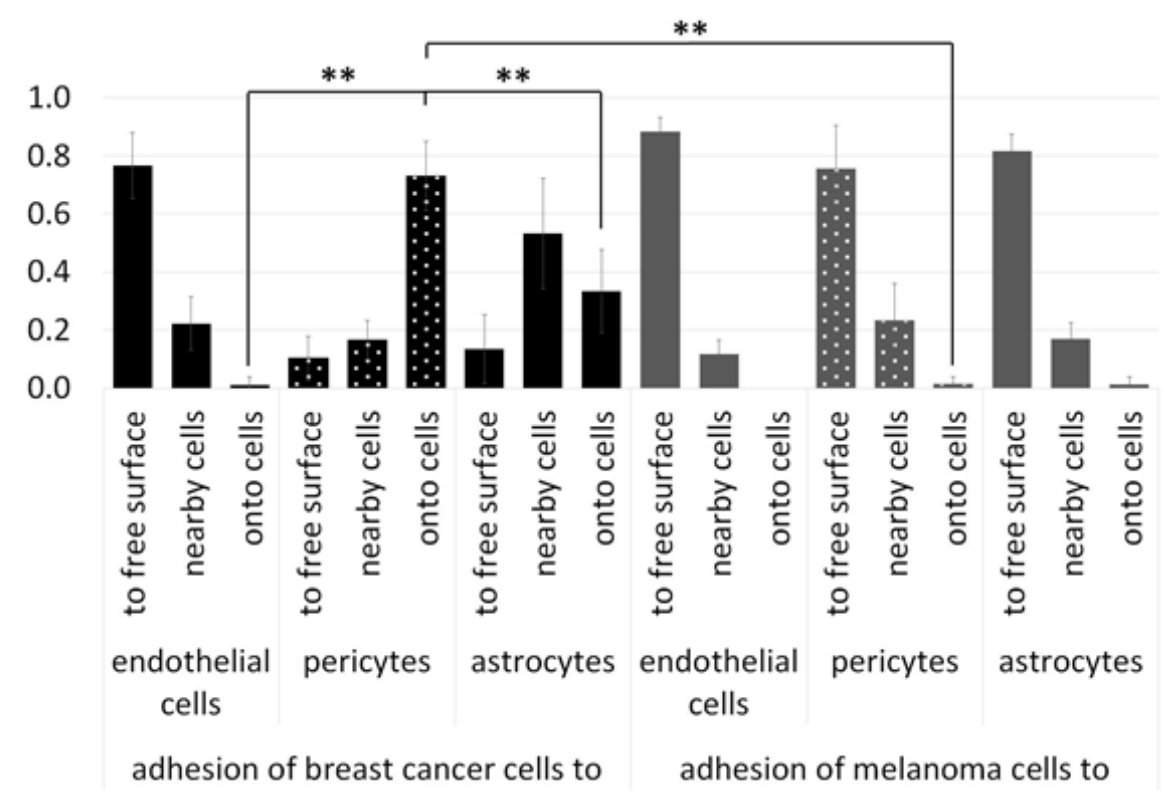

Figure 7: Quantification of tumour cell adhesion to cells of the NVU. (A) Comparison of human breast cancer cell (EGFP-MDA) adhesion to D3 and HBVP cells cultured on different surfaces. $\mathrm{N}=3$, average $\pm \mathrm{SD}, * * \mathrm{P}<$ 0.01 (ANOVA and Bonferroni's post-hoc test). (B) Comparison of cancer cells' adhesion to the cells of the NVU 24 hours after seeding onto brain cells cultured in poly-L-lysine-coated dishes. Breast cancer cells: EGFP-MDA, melanoma cells: EGFP-A2058, endothelial cells: D3, pericytes: HBVP, astrocytes: HA. $\mathrm{N}=5$, average $\pm \mathrm{SD}$, ** $\mathrm{P}<0.01$ (ANOVA and Bonferroni's post-hoc test). 
Therefore, we explored whether breast cancer cells could actively migrate in the direction of brain pericytes. In our in vitro wound healing assay, carcinoma cells readily migrated towards pericytes, covering a significantly larger distance on their way to brain pericytes than to endothelial cells (Figure 8A, B).

A
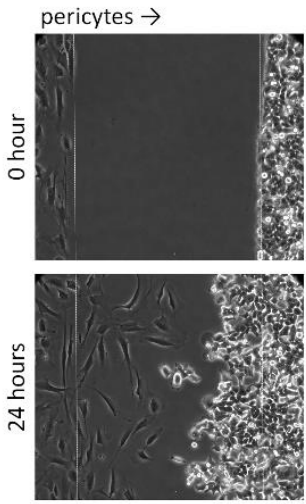

$\leftarrow$ breast cancer cells endothelial cells $\rightarrow$
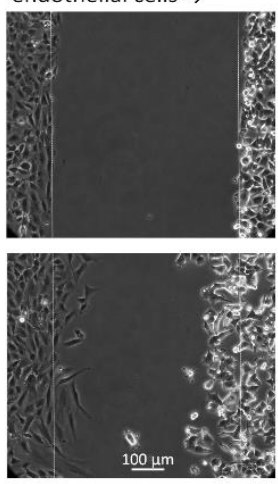

$\leftarrow$ breast cancer cells
B

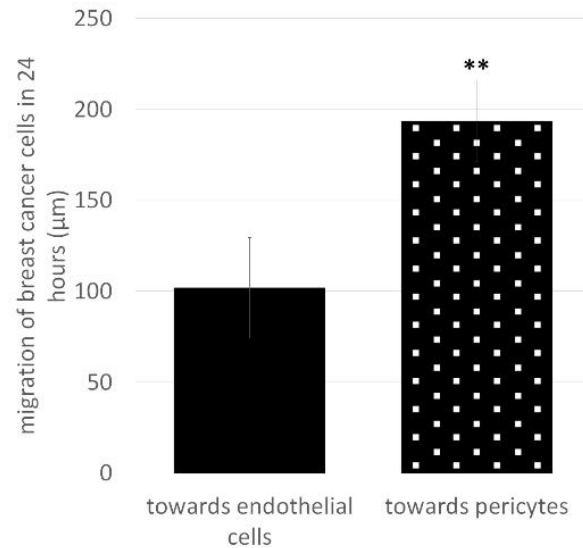

C
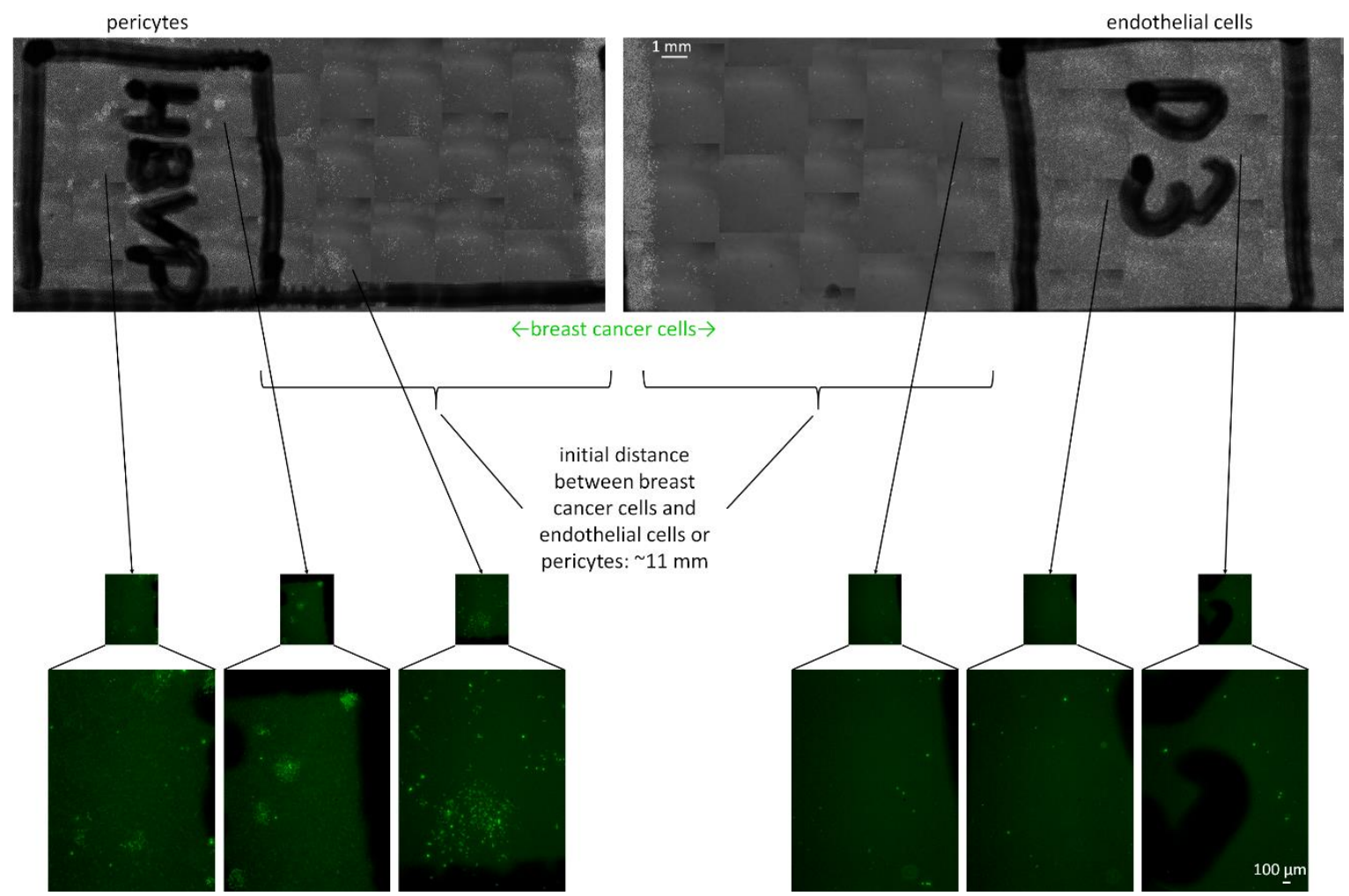

initial distance between breast cancer cells and endothelial cells or pericytes: 11 $\mathrm{mm}$
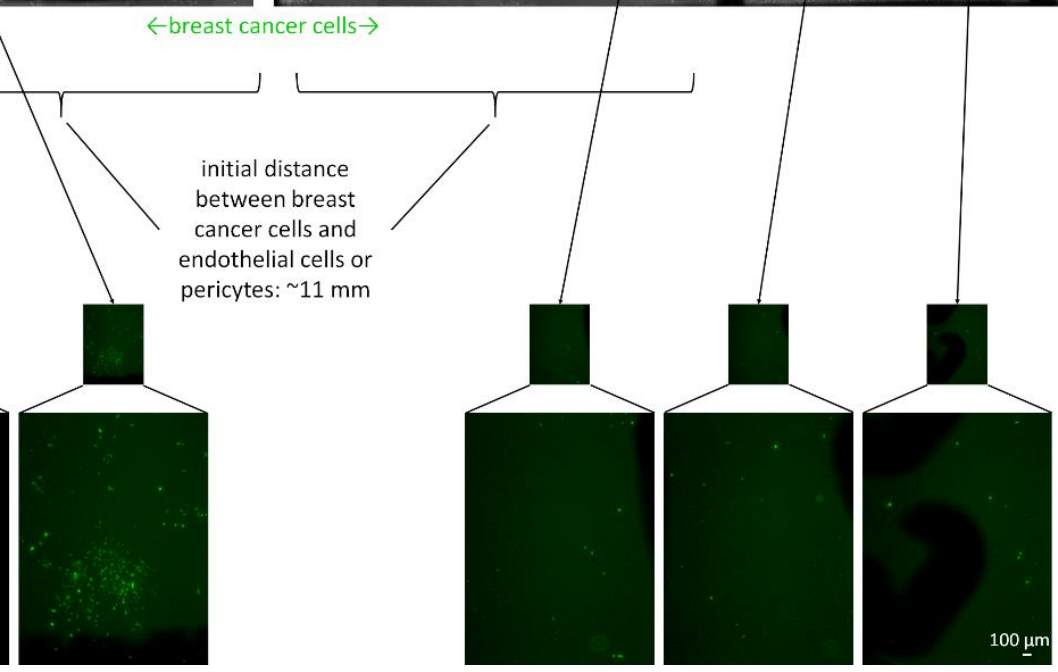

Figure 8: Migration of breast cancer cells towards brain pericytes. (A) Representative phase-contrast images of pericyte-breast cancer cell and brain endothelial-breast cancer cell migration (short distance invasion assay described in Materials and methods). (B) Quantitative analysis of the short distance wound assays at 24 hours. N $=5$, average $+/$ - SD, $* * \mathrm{P}<0.01$ (Student's t-test). (C) Phase-contrast and fluorescence (green insets) images of HBVP, D3 and EGFP-MDA cells after 5 days of migration in the long distance invasion assay. 
When leaving a much longer distance (more than $1 \mathrm{~cm}$ ) between tumour cells and the two different brain cells (endothelial cells and pericytes, respectively), breast carcinoma cells preferentially migrated in the direction of pericytes. After a few days, several breast cancer cells were detected in the initially cell-free area between tumour cells and pericytes and large breast cancer cell colonies were formed among pericytes. In contrast, only a few scattered mammary carcinoma cells were observed in the direction of and among endothelial cells (Figure 8C). These results indicate that pericytes might communicate with tumour cells through secreted factors. Therefore, we conditioned culture medium on brain pericytes to characterize in details its effects on neoplastic cells.

\subsection{Effects of pericytes on tumour cell adhesion}

First, we seeded breast cancer and melanoma cells in control and pericyte-conditioned media and performed an adhesion assay. As shown in Figure 9, both human and mouse breast cancer cells and melanoma cells as well attached to the culture dish surface and elongated more rapidly in pericyte-conditioned media, than in control conditions. The difference between cells seeded in control and conditioned media was very high and significant. 
A

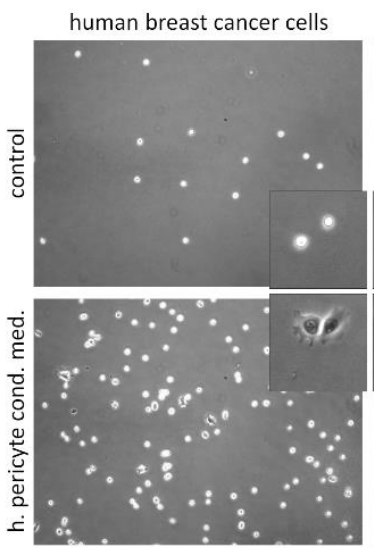

C

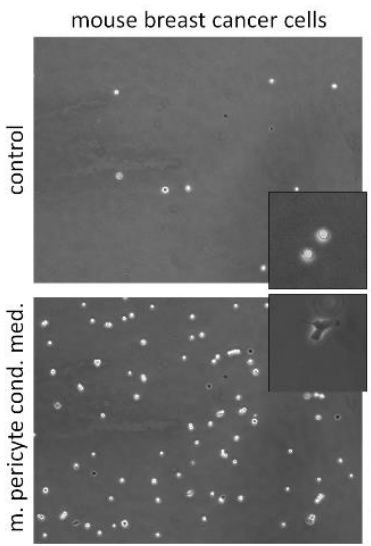

human melanoma cells

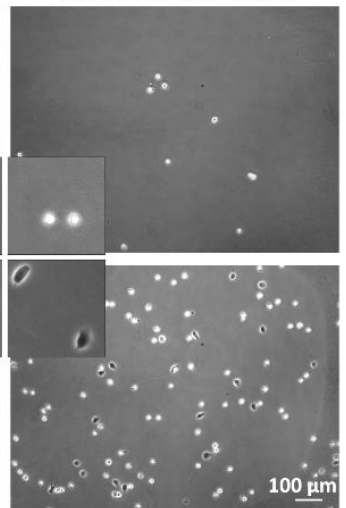

mouse melanoma cells

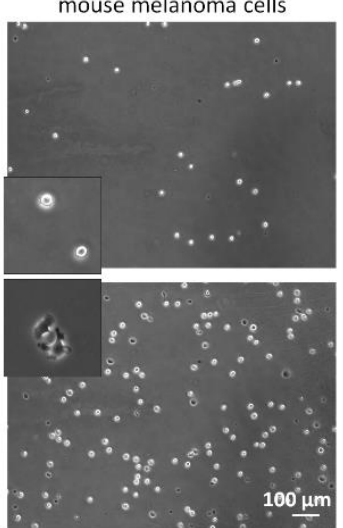

B

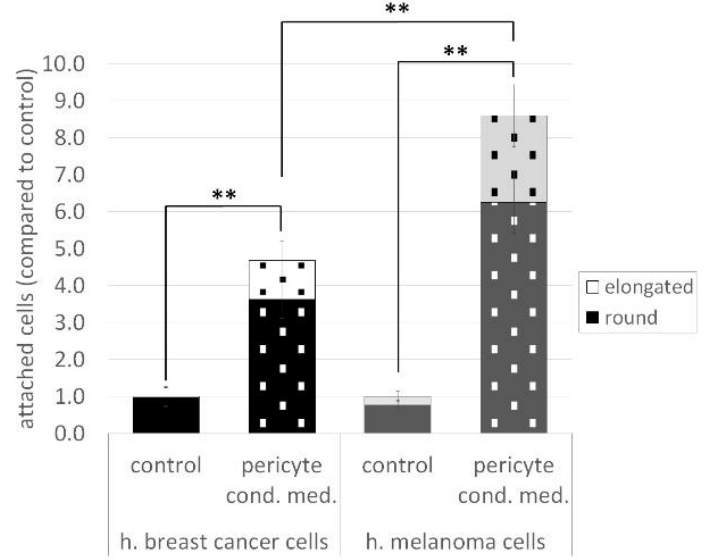

D

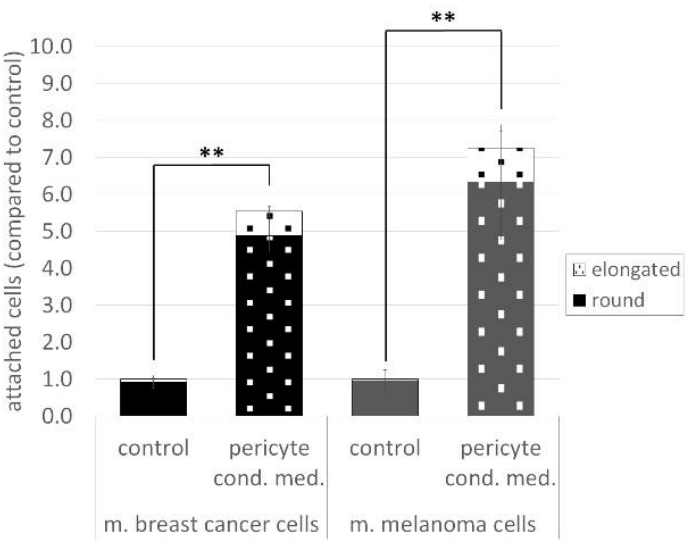

Figure 9: Role of pericyte-secreted factors in tumour cell adhesion. (A) Representative phase-contrast images of human breast cancer or melanoma cells (MDA or A2058, respectively) attached to non-coated cell culture dishes in control or pericyte-conditioned media after 120 minutes (MDA) or 20 minutes (A2058). (B) Quantification of adhesion results shown in (A). $\mathrm{N}=5$, average $\pm \mathrm{SD}, * * \mathrm{P}<0.01$ (ANOVA and Bonferroni's post-hoc test). (C) Representative phase-contrast images of mouse breast cancer or melanoma cell adhesion (4T1 and B16 cells, respectively) 20 minutes after plating. (D) Quantification of adhesion results shown in (C). $\mathrm{N}=5$, average $\pm \mathrm{SD}$, ** $\mathrm{P}<0.01$ (ANOVA and Bonferroni's post-hoc test). Insets in (A) and (C) show cells having typical round and elongated morphology (upper and bottom panels, respectively) (2.5-times magnification compared to whole images).

A feasible explanation for the prominent adhesion enhancing effect of conditioned media is that pericytes - similarly to astrocytes - secreted high amounts of collagen type IV and fibronectin (Figure 10A). In addition, we observed increased levels of phosphorylated FAK (focal adhesion kinase) and Src focal adhesion proteins in breast cancer and melanoma cells seeded in pericyte-conditioned media (Figure 10B, C). The adhesion enhancing effect of pericytes could be eliminated by using the specific Src inhibitor PP2 (Figure 10B). 
A
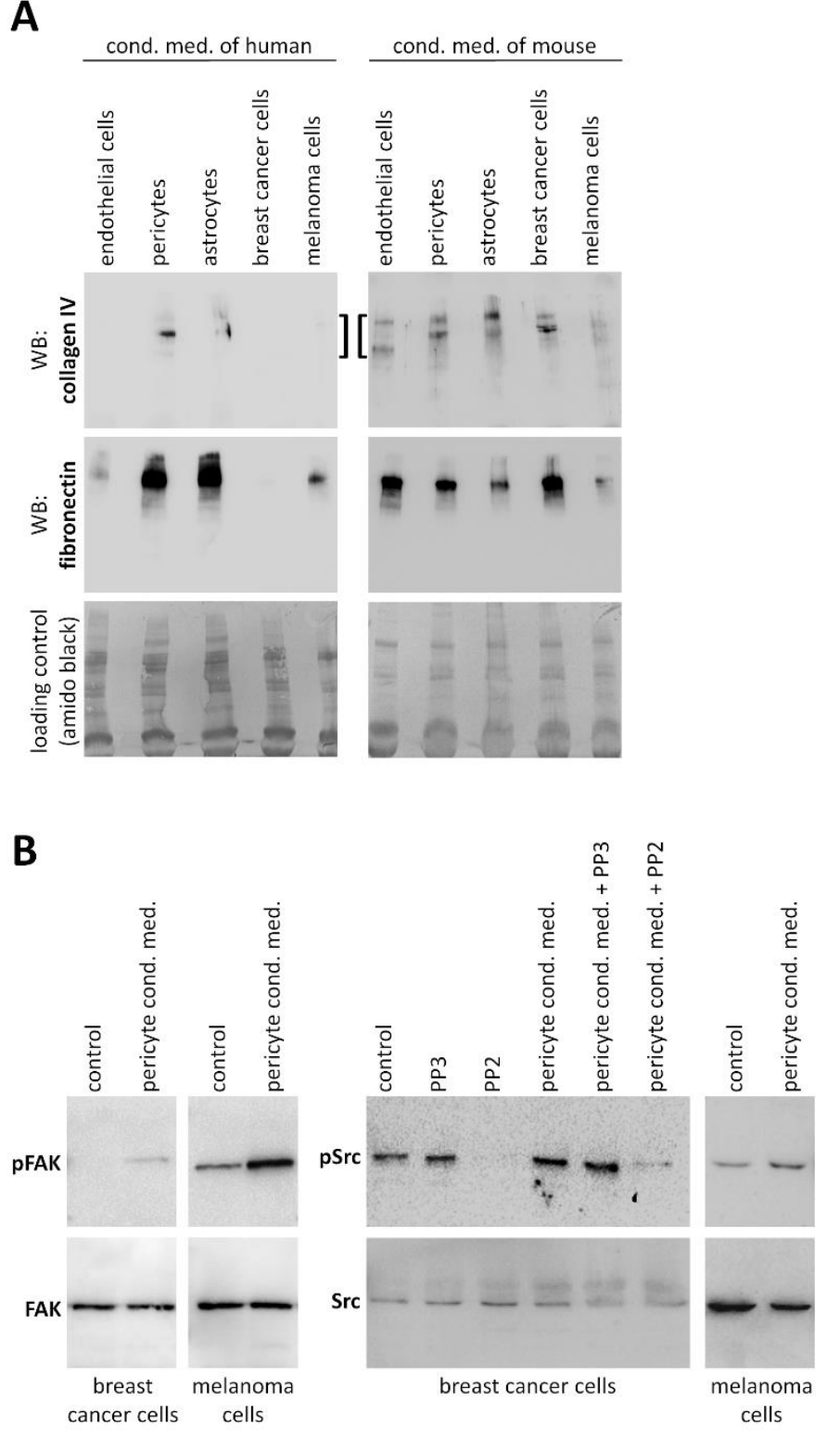

C
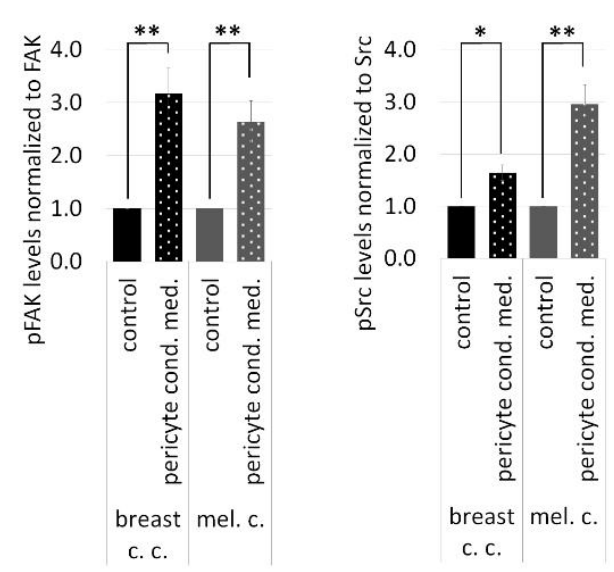

Figure 10: Role of pericyte-secreted factors in tumour cell adhesion. (A) Secretion of collagen type IV and fibronectin into culture media of brain and tumour cells (representative western-blot images). (B) Representative western-blots showing FAK and Src phosphorylation in MDA and A2058 cells cultured in HBVP-conditioned media, 120 minutes and 20 minutes after seeding, respectively. (C) Quantification of blots shown in (A). $\mathrm{N}=2$ (pFAK), $\mathrm{N}=3(\mathrm{pSrc})$, average $\pm \mathrm{SD}, * \mathrm{P}<0.05, * * \mathrm{P}<0.01$.

\subsection{Effects of pericytes on tumour cell proliferation}

As a next step, we aimed to understand how brain pericytes influence tumour growth. Therefore, we performed a tumour cell proliferation assay in the presence and absence of factors released by pericytes. Four days after plating, the number of breast cancer cells was substantially higher in pericyte-conditioned media than in control (Figure 11A, B). This was clearly observed in both human and mouse model. On the other hand, melanoma cells did not 
respond with increased proliferation to the presence of pericyte-secreted factors (Figure 11A, B).

A
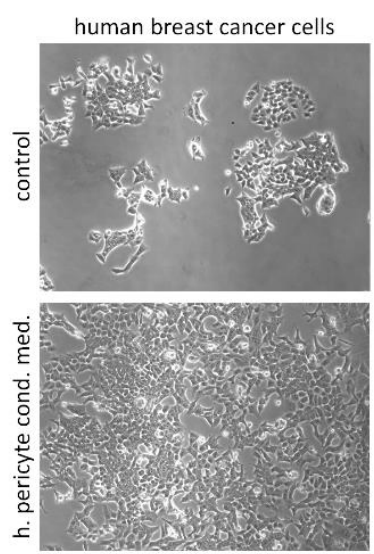

C

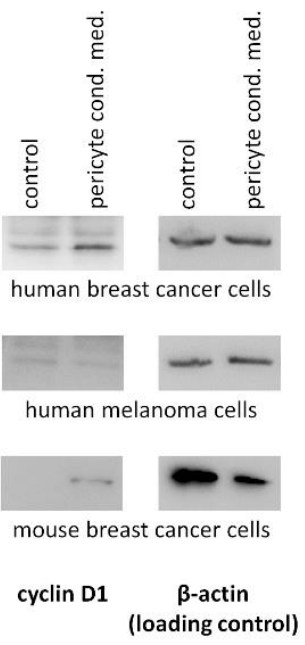

B
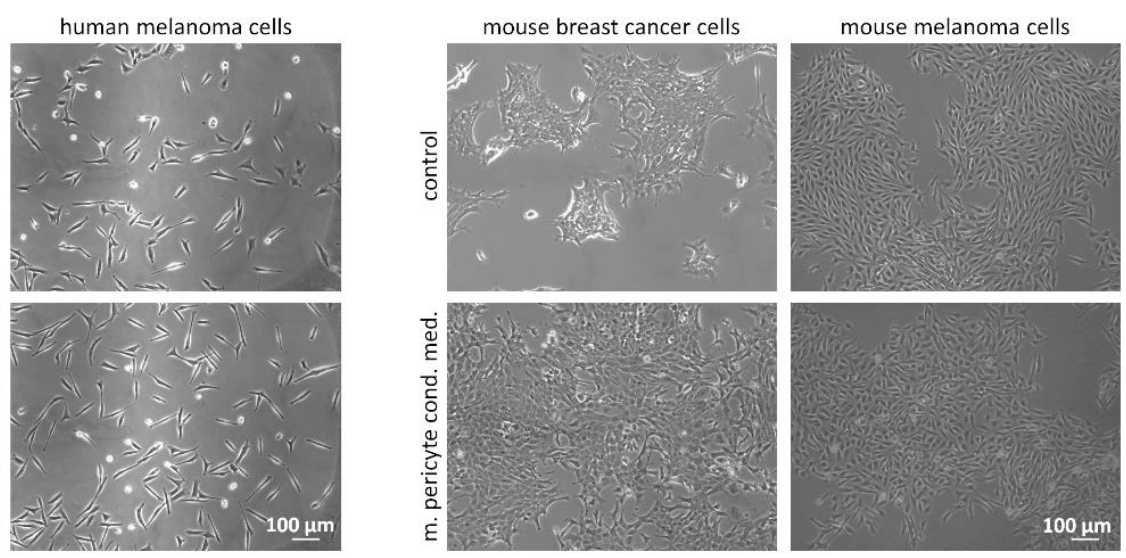

D

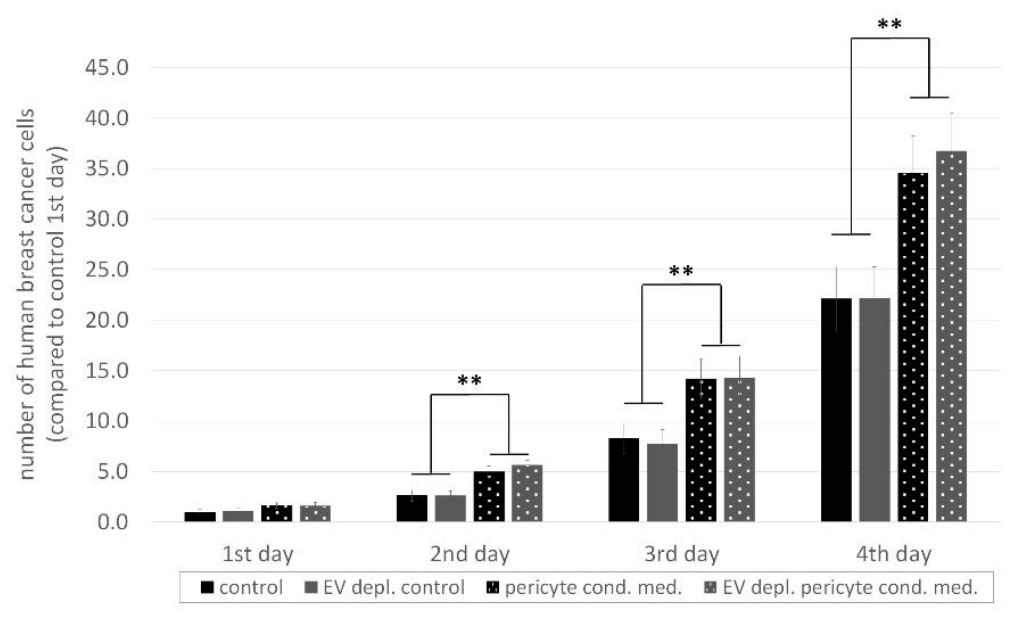

Figure 11: Role of pericyte-secreted factors in tumour cell proliferation. (A)(B) Representative phase-contrast images of tumour cells grown in control or pericyte-conditioned medium for 4 days. (C) Cyclin D1 expression in tumour cells grown in control or pericyte-conditioned medium for 4 days. (D) Quantification of cell numbers of MDA cells grown in control, pericyte-conditioned and EV-depleted media. $\mathrm{N}=4, * * \mathrm{P}<0.01$.

In parallel, there was a significant increase in the expression of cyclin D1 in human and mouse breast cancer cells, but not in melanoma cells cultured in pericyte-conditioned media (Figure 11C).

Apart from soluble factors, conditioned media may contain EVs, such as microvesicles and exosomes. In order to distinguish between effects of EVs and soluble factors, we prepared EVdepleted conditioned medium and compared it with complete conditioned medium in a proliferation assay. EV depletion did not influence the proliferation-increasing effect of pericyte-conditioned medium (Figure 11D); therefore, soluble factors released by pericytes are responsible for the observed phenomenon. 
Interestingly, breast cancer cells in the conditioned media, although higher in number, appeared to have fewer contact points with each other and became more dissociated (Figure 12A). In line with this, E-cadherin expression decreased significantly in breast cancer cells exposed to pericyte-secreted factors (Figure 12B).
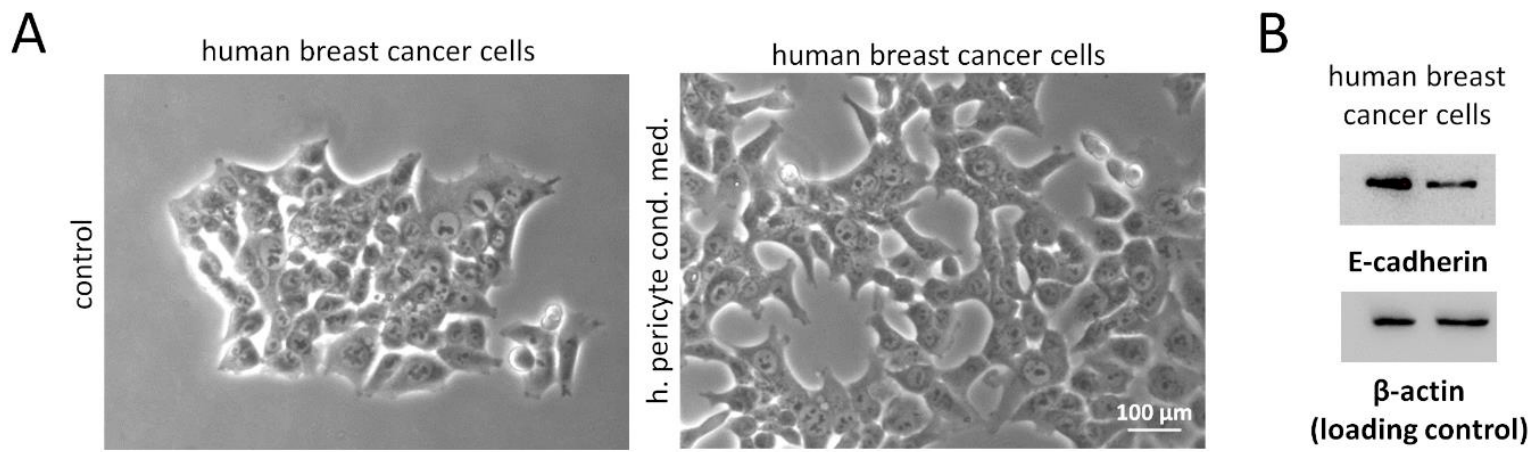

Figure 12: Effects of pericyte-secreted factors on tumour cell connections. (A) Representative highmagnification phase-contrast images of MDA cells grown in control or pericyte-conditioned medium for 4 days. (B) E-cadherin expression in MDA cells grown in control or pericyte-conditioned medium for 4 days.

\subsection{Insulin-like growth factor (IGF) expression in cerebral pericytes}

In order to identify which cerebral pericyte-secreted factors might be involved in enhancing tumour cell proliferation, we first performed a database search. In the http://betsholtzlab.org/VascularSingleCells/database.html collection [62] we found Igf2 mRNA having the highest expression in pericytes among cells of the NVU. Igf2 mRNA expression level was 487.25-times higher in pericytes than in endothelial cells, and 86.62-times more in pericytes than in astrocytes in the mouse brain. In our human and mouse pericytes, not only Igf2, but Igf1 mRNA was also expressed (Figure 13A, B). More Igf2 than Igf1 mRNA was found in both human and mouse pericytes; however, the ratio was higher in human cells. Mouse astrocytes expressed very low amounts of Igf1 and Igf2 mRNA, while in human astrocytes both Igf1 and Igf 2 mRNA levels were higher than in tumour cells, but still lower than in pericytes. 


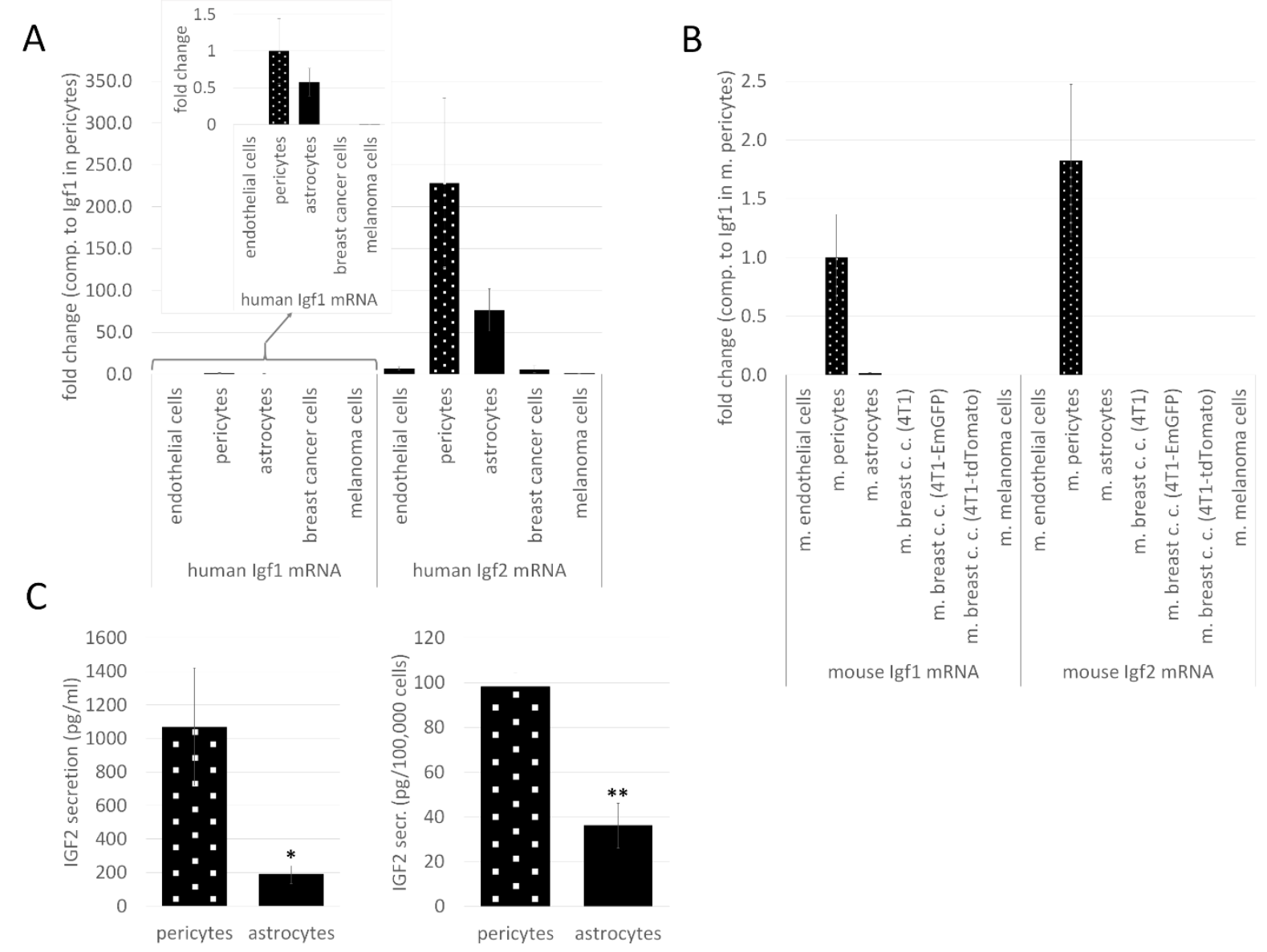

Figure 13: Insulin-like growth factor expression in pericytes. (A) (B) Igf1 and Igf2 mRNA expression in human and mouse brain and tumour cells, as assessed by qPCR with Gapdh as housekeeping gene. Results are shown as fold change in comparison to Igf1 in pericytes. Inset in (A) shows human Igf1 expression in a lower scale range. $\mathrm{N}=3$, average $\pm \mathrm{SD}$ (statistically not analysed). (C) IGF2 secretion in human brain pericytes and astrocytes, as assessed by ELISA. $\mathrm{N}=3$ pericytes, $\mathrm{N}=2$ astrocytes, average $\pm \mathrm{SD}, * \mathrm{P}<0.05$, $* * \mathrm{P}<0.01$ (Student's t-test).

These data were confirmed at the protein level using ELISA. Human pericytes secreted more than $1,000 \mathrm{pg} / \mathrm{ml}$ IGF2 corresponding to almost $100 \mathrm{pg} / 100,000$ cells, while in astrocytes we detected significantly less IGF2 ( $<200$ pg/ml, $<40$ pg/100,000 cells) (Figure 13C). IGF1 levels in both pericyte- and astrocyte-conditioned media were below the detection limit of $1.95 \mathrm{ng} / \mathrm{ml}$.

By using immunofluorescence, we found both IGF1 and IGF2 to be expressed in CD13positive pericytes in the normal human brain. IGF1 was also detected in a few CD13-negative cells, probably in astrocyte end-feet, while IGF2 was mainly expressed in pericytes (Figure 14A, B). In human TNBC brain metastatic lesions, IGF1 and IGF2 expression were highly restricted to perivascular cells (Figure 14C, D). 
A

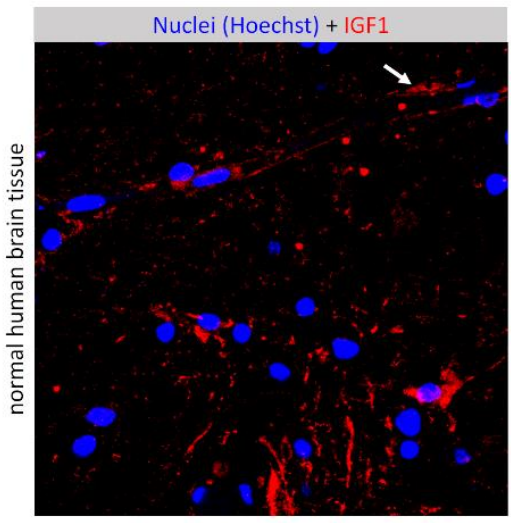

B

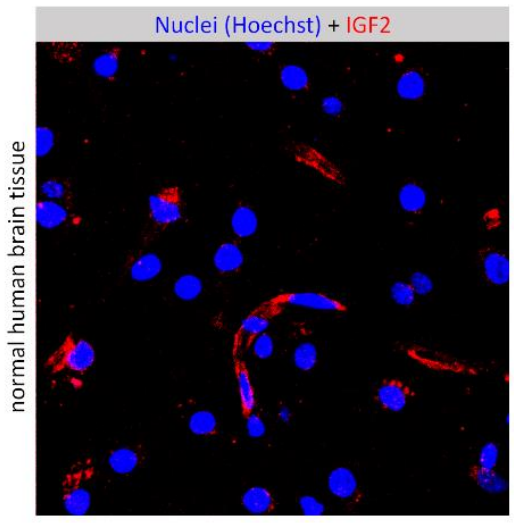

C

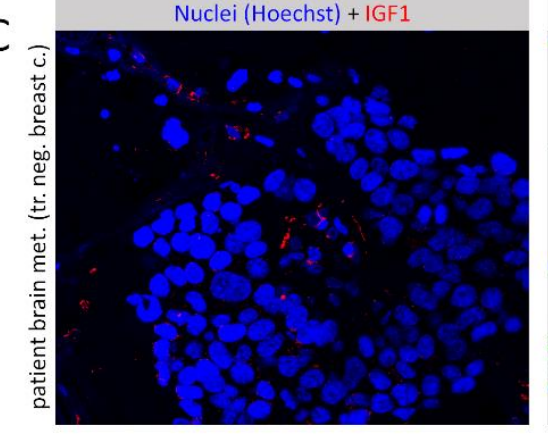

D

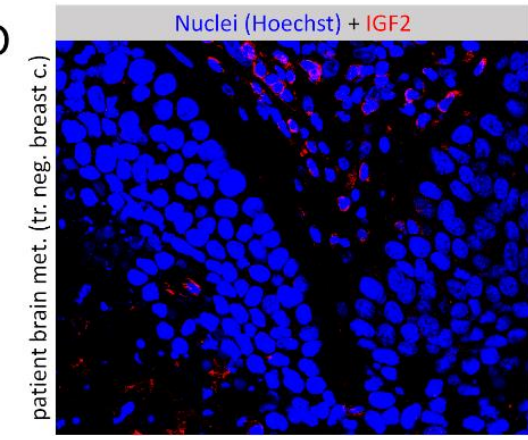

Nuclei (Hoechst) + pericytes (CD13)

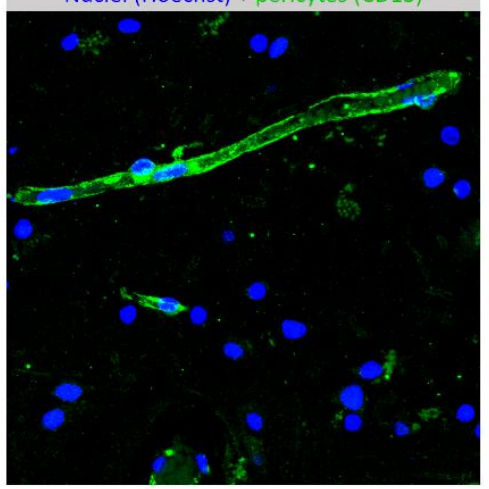

Nuclei (Hoechst) + pericytes (CD13)

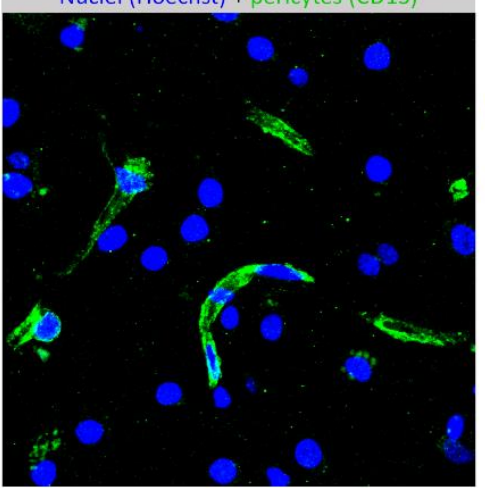

Nuclei (Hoechst) + pericytes (CD13)

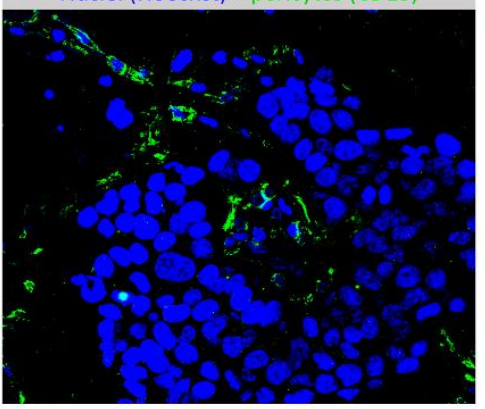

Nuclei (Hoechst) + pericytes (CD13)

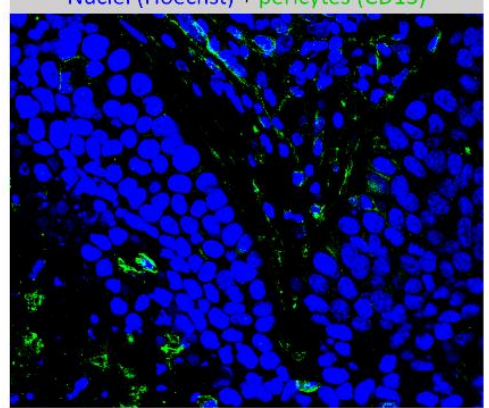

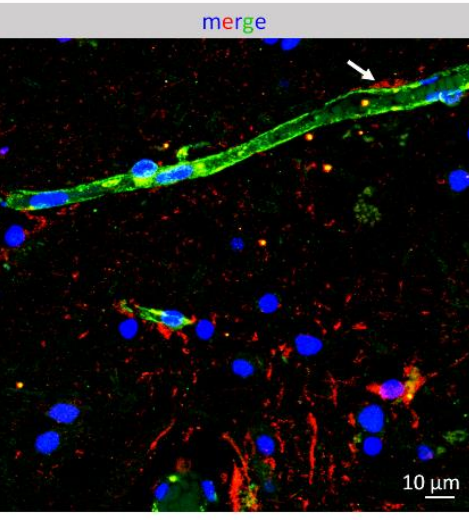

merge

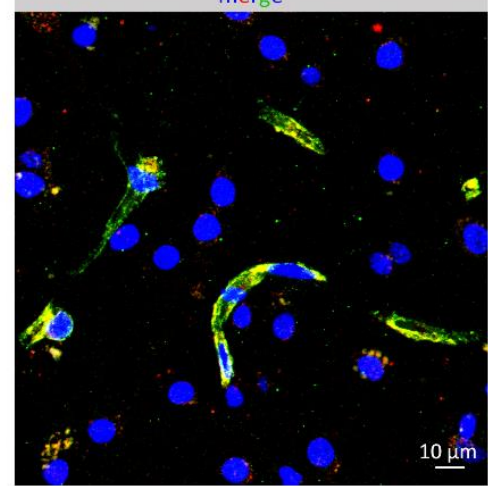

merge

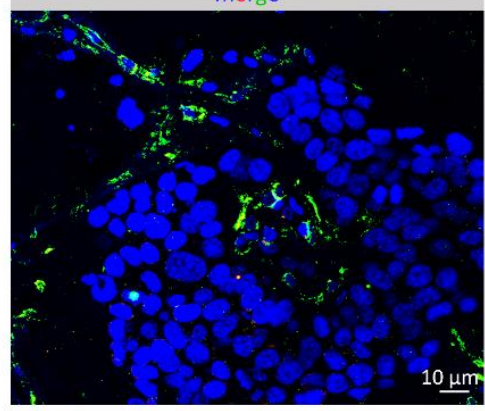

merge

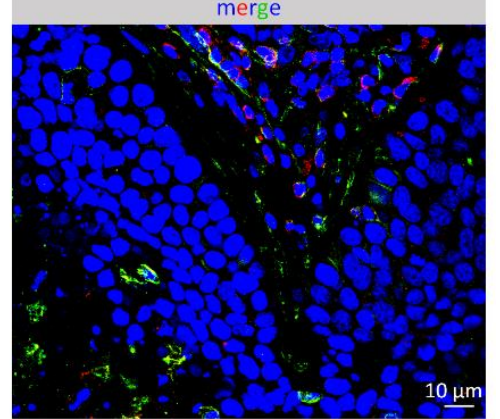

Figure 14: Distribution of IGFs in normal or metastatic human brain samples. (A) Representative immunofluorescence staining showing co-localization of IGF1 and CD13 in normal human brain tissue. White arrow indicates an IGF1-positive, but CD13-negative astrocyte end-foot-like structure. (B) Representative immunofluorescence staining showing co-localization of IGF2 and CD13 in normal human brain tissue. (C) Representative immunofluorescence staining showing co-localization of IGF1 and CD13 in human TNBC brain metastatic tissue. (D) Representative immunofluorescence staining showing co-localization of IGF2 and CD13 in human TNBC brain metastatic tissue. 


\subsection{Role of brain pericyte-secreted IGFs in proliferation of TNBC cells}

By binding to the type 1 insulin-like growth factor receptor (IGF1R), IGFs are involved in growth and survival of both normal and neoplastic cells [63]. Therefore, we next tested whether pericyte-secreted IGFs are responsible for the increased proliferation rate of breast cancer cells. For this purpose, we used a selective inhibitor of IGF1R, PPP, which efficiently blocks IGF1R without inhibiting the insulin receptor, and has low toxicity in rodents [64]. Addition of PPP to pericyte-conditioned medium reduced proliferation-inducing effect of pericytes to almost control levels in both human and mouse breast cancer cells (Figure 15A, B).

In addition, we silenced Igf 2 gene in pericytes, collected conditioned media and performed a proliferation assay (Figure 15C). Igf2 silencing was very efficient, and although slightly affected Igf1 mRNA expression as well (Figure 15D), it can be considered specific, due to the much higher expression of IGF2 compared to IGF1 in brain pericytes (Figure 13A). Proliferation rate of breast cancer cells in conditioned media of Igf2-silenced pericytes was similar to control cells, or cells cultured in pericyte-conditioned media in the presence of PPP (Figure 15C).

In order to understand differences between their proliferation, we analysed IGFR expression level of breast cancer and melanoma cells. Igf1R mRNA expression level was similar in the two cell types; however, melanoma cells expressed almost two-times more Igf2R mRNA than breast cancer cells (Figure 15E). This corresponds with data from the Human Protein Atlas (https://www.proteinatlas.org/ENSG00000197081-IGF2R/pathology) which indicates a higher average mRNA and protein expression of Igf2R/IGF2R in melanoma than in breast cancer. 
A

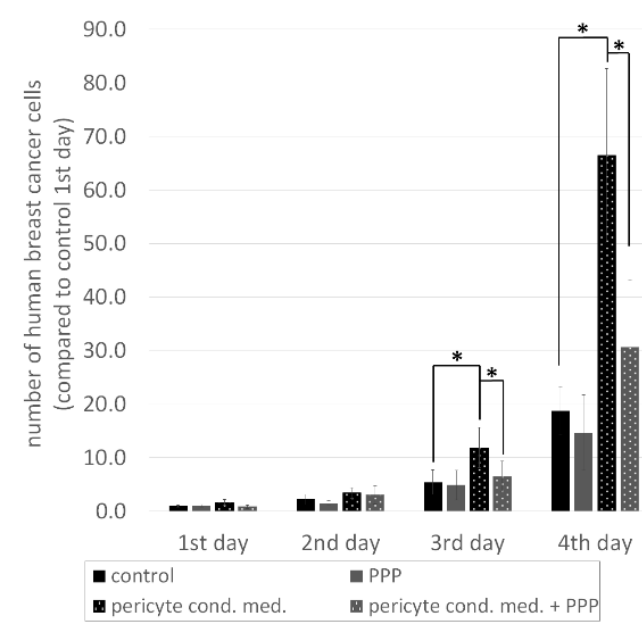

C

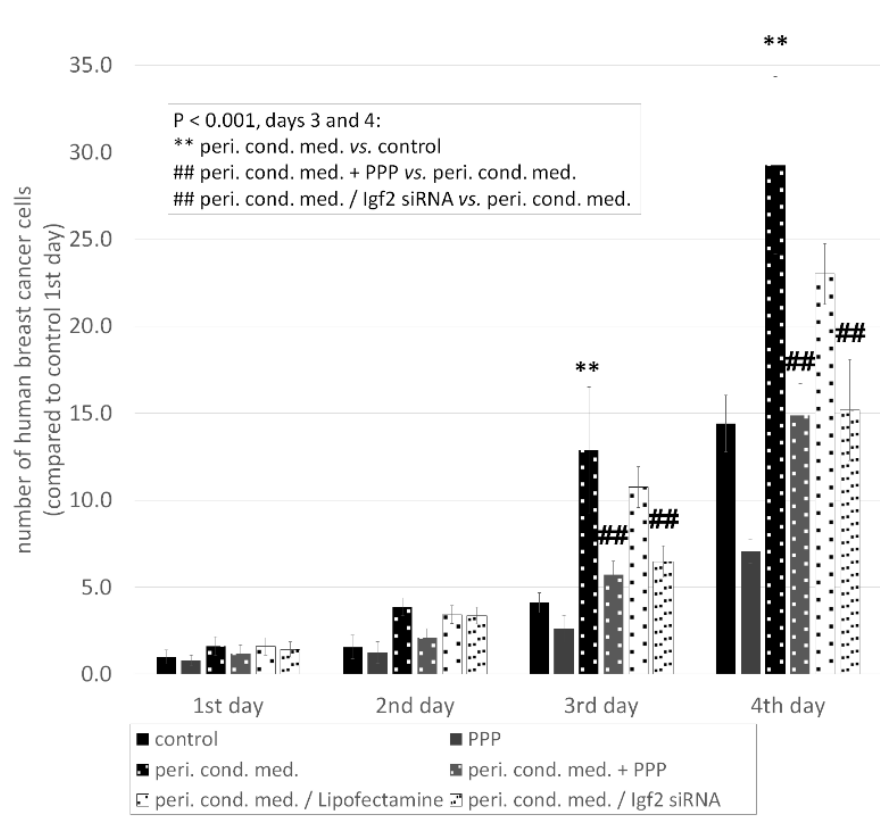

B

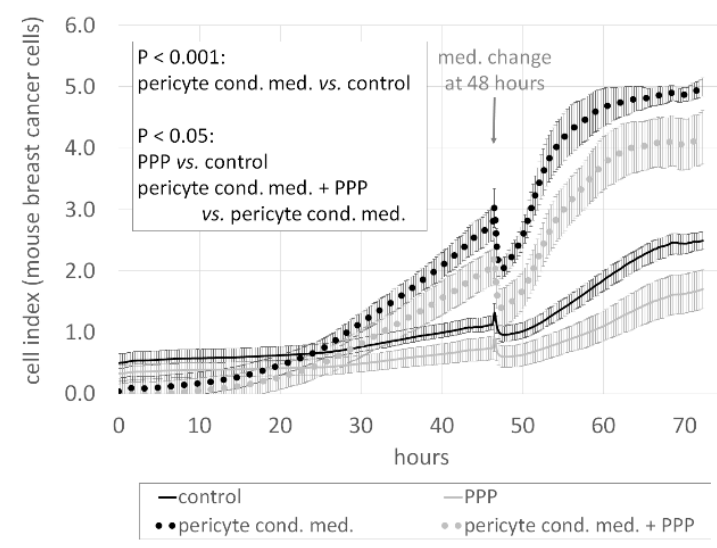

D

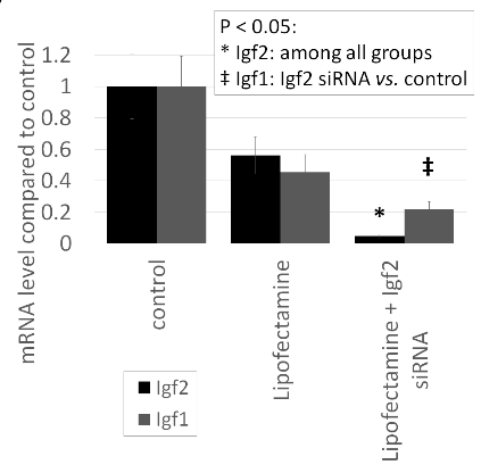

$\mathrm{E}$

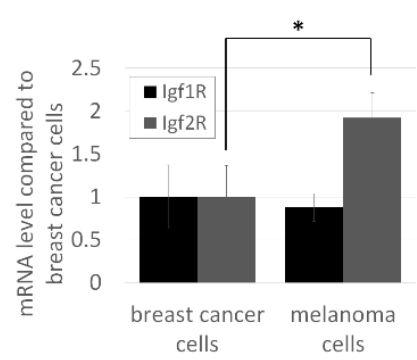

Figure 15: Role of IGFs in breast cancer cell proliferation in vitro. (A) Quantification of MDA cell growth in control or pericyte-conditioned media in the presence or absence of PPP. Cells were counted in phase-contrast micrographs. $\mathrm{N}=5$, average $\pm \mathrm{SD},{ }^{*} \mathrm{P}<0.05$ (ANOVA and Bonferroni's post-hoc test). (B) Growth of 4T1 cells in control or pericyte-conditioned media in the presence or absence of PPP, as assessed by impedance measurements. $\mathrm{N}=4$, average $\pm \mathrm{SD}, \mathrm{P}<0.001$ (cells cultured in pericyte-conditioned media compared to control), $\mathrm{P}<0.05$ (cells treated with PPP compared to control; cells cultured in pericyte-conditioned media and PPP compared to cells cultured in pericyte-conditioned media) (two-way ANOVA with repeated measures and Tukey's post-hoc test). (C) Growth of MDA cells cultured in control or pericyte-conditioned media in the presence or absence of PPP, or in conditioned media of Lipofectamine-treated or Igf2-silenced pericytes. $\mathrm{N}=5$, average $\pm \mathrm{SD}$, ** $\mathrm{P}<0.01$ (compared to control), \#\# $\mathrm{P}<0.01$ (compared to cells cultured in pericyte-conditioned media) (ANOVA and Bonferroni's post-hoc test). (D) Effect of Igf2 silencing on Igf2 and Igf1 mRNA expression in HBVP cells, as assessed by qPCR with Gapdh as housekeeping gene. $\mathrm{N}=3$, average $\pm \mathrm{SD}, \mathrm{P}<0.05$ (ANOVA and Bonferroni's post-hoc test). (E) Igf1R and Igf2R mRNA expression in human tumour cells. Results are shown as fold change in comparison to Igf1R in breast cancer cells. $\mathrm{N}=3$, average $\pm \mathrm{SD}, * \mathrm{P}<0.05$ (ANOVA and Bonferroni's post-hoc test). 
A
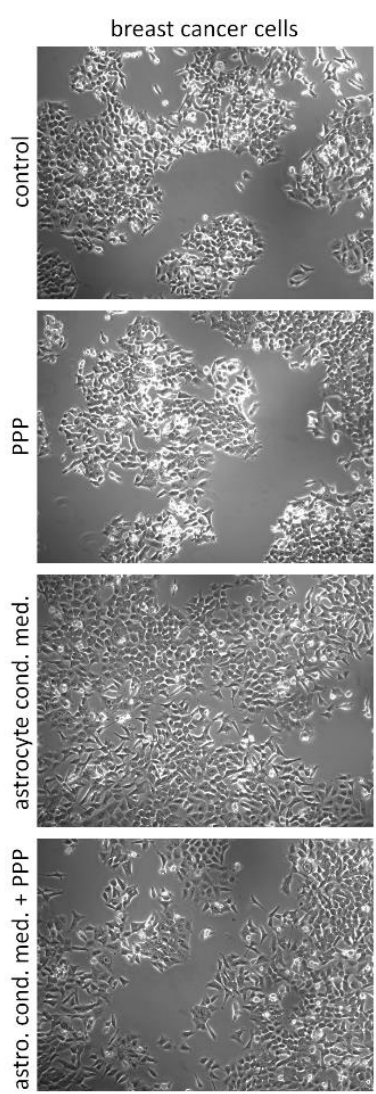

melanoma cells
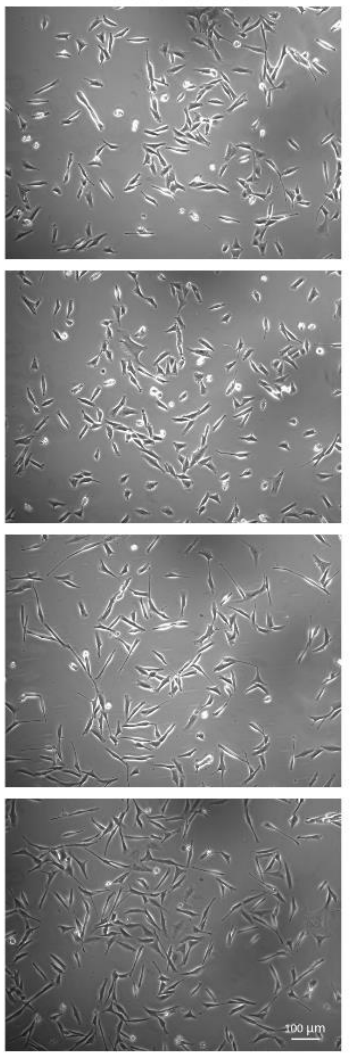

B

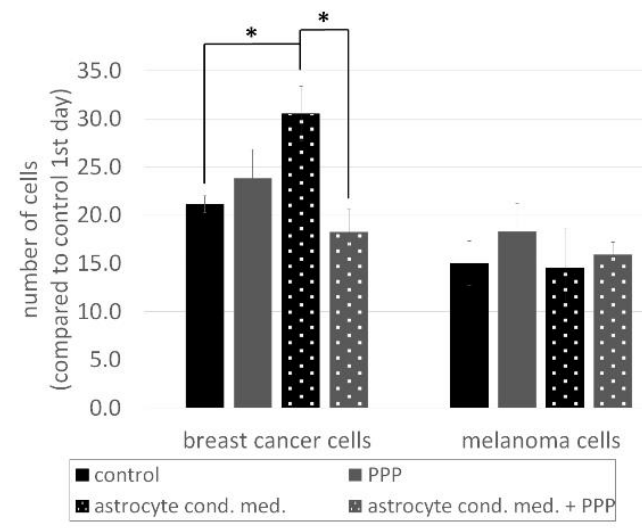

C

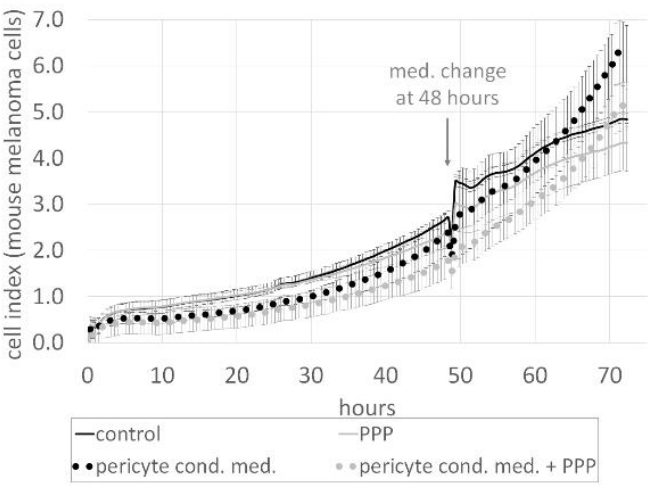

Figure 16: Effect of IGF inhibition on tumour cell proliferation. (A) Representative phase-contrast images of MDA and A2058 cells grown for 4 days in control or HA-conditioned media, in the presence or absence of PPP. (B) Quantification of data shown in (A). N = 3, average $\pm \mathrm{SD}$, * P $<0.05$. (C) Growth of B16 cells in control or mouse pericyte-conditioned media in the presence or absence of PPP, as assessed by impedance measurements. $\mathrm{N}=3$, average $\pm \mathrm{SD}$.

In consistent with secreted IGF2 levels, astrocyte-conditioned media had a much less pronounced effect on proliferation of breast cancer cells and no effect on melanoma cell division. PPP reversed the astrocyte-conditioned medium-induced slight increase in breast cancer cell proliferation (Figure 16A, B).

In contrast to breast cancer cells, proliferation of melanoma cells was not affected by PPP (Figure 16C). Resistance of melanoma cells to IGFs might be partly explained by the difference in Igf2R expression (Figure 15E), because IGF2R directs IGF2 to lysosomes to attenuate signalling [65]. 
A

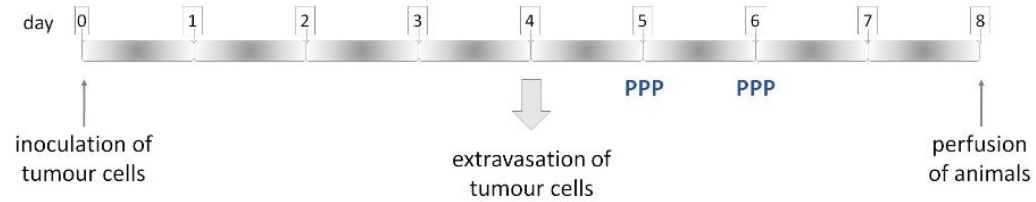

B

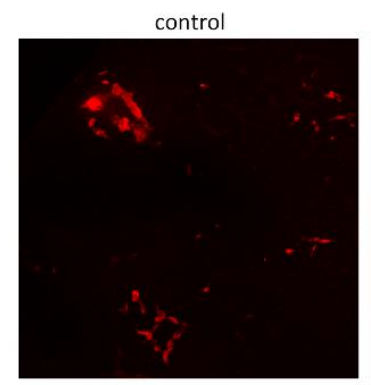

C

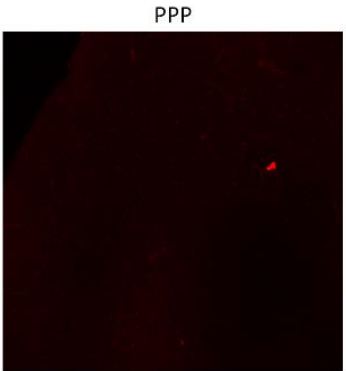

D

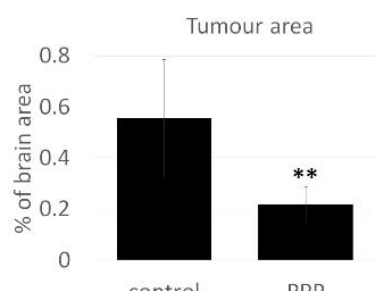

PPP
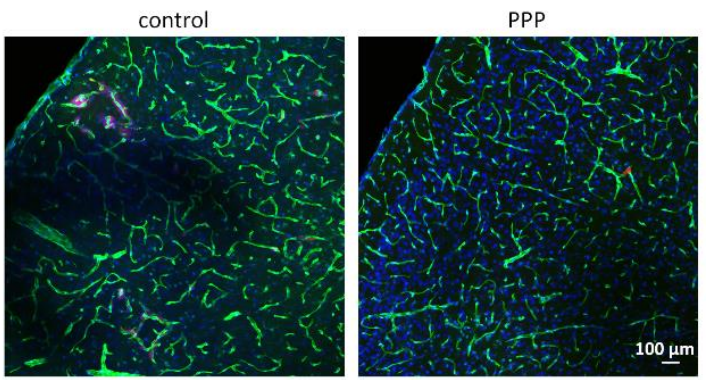

Nuclei (Hoechst)

4T1-tdTomato (tumour cell)

endothelial cells (Venus-YFP)

mouse brain sections ( 8 days after inoculation of breast cancer cells)

Figure 17: Role of IGFs in breast cancer cell proliferation in vivo. (A) Experimental design of studying the role of IGFs in TNBC proliferation in the brains of mice. (B) (C) Representative confocal micrographs of parietal brain sections of control and PPP-treated FVB/Ant:TgCAG-yfp mice, 8 days after inoculation of tdTomato-4T1 cells. Red channel represents tumour cells (B). In (C) the same sections are shown as in (B) in three channels: red, green (endothelium) and blue (nuclei) channels. (D) Quantification of tumour size in control and PPP-treated mice. Tumour area is presented as percentage of brain area, as calculated from 17 brain sections of 3 animals/treatment. Average $\pm \mathrm{SEM}, * * \mathrm{P}<0.01$ (two-way ANOVA without replication).

Since PPP can cross the BBB [66], we next designed an in vivo setup to test the role of IGFs in breast cancer brain metastasis development. In order to test metastatic cell proliferation in the brain parenchyma, PPP was administered on days 5 and 6 after inoculation of tumour cells (Figure 17A), when majority of cells have completed extravasation from cerebral capillaries. Our results clearly showed that PPP inhibited proliferation of breast cancer cells in the brains of mice (Figure 17B, C). The brain area covered by tumour cells became significantly, more than 2.5-times smaller in animals treated with the IGF1R inhibitor (Figure 17D). 


\section{Discussion}

Implicated in extravasation of malignant cells through the BBB and influencing their ability to survive and proliferate in the cerebral environment, cells of the NVU have been increasingly recognized as key players in brain metastasis formation. Among cells of the NVU, CECs and astrocytes are the most active in immediately responding to and continuously associating with invading tumour cells [67]. Both of them have Janus-faced attitude, bearing both tumourdestructive and -protective mechanisms; however, these mechanisms are by far not well characterized. Even less is known about the importance of pericytes in the brain metastatic process, except for their role in regulating the permeability of the blood-tumour barrier [68], and their contribution to connective tissue accumulation in the metastases [61].

\subsection{Endothelial-tumour cell interactions during brain metastasis formation}

Among brain metastatic tumours, melanoma has the highest affinity for the CNS. Earlier, this has been explained by the good capacity of melanoma cells to proliferate in the brain parenchyma [69]. However, our previous results suggested that melanoma cells might also have an increased ability to migrate through cerebral endothelial layers in comparison to breast cancer cells [55]. Especially, impairment of tight junctions of CECs was more pronounced in the presence of melanoma than mammary cancer cells.

Our present results are in agreement with these data, showing that melanoma cells can effectively use the paracellular route of transmigration. This pathway was also exploited by TNBC cells; however, to a lower extent. In addition, the paracellular pathway was not the only one utilized by breast cancer cells during their diapedesis through the cerebral endothelium. To our best knowledge, we are the first to show direct evidence of transcellular migration of tumour cells through the BBB. The transcellular route of migration has initially been recognized for leukocytes [36], especially in the brain microvasculature [70]. As for tumour cells, the transcellular route of migration has only been described in the diapedesis of breast cancer cells through an in vitro vascular network [71], or through human umbilical vein endothelial cells (HUVECs) [72].

During their paracellular migration, melanoma cells open not only tight junctions, but also adherens junctions of CECs. N-cadherin-mediated interaction was shown to be involved in this process, which was upregulated in melanoma-endothelial contact regions. We observed increased $\mathrm{N}$-cadherin expression in CECs in response to breast cancer cells too; however, the 
protein was not localized to tumour cell-endothelial cell contacts. It was rather upregulated in CECs neighbouring those endothelial cells that came into direct contact with the tumour cells.

Overexpression of N-cadherin was accompanied by morphological changes in endothelial cells. Our results indicate that CECs play an active role in the transendothelial migration of tumour cells by extending filopodia-like processes, which might guide invading cells towards low resistance points [73]. Through this mechanism, endothelial cells may also incorporate the tumour cells or their extracellular vesicles, or isolate them from the circulating blood in vivo. Furthermore, we observed protrusion of endothelial cell nuclei into the lumens of capillaries upstream and downstream of breast cancer cells. This type of tumour cell isolation from the circulating blood may have several consequences on the metastatic process, primarily protection from shear stress and immune attacks. However, the role of shear stress is complex, because it may differently influence different steps of tumour cell extravasation. In a zebrafish model, reduced flow was found to promote early arrest of tumour cells, while increased flow enhanced extravasation because integrin-dependent adhesion forces rapidly exceeded shear forces [74].

\subsection{Metastasis-induced changes in astrocytes}

We observed that that tumour cells breach not only the endothelium, but also the glia limitans perivascularis during their extravasation. This is an important step because immune cellsdiapedesis of which is used as a reference in deciphering mechanisms of extravasation of tumour cells $[35,75]$ - also have to migrate through the glia limitans perivascularis to induce neuro-inflammation [76, 77]. However, as metastatic lesion is growing, AQP4-positive astrocyte end-feet are disappearing from the vessel to cover the surface of the tumour, from which reactive astrocytes are completely expelled. Since AQP4 accumulates at the border of the tumour in parallel with vanishing from the capillaries, we conclude that this is an extraction of astrocyte end-feet from the vessels rather than loss of polarization, as previously suggested [68]. Interestingly, claudin-5 staining of the vessels remained continuous even after loss of direct contact with astrocyte end-feet, probably due to the presence of pericytes. Indeed, disappearance of astrocyte foot processes from metastatic vessels did not show any correlation with the permeability [68].

Astrocytes are well known to actively interact with tumour cells and to have a Janus-faced role in either restricting or promoting tumour cell proliferation in the brain. At the molecular level, secretion of PA restricts metastasis development; otherwise, activated astrocytes can 
protect melanoma cells from chemotherapeutic agents-induced apoptosis by sequestering $\mathrm{Ca}^{2+}$ from tumour cells $[43,47]$.

Here we found a novel mechanism possibly involved in tumour cell-astrocyte communication. Our study revealed the early alteration in the expression levels of several miRNAs, and particularly the downregulation of miR-802-5p and miR-194-5p in the plasma of mice with brain metastatic breast tumours. This correlated with overexpression of MEF2C, their common target, in cancer cells and in surrounding astrocytes. Further studies are needed to understand the role of these two miRNAs and MEF2C in the interaction of metastatic TNBC cells and cells of the NVU, especially astrocytes along cerebral secondary tumour formation.

\subsection{Pro-metastatic role of cerebral pericytes}

Although interactions between metastatic cells and CECs, astrocytes or microglia have been intensively studied, importance of pericytes has been highly neglected so far. Our knowledge about the role of pericytes is limited to indirect effects on tumour cells, including regulation of blood-tumour barrier permeability [68] and secretion of connective tissue proteins [61]. By remodelling the perivascular niche [78], increasing angiogenesis [79] and acquiring an immunosuppressive function [80,81], pericytes have undisputed roles in promoting primary brain tumours. Therefore, we hypothesized that pericytes might facilitate progression of brain metastases as well.

By using in vivo and in vitro techniques and human samples, here we show and characterize direct interactions of brain pericytes with metastatic cells. First, we observed that pericytes remain attached to the vessels and are retained in metastatic lesions. Co-option of brain pericytes in metastases has been previously observed in epithelial and fibrosarcoma tumours formed by injection of the cells into the brain [82]. Here we show that pericytes are co-opted in metastatic brain tumours after transmigration of invading cells through the BBB. In addition, inside the tumour mass, we found PDGFR $\beta$ and CD13 double-positive, non-perivascular pericyte-like cells, origin of which is unknown. Second, we proved direct interaction between tumour cells and pericytes in vitro as well, by showing that breast cancer cells preferentially attach to pericytes.

Our results highlight a pronounced role of pericyte-secreted soluble factors, having chemoattractant, adhesion- and proliferation-enhancing effects mainly on triple-negative mammary carcinoma cells. As shown in our in vitro models, tumour cells actively migrated towards pericytes. In cancer, chemotaxis is thought to be involved in tumour cell dissemination, 
survival and growth and is often mediated by chemokines and growth factors [83]. We observed that pericytes secreted proteins of the extracellular matrix to enhance formation of tumour cell focal adhesions. In the brain, interaction with the vascular basement membrane is critical for the survival of metastatic cells $[47,84]$. Embedded in the inner, endothelial layer of the vascular basal lamina, pericytes substantially contribute to the secretion of matrix proteins [12], which might be particularly important in metastatic tumours, which tend to detach astrocytes - another major source of basal membrane proteins-from co-opted vessels. This corresponds with the accumulation of collagen secreted by perivascular cells observed in papillary-type human brain metastases [61].

While pericytes enhanced adhesion to the substrate, they inhibited intercellular adhesions and expression of E-cadherin, conferring breast cancer cells a migratory, invasive phenotype, characteristic of cells undergoing epithelial-to-mesenchymal transition (EMT) [83]. In consonance with these results, pericytes have been shown to be major sources of EMT factors in glioma [85]. We have also found that pericytes have a prompt effect on the proliferation of TNBC, but not that of melanoma cells. Bioinformatics analysis, followed by experimental approaches confirmed high expression of IGFs in pericytes, contributing to breast cancer cell proliferation. Indeed, in addition to regulating cell division, the IGF system has also been shown to promote induction of the EMT phenotype in epithelial tumours $[86,87]$ and to play an important role in the maintenance of cancer stem cells in breast cancer [88].

IGF signalling has been implicated in the growth and survival of both normal and malignant cells. IGF1R expression and activity increase in several tumour types, including breast cancer [89], resulting in enhanced proliferation rate, metastatic capacity and resistance to chemotherapy [90]. Therefore, targeting of the IGF axis has been in the focus of therapeutic approach developments in numerous malignant diseases [91]. However, since many clinical trials failed and further studies have been discontinued due to toxicity or low efficacy of the tested compounds, identification of predictive biomarkers has been urged to define potentially responsive patient subgroups. Nevertheless, brain metastatic disease has not been specifically investigated in IGF1-targeting clinical trials, although inhibition of IGF1R has been shown to reduce breast cancer brain metastasis development in experimental models [92]. Moreover, a clinical phase I study has been completed with PPP (AXL1717) in patients with primary brain tumours, showing that the drug is well tolerated with no major side effects [93].

Taken together, our results show that pericytes play crucial role in the development of brain secondary tumours by directly influencing key steps of metastatic colonization of the CNS. 
Secretion of soluble factors, including extracellular matrix proteins and growth factors, endows brain pericytes with significant pro-metastatic features, especially in breast cancer. Therefore, altering pericyte functions might represent a future therapeutic opportunity in brain metastatic disease. This is in line with emerging approaches, which tend to target the more stable tumour microenvironment in addition to the very plastic cancer cells. Moreover, our study underlines the importance of IGF axis inhibition as a potential strategy in brain metastases, especially as there exists a compound (PPP/AXL1717) with high selectivity on IGF1R that not only has low toxicity, but is also BBB permeable. This is a great advantage, since the BBB represents the highest obstacle in the development of drugs targeting the CNS.

In conclusion, we achieved the proposed aims and showed that:

- Breast cancer cells not only use the paracellular, but also the transcellular way during their migration through the cerebral endothelium.

- CECs actively take part in the metastatic process by extending filopodia-like processes towards the tumour cells and isolating them from the circulation before extravasation.

- $\quad$ TNBC cells first breach the glia limitans perivascularis, while later astrocytic end-feet are retracted onto the outer surface of the growing tumour.

- MiR-802-5p and miR-194-5p and their target, MEF2C transcription factor are possible new players in astrocyte-tumour cell interaction.

- Brain pericytes increase adhesion of both breast cancer and melanoma cells.

- Brain pericytes enhance proliferation of breast cancer, but not that of melanoma cells.

- Pericyte-secreted IGF2 has a crucial role in proliferation of TNBC cells in the brain. 


\section{Summary}

Brain metastases are life-threatening complications of breast cancer, melanoma and a few other tumour types. Poor outcome of cerebral malignancies largely depends on the microenvironment formed by cells of the NVU. Despite the unquestionable clinical significance, important aspects of the development of secondary tumours of the CNS are largely uncharacterized. By using in vivo and in vitro techniques and human samples, here we identified novel mechanisms related to CECs, astrocytes and brain pericytes, involved in brain metastasis development.

Our results indicate that the microvascular endothelium is directly involved in extravasation of tumour cells into the brain. CECs extend filopodia-like membrane protrusions towards the tumour cells to engulf them. Moreover, endothelial cells isolate invading cells from the circulation by vessel obstruction, before tumour cells proceed to extravasation. We also show that melanoma cells primarily utilize the paracellular route of transendothelial migration, while breast cancer cells are able to transcellularly migrate through the brain endothelium. After overcoming the endothelium, mammary carcinoma cells breach the glia limitans perivascularis formed by astrocytic end-feet. As breast cancer cells start to proliferate in the brain, they coopt the vessels, including endothelial cells and pericytes, and exclude astrocytes, which retract their foot processes onto the surface of the tumour.

We also show that during breast cancer brain metastasis formation, circulating miR-802 and miR-194 are deregulated in a time-dependent manner. Along with this, we observed overexpression of MEF2C, a target of both miR-802-5p and miR-194-5p, in both metastatic cells and peri-tumoural astrocytes, underlining the interplay between glial and malignant cells.

Finally, we show for the first time that cerebral pericytes have significant pro-metastatic roles. Brain pericytes have a prompt chemoattractant effect on breast cancer cells and establish direct contacts with them. By secreting high amounts of extracellular matrix proteins, pericytes enhance adhesion of both melanoma and triple negative cancer cells, which might be particularly important in the exclusive perivascular growth of these tumour cells. In addition, pericytes secrete IGF2, which has a very significant pro-proliferative effect on mammary carcinoma, but not on melanoma cells. 


\section{References}

1. Davis, F.G., et al., Toward determining the lifetime occurrence of metastatic brain tumors estimated from 2007 United States cancer incidence data. Neuro Oncol, 2012. 14(9): p. 11717.

2. Platta, C.S., et al., Current treatment strategies for brain metastasis and complications from therapeutic techniques: a review of current literature. Am J Clin Oncol, 2010. 33(4): p. 398-407.

3. Wilhelm, l., et al., Role of the blood-brain barrier in the formation of brain metastases. Int J Mol Sci, 2013. 14(1): p. 1383-411.

4. Schuette, W., Treatment of brain metastases from lung cancer: chemotherapy. Lung Cancer, 2004. 45 Suppl 2: p. S253-7.

5. Polyak, K., Breast cancer: origins and evolution. J Clin Invest, 2007. 117(11): p. 3155-63.

6. Ferlay, J., et al., Cancer incidence and mortality worldwide: sources, methods and major patterns in GLOBOCAN 2012. Int J Cancer, 2015. 136(5): p. E359-86.

7. Cheng, X. and M.C. Hung, Breast cancer brain metastases. Cancer Metastasis Rev, 2007. 26(34): p. 635-43.

8. Sloan, A.E., C.J. Nock, and D.B. Einstein, Diagnosis and treatment of melanoma brain metastasis: a literature review. Cancer Control, 2009. 16(3): p. 248-55.

9. Ostrom, Q.T., C.H. Wright, and J.S. Barnholtz-Sloan, Brain metastases: epidemiology. Handb Clin Neurol, 2018. 149: p. 27-42.

10. Iadecola, C., The Neurovascular Unit Coming of Age: A Journey through Neurovascular Coupling in Health and Disease. Neuron, 2017. 96(1): p. 17-42.

11. Netto, J.P., et al., Neurovascular Unit: Basic and Clinical Imaging with Emphasis on Advantages of Ferumoxytol. Neurosurgery, 2018. 82(6): p. 770-780.

12. Thomsen, M.S., L.J. Routhe, and T. Moos, The vascular basement membrane in the healthy and pathological brain. J Cereb Blood Flow Metab, 2017. 37(10): p. 3300-3317.

13. Bauer, H.C., et al., "You Shall Not Pass"-tight junctions of the blood brain barrier. Front Neurosci, 2014. 8: p. 392.

14. Zlokovic, B.V., The blood-brain barrier in health and chronic neurodegenerative disorders. Neuron, 2008. 57(2): p. 178-201.

15. Daneman, R., The blood-brain barrier in health and disease. Ann Neurol, 2012. 72(5): p. 64872.

16. Daneman, R. and A. Prat, The blood-brain barrier. Cold Spring Harb Perspect Biol, 2015. 7(1): p. a020412.

17. Abbott, N.J., et al., Structure and function of the blood-brain barrier. Neurobiol Dis, 2010. 37(1): p. 13-25.

18. Wilhelm, I., C. Fazakas, and I.A. Krizbai, In vitro models of the blood-brain barrier. Acta Neurobiol Exp (Wars), 2011. 71(1): p. 113-28.

19. Luissint, A.C., et al., Tight junctions at the blood brain barrier: physiological architecture and disease-associated dysregulation. Fluids Barriers CNS, 2012. 9(1): p. 23.

20. Stamatovic, S.M., et al., Junctional proteins of the blood-brain barrier: New insights into function and dysfunction. Tissue Barriers, 2016. 4(1): p. e1154641.

21. Gerhardt, H. and H. Semb, Pericytes: gatekeepers in tumour cell metastasis? J Mol Med (Berl), 2008. 86(2): p. 135-44.

22. Armulik, A., G. Genove, and C. Betsholtz, Pericytes: developmental, physiological, and pathological perspectives, problems, and promises. Dev Cell, 2011. 21(2): p. 193-215.

23. Armulik, A., et al., Pericytes regulate the blood-brain barrier. Nature, 2010. 468(7323): p. 55761.

24. Bergers, G. and S. Song, The role of pericytes in blood-vessel formation and maintenance. Neuro Oncol, 2005. 7(4): p. 452-64. 
25. Hill, J., et al., Emerging roles of pericytes in the regulation of the neurovascular unit in health and disease. J Neuroimmune Pharmacol, 2014. 9(5): p. 591-605.

26. Dore-Duffy, P., Pericytes: pluripotent cells of the blood brain barrier. Curr Pharm Des, 2008. 14(16): p. 1581-93.

27. Hall, C.N., et al., Capillary pericytes regulate cerebral blood flow in health and disease. Nature, 2014. 508(7494): p. 55-60.

28. Abbott, N.J., L. Ronnback, and E. Hansson, Astrocyte-endothelial interactions at the blood-brain barrier. Nat Rev Neurosci, 2006. 7(1): p. 41-53.

29. Walz, W., Role of astrocytes in the clearance of excess extracellular potassium. Neurochem Int, 2000. 36(4-5): p. 291-300.

30. Mathiisen, T.M., et al., The perivascular astroglial sheath provides a complete covering of the brain microvessels: an electron microscopic 3D reconstruction. Glia, 2010. 58(9): p. 1094-103.

31. Szu, J.I. and D.K. Binder, The Role of Astrocytic Aquaporin-4 in Synaptic Plasticity and Learning and Memory. Front Integr Neurosci, 2016. 10: p. 8.

32. van Zijl, F., G. Krupitza, and W. Mikulits, Initial steps of metastasis: cell invasion and endothelial transmigration. Mutat Res, 2011. 728(1-2): p. 23-34.

33. Han, C.H. and P.K. Brastianos, Genetic Characterization of Brain Metastases in the Era of Targeted Therapy. Front Oncol, 2017. 7: p. 230.

34. Fischer, G.M., et al., Molecular Profiling Reveals Unique Immune and Metabolic Features of Melanoma Brain Metastases. Cancer Discov, 2019. 9(5): p. 628-645.

35. Strell, C. and F. Entschladen, Extravasation of leukocytes in comparison to tumor cells. Cell Commun Signal, 2008. 6: p. 10.

36. Carman, C.V., Mechanisms for transcellular diapedesis: probing and pathfinding by 'invadosome-like protrusions'. J Cell Sci, 2009. 122(Pt 17): p. 3025-35.

37. Dejana, E., The transcellular railway: insights into leukocyte diapedesis. Nat Cell Biol, 2006. 8(2): p. 105-7.

38. Fazakas, C., et al., Transmigration of melanoma cells through the blood-brain barrier: role of endothelial tight junctions and melanoma-released serine proteases. PLoS One, 2011. 6(6): p. e20758.

39. Guo, P., et al., Differential arrest and adhesion of tumor cells and microbeads in the microvasculature. Biomech Model Mechanobiol, 2014. 13(3): p. 537-50.

40. Jahroudi, N. and J.S. Greenberger, The role of endothelial cells in tumor invasion and metastasis. J Neurooncol, 1995. 23(2): p. 99-108.

41. Kuczynski, E.A., et al., Vessel co-option in cancer. Nat Rev Clin Oncol, 2019. 16(8): p. 469-493.

42. Wasilewski, D., et al., Reactive Astrocytes in Brain Metastasis. Front Oncol, 2017. 7: p. 298.

43. Lin, Q., et al., Reactive astrocytes protect melanoma cells from chemotherapy by sequestering intracellular calcium through gap junction communication channels. Neoplasia, 2010. 12(9): p. 748-54.

44. Marchetti, D., J. Li, and R. Shen, Astrocytes contribute to the brain-metastatic specificity of melanoma cells by producing heparanase. Cancer Res, 2000. 60(17): p. 4767-70.

45. Mendes, O., et al., MMP2 role in breast cancer brain metastasis development and its regulation by TIMP2 and ERK1/2. Clin Exp Metastasis, 2007. 24(5): p. 341-51.

46. Kim, S.W., et al., Role of the endothelin axis in astrocyte- and endothelial cell-mediated chemoprotection of cancer cells. Neuro Oncol, 2014. 16(12): p. 1585-98.

47. Valiente, M., et al., Serpins promote cancer cell survival and vascular co-option in brain metastasis. Cell, 2014. 156(5): p. 1002-16.

48. Dalkara, T., Y. Gursoy-Ozdemir, and M. Yemisci, Brain microvascular pericytes in health and disease. Acta Neuropathol, 2011. 122(1): p. 1-9.

49. Winkler, E.A., R.D. Bell, and B.V. Zlokovic, Central nervous system pericytes in health and disease. Nat Neurosci, 2011. 14(11): p. 1398-1405.

50. Cheng, L., et al., Glioblastoma stem cells generate vascular pericytes to support vessel function and tumor growth. Cell, 2013. 153(1): p. 139-52. 
51. Sun, H., et al., Hyperplasia of pericytes is one of the main characteristics of microvascular architecture in malignant glioma. PLoS One, 2014. 9(12): p. e114246.

52. Caspani, E.M., et al., Glioblastoma: a pathogenic crosstalk between tumor cells and pericytes. PLoS One, 2014. 9(7): p. e101402.

53. Murgai, M., et al., KLF4-dependent perivascular cell plasticity mediates pre-metastatic niche formation and metastasis. Nat Med, 2017. 23(10): p. 1176-1190.

54. Wilhelm, I., et al., Hyperosmotic stress induces Axl activation and cleavage in cerebral endothelial cells. J Neurochem, 2008. 107(1): p. 116-26.

55. Molnar, J., et al., Transmigration characteristics of breast cancer and melanoma cells through the brain endothelium: Role of Rac and PI3K. Cell Adh Migr, 2016. 10(3): p. 269-81.

56. Qi, J., et al., Transendothelial migration of melanoma cells involves $N$-cadherin-mediated adhesion and activation of the beta-catenin signaling pathway. Mol Biol Cell, 2005. 16(9): p. 4386-97.

57. Qi, J., et al., Involvement of Src family kinases in N-cadherin phosphorylation and beta-catenin dissociation during transendothelial migration of melanoma cells. Mol Biol Cell, 2006. 17(3): p. 1261-72.

58. Lorger, M. and B. Felding-Habermann, Capturing changes in the brain microenvironment during initial steps of breast cancer brain metastasis. Am J Pathol, 2010. 176(6): p. 2958-71.

59. Zhang, M. and Y. Olsson, Hematogenous metastases of the human brain--characteristics of peritumoral brain changes: a review. J Neurooncol, 1997. 35(1): p. 81-9.

60. Dong, C., et al., Myocyte enhancer factor 2C and its directly-interacting proteins: A review. Prog Biophys Mol Biol, 2017. 126: p. 22-30.

61. Teglasi, V., et al., Origin and Distribution of Connective Tissue and Pericytes Impacting Vascularization in Brain Metastases With Different Growth Patterns. J Neuropathol Exp Neurol, 2019. 78(4): p. 326-339.

62. Vanlandewijck, M., et al., A molecular atlas of cell types and zonation in the brain vasculature. Nature, 2018. 554(7693): p. 475-480.

63. Ellis, M.J., et al., Insulin-like growth factors in human breast cancer. Breast Cancer Res Treat, 1998. 52(1-3): p. 175-84.

64. Girnita, A., et al., Cyclolignans as inhibitors of the insulin-like growth factor-1 receptor and malignant cell growth. Cancer Res, 2004. 64(1): p. 236-42.

65. Martin-Kleiner, I. and K. Gall Troselj, Mannose-6-phosphate/insulin-like growth factor 2 receptor (M6P/IGF2R) in carcinogenesis. Cancer Lett, 2010. 289(1): p. 11-22.

66. Yin, S., et al., Targeting the insulin-like growth factor-1 receptor by picropodophyllin as a treatment option for glioblastoma. Neuro Oncol, 2010. 12(1): p. 19-27.

67. Kienast, $Y$., et al., Real-time imaging reveals the single steps of brain metastasis formation. Nat Med, 2010. 16(1): p. 116-22.

68. Lyle, L.T., et al., Alterations in Pericyte Subpopulations Are Associated with Elevated BloodTumor Barrier Permeability in Experimental Brain Metastasis of Breast Cancer. Clin Cancer Res, 2016. 22(21): p. 5287-5299.

69. Fidler, I.J., et al., The biology of melanoma brain metastasis. Cancer Metastasis Rev, 1999. 18(3): p. 387-400.

70. Wolburg, H., K. Wolburg-Buchholz, and B. Engelhardt, Diapedesis of mononuclear cells across cerebral venules during experimental autoimmune encephalomyelitis leaves tight junctions intact. Acta Neuropathol, 2005. 109(2): p. 181-90.

71. Khuon, S., et al., Myosin light chain kinase mediates transcellular intravasation of breast cancer cells through the underlying endothelial cells: a three-dimensional FRET study. J Cell Sci, 2010. 123(Pt 3): p. 431-40.

72. Arvanitis, C., et al., Structure and biomechanics of the endothelial transcellular circumferential invasion array in tumor invasion. PLoS One, 2014. 9(2): p. e89758.

73. Varga, B., et al., De-adhesion dynamics of melanoma cells from brain endothelial layer. Biochim Biophys Acta Gen Subj, 2018. 1862(3): p. 745-751. 
74. Follain, G., et al., Hemodynamic Forces Tune the Arrest, Adhesion, and Extravasation of Circulating Tumor Cells. Dev Cell, 2018. 45(1): p. 33-52 e12.

75. Paku, S., et al., The evidence for and against different modes of tumour cell extravasation in the lung: diapedesis, capillary destruction, necroptosis, and endothelialization. J Pathol, 2017. 241(4): p. 441-447.

76. Horng, S., et al., Astrocytic tight junctions control inflammatory CNS lesion pathogenesis. J Clin Invest, 2017. 127(8): p. 3136-3151.

77. Engelhardt, B., P. Vajkoczy, and R.O. Weller, The movers and shapers in immune privilege of the CNS. Nat Immunol, 2017. 18(2): p. 123-131.

78. Schiffer, D., et al., Glioblastoma: Microenvironment and Niche Concept. Cancers (Basel), 2018. 11(1).

79. Krenzlin, H., et al., Cytomegalovirus promotes murine glioblastoma growth via pericyte recruitment and angiogenesis. J Clin Invest, 2019. 129(4): p. 1671-1683.

80. Valdor, R., et al., Glioblastoma ablates pericytes antitumor immune function through aberrant up-regulation of chaperone-mediated autophagy. Proc Natl Acad Sci U S A, 2019. 116(41): p. 20655-20665.

81. Valdor, R., et al., Glioblastoma progression is assisted by induction of immunosuppressive function of pericytes through interaction with tumor cells. Oncotarget, 2017. 8(40): p. 6861468626.

82. Bugyik, E., et al., Lack of angiogenesis in experimental brain metastases. J Neuropathol Exp Neurol, 2011. 70(11): p. 979-91.

83. Roussos, E.T., J.S. Condeelis, and A. Patsialou, Chemotaxis in cancer. Nat Rev Cancer, 2011. 11(8): p. 573-87.

84. Carbonell, W.S., et al., The vascular basement membrane as "soil" in brain metastasis. PLoS One, 2009. 4(6): p. e5857.

85. Mader, L., et al., Pericytes/vessel-associated mural cells (VAMCs) are the major source of key epithelial-mesenchymal transition (EMT) factors SLUG and TWIST in human glioma. Oncotarget, 2018. 9(35): p. 24041-24053.

86. Cevenini, A., et al., Molecular Signatures of the Insulin-like Growth Factor 1-mediated Epithelial-Mesenchymal Transition in Breast, Lung and Gastric Cancers. Int J Mol Sci, 2018. 19(8).

87. Li, H., et al., IGF-IR signaling in epithelial to mesenchymal transition and targeting IGF-IR therapy: overview and new insights. Mol Cancer, 2017. 16(1): p. 6.

88. Chang, W.W., et al., The expression and significance of insulin-like growth factor-1 receptor and its pathway on breast cancer stem/progenitors. Breast Cancer Res, 2013. 15(3): p. R39.

89. Yee, D., Anti-insulin-like growth factor therapy in breast cancer. J Mol Endocrinol, 2018. 61(1): p. T61-T68.

90. Yuan, J., et al., Function of insulin-like growth factor 1 receptor in cancer resistance to chemotherapy. Oncol Lett, 2018. 15(1): p. 41-47.

91. Osher, E. and V.M. Macaulay, Therapeutic Targeting of the IGF Axis. Cells, 2019. 8(8).

92. Saldana, S.M., et al., Inhibition of type I insulin-like growth factor receptor signaling attenuates the development of breast cancer brain metastasis. PLoS One, 2013. 8(9): p. e73406.

93. Aiken, R., et al., Phase I clinical trial of AXL1717 for treatment of relapsed malignant astrocytomas: analysis of dose and response. Oncotarget, 2017. 8(46): p. 81501-81510. 


\section{Acknowledgements}

I would like to express my deepest gratitude to my supervisor Dr. Imola Wilhelm for scientific guidance and support throughout my Ph.D. studies. I am very grateful to Dr. István Krizbai, the head of the Neurovascular Research Group for providing me the opportunity to learn and conduct research in the laboratory.

I am thankful to all the members of the Institute of Biophysics for the stimulating scientific atmosphere.

I am very thankful to my colleague Dr. Csilla Fazakas for the fruitful discussions and encouragement, to Ádám Mészáros for his help in the tumour cell inoculation methods and to Dr. János Haskó for his expert support in intravital microscopy. My appreciation also extends to my present and former colleagues, Mihály Kozma, Dr. Attila E. Farkas, Dr. Ádám NyúlTóth, Tamás Dudás and Fanni Győri for excellent teamwork, inspiring scientific and personal discussions.

I am grateful to all my collaborators and co-authors for enthusiastic participation in experiments and manuscripts, especially to Dr. László Tiszlavicz (Department of Pathology, University of Szeged) for the human tumour samples, to Marta Sereno and Dr. Maria Alexandra Brito (Faculty of Pharmacy, University of Lisbon) for our collaboration on the miRNA project and to Hildegard Herman and Dr. Anca Hermenean (Institute of Life Sciences, Vasile Goldis Western University of Arad) for the TEM images.

I would like to show my gratitude to my friends, Ilona Gróf, Gabriella Für, Bernát Nógrádi, Dr. Roland Patai and Rebeka Kristóf for sharing excitement of research, big laughters and support.

I am eternally grateful to my family for their emotional support, unconditional love and for always being there for me.

Finally, I want to thank to New National Excellence Program of the Ministry for Innovation and Technology ÚNKP-20-4-SZTE-138 for financial support. The present work was partly supported by the GINOP-2.3.2-15-2016-00020 and GINOP-2.3.2-15-2016-00034 projects. 
Annex

I. 